
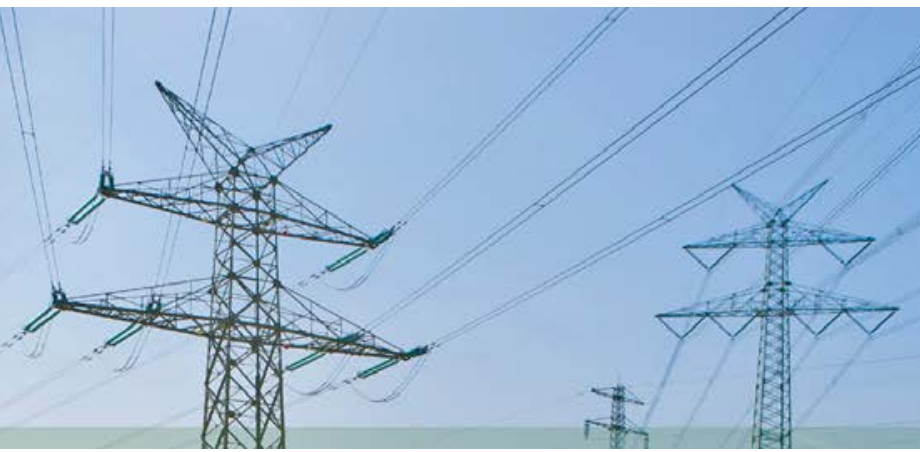

\title{
Designing Distributed Generation in Mexico
}

Carl Linvill and Donna Brutkoski Regulatory Assistance Project

Montpelier, Vermont

NREL Technical Monitor: Ricardo Bracho

Period of Performance: December 2014-June 2015

Subcontract Report

NREL/SR-6A50-66026

May 2017 


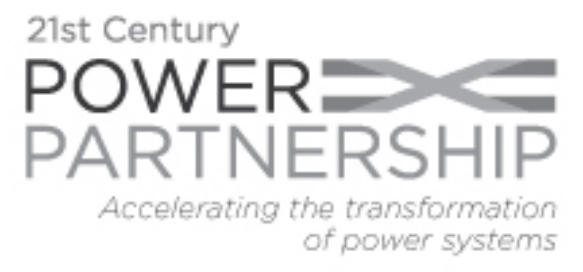

\title{
Designing Distributed Generation in Mexico
}

\author{
Carl Linvill and Donna Brutkoski \\ Regulatory Assistance Project \\ Montpelier, Vermont
}

NREL Technical Monitor: Ricardo Bracho

Prepared under Subcontract Number KAFC-4-42072-02

Period of Performance: December 2014-June 2015

NREL is a national laboratory of the U.S. Department of Energy, Office of Energy

Efficiency \& Renewable Energy, operated by the Alliance for Sustainable Energy, LLC.

National Renewable Energy Laboratory

15013 Denver West Parkway

Golden, CO 80401

303-275-3000 • www.nrel.gov
Subcontract Report

NREL/SR-6A50-66026

May 2017

Contract No. DE-AC36-08GO28308 


\section{This publication was reproduced from the best available copy submitted by the subcontractor and received minimal editorial review at NREL.}

\section{NOTICE}

This report was prepared as an account of work sponsored by an agency of the United States government. Neither the United States government nor any agency thereof, nor any of their employees, makes any warranty, express or implied, or assumes any legal liability or responsibility for the accuracy, completeness, or usefulness of any information, apparatus, product, or process disclosed, or represents that its use would not infringe privately owned rights. Reference herein to any specific commercial product, process, or service by trade name, trademark, manufacturer, or otherwise does not necessarily constitute or imply its endorsement, recommendation, or favoring by the United States government or any agency thereof. The views and opinions of authors expressed herein do not necessarily state or reflect those of the United States government or any agency thereof.

This report is available at no cost from the National Renewable Energy Laboratory (NREL) at www.nrel.gov/publications.

Available electronically at SciTech Connect http:/www.osti.gov/scitech

Available for a processing fee to U.S. Department of Energy and its contractors, in paper, from:

U.S. Department of Energy

Office of Scientific and Technical Information

P.O. Box 62

Oak Ridge, TN 37831-0062

OSTI http://www.osti.gov

Phone: 865.576.8401

Fax: 865.576.5728

Email: reports@osti.gov

Available for sale to the public, in paper, from:

U.S. Department of Commerce

National Technical Information Service

5301 Shawnee Road

Alexandria, VA 22312

NTIS http://www.ntis.gov

Phone: 800.553 .6847 or 703.605 .6000

Fax: 703.605.6900

Email: orders@ntis.gov

NREL prints on paper that contains recycled content. 


\section{Acknowledgments}

The individuals listed below provided much of the description and data regarding Mexico's current context and effort, and their contributions and feedback are appreciated. However, the options that are presented are the authors' and do not constitute consensus of all who commented on the project.

- Edmundo Gil Borja, Mexico Ministry of Energy (SENER)

- $\quad$ Miguel Genel Cruz, SENER

- Fidel Carrasco Gonzalez, SENER

- Efrain Villanueva Arcos, SENER

- Hector Alejandro Beltran Mora, Mexico Energy Regulatory Commission (CRE)

- Paola del Rocio Madrigal Montores, CRE

- Ricardo Bracho, National Renewable Energy Laboratory (NREL)

- Patricia Statwick, NREL. 


\section{List of Acronyms}

ANEEL

CENACE

CFE

CHP

$\mathrm{CO}_{2}$

CPP

CPUC

CRE

DER

DG

DOE

EE

EIA

ENTEASE

FIDE

FIRCO

FIT

FOTEASE

GSE

GW

IDB

IEEE

$\mathrm{kVA}$

$\mathrm{kW}$

$\mathrm{kWh}$

LAERFTE

LCOE

MECO

MW

$\mathrm{MWh}$

NEA

NEM

NERSA

NITI

NREL

O\&M

PACT

PCT
Agência Nacional de Energia Elétrica (Brazilian Electricity Regulatory

Agency)

El Centro Nacional de Control de Energía (The National Energy Control

Center)

Comision Federal de Electricidad (Federal Electricity Commission)

combined heat and power

carbon dioxide

critical peak pricing/price

California Public Utilties Commission

Comisión Reguladora de Energía (Energy Regulatory Commission)

distributed energy resources

distributed generation

Department of Energy

energy efficiency

Energy Information Administration

La Estrategia Nacional de Transición Energética y Aprovechamiento

Sustentable de la Energía (National Strategy for Energy Transition and

Sustainable Use of Energy)

Fideicomiso para el Ahorro de Energía Eléctrica (Electric Power Saving Trust)

Fideicomiso de Riesgo Compartido (Shared Risk Trust)

feed-in tariff

Fondo para la Transición Energética y el Aprovechamiento Sustentable de la

Energía (Fund for Energy Transition and Sustainable Utilization of Energy)

Gestore dei Servizi Energetici (Operator of Energy Services)

Gigawatt

Inter-American Development Bank

Institute of Electrical and Electronics Engineers

kilo-volt-ampere

kilowatt

kilowatt hour

Ley para el Aprovechamiento de Energías Renovables y el Financiamiento de

la Transición Energética (Law for the Use of Renewable Energy)

levelized cost of energy

Maui Electric Company

megawatt

megawatt hour

National Energy Administration

net energy metering

National Energy Regulator of South Africa

National Institution for Transforming India

National Renewable Energy Laboratory

operations \& maintenance

Program Administrator Cost Test

Participant Cost Test 
PEAER Programa Especial para el Aprovechamiento de Energías Renovables (Special Program for the Development of Renewable Energy)

PER Prospectiva de Energías Renovables (Renewable Energy Prospective)

PRODESEN Programa de Desarrollo del Sistema Eléctrico Nacional (Development

Program for the National Electric System)

POISE Programa de Obras e Inversiones del Sector Eléctrico (Program for

Construction Development and Investment of the Electric Sector)

PUC public utility commission

PURPA Public Utility Regulatory Policies Act

PV photovoltaic

R\&D research and development

$\mathrm{RE} \quad$ renewable energy

REC renewable energy certificate

RIM Ratepayer Impact Measure

RTP real time pricing/price

SAIC APS Science Applications International Corporation / Applied Physical Sciences

SDE

stimulering duurzame energie

SDG\&E San Diego Gas \& Electric

SENER

SCT

TOU

Secretaría de Energía (Secretary of Energy)

TRC Total Resource Cost

UCT Utility Cost Test

VOS value of solar 


\section{Table of Contents}

Introduction: Mexico's Energy Reform and Distributed Generation Policy Goals ........................... 1

1 Distributed Generation Policy and Deployment in Mexico ............................................................ 3

1.1 Legal Framework for the Electric Sector: Before and After Energy Reform ............................ 3

1.2 Definition of Distributed Generation in the Scope of This Report............................................ 7

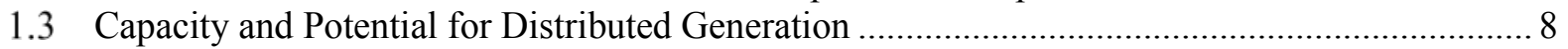

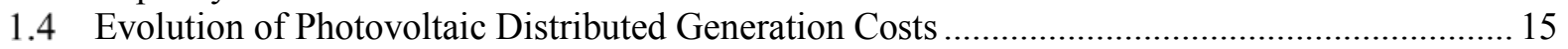

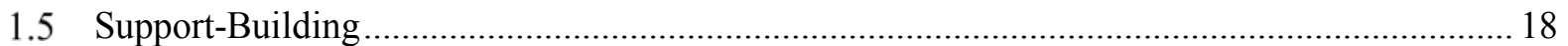

1.6 Policies That Have Led to Distributed Generation Adoption...................................................... 19

1.7 Regulatory Mechanisms That Have Supported Adoption ................................................... 20

1.8 Impact of the Energy Reform on the Deployment of Distributed Generation ............................ 22

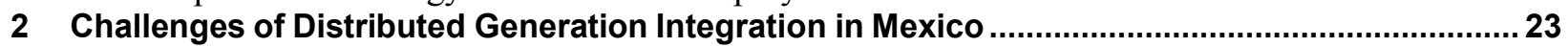

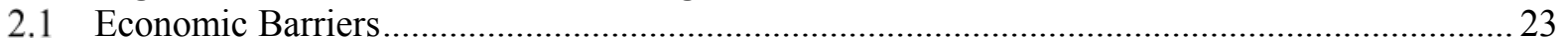

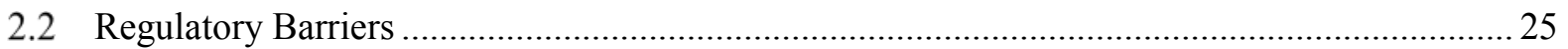

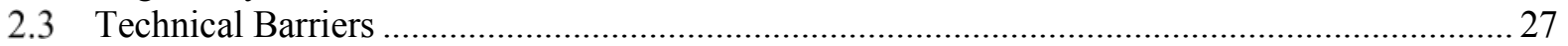

3 International Survey of Economic and Regulatory Policies to Address Economic, Regulatory,

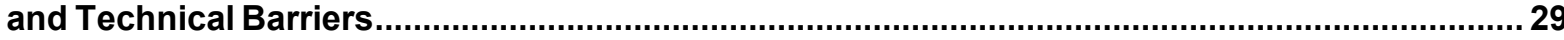

3.1 Categories of Economic and Regulatory Policy Support ..........................................................2 29

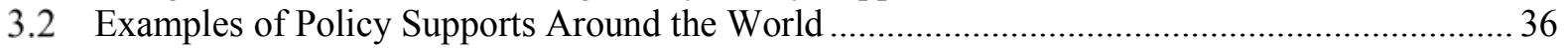

3.3 Identifying the Right Portfolio of Policies for Mexico ........................................................... 43

4 Ensuring Equity and Fairness through Proper Valuation of Distributed Generation.................. 44

4.1 Specific Sources of Distributed Generation Benefits and Costs ............................................. 44

4.2 Cost Testing from Various Stakeholder Perspectives ............................................................... 46

4.3 The Utility Net Value Proposition from the Administrator Perspective ................................... 47

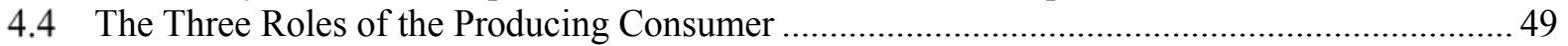

4.5 The Net Value Proposition from a Societal Perspective ...................................................... 50

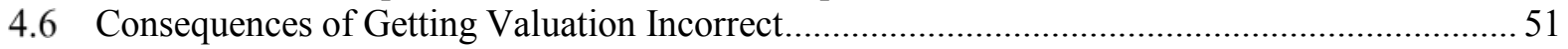

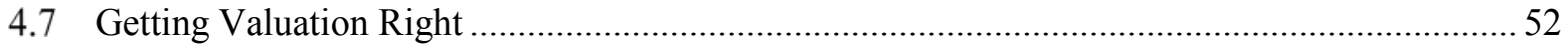

5 Designing Distributed Generation Tariff, Rate Design, and Policy Options ................................53

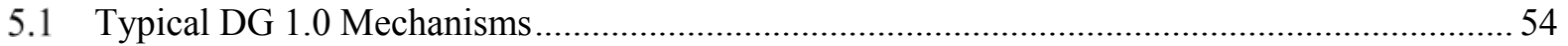

5.2 DG 2.0 Tariff Mechanisms: Where are We Heading? .............................................................. 55

5.3 Toward DG 2.0: Improving Net Energy Metering through Rate Design Improvements without

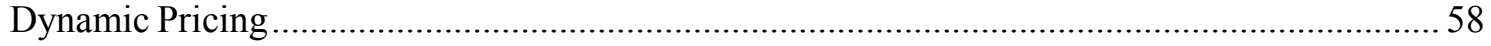

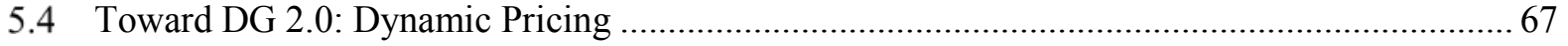

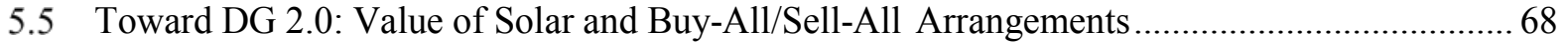

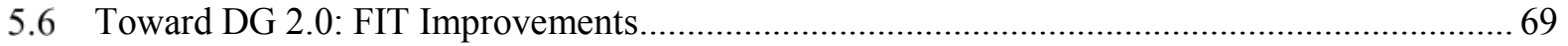

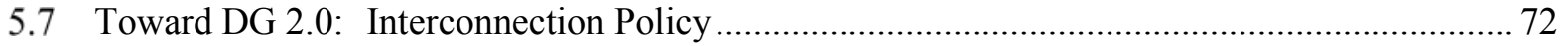

5.8 Toward DG 2.0: Commercial and Industrial DG Tariff and Market Access Issues ................... 74

5.9 Toward DG 2.0: Best-Practice Economic and Market Development Support Policies............... 76

5.10 Toward DG 2.0: Best-Practice Performance Regulation Options ............................................ 77

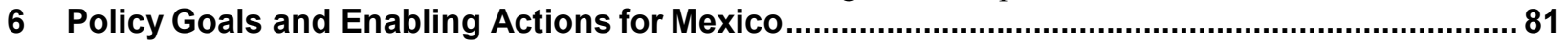

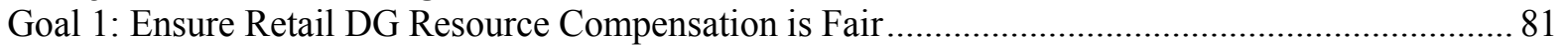

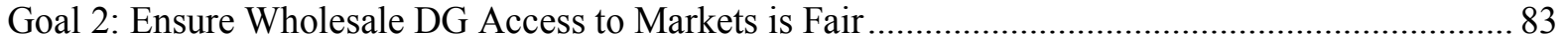

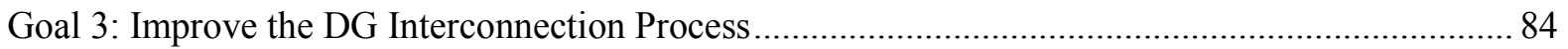

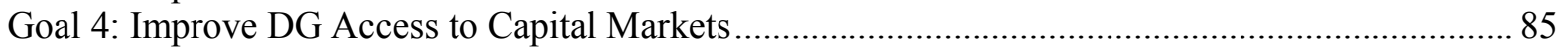

Goal 5: Expand Customer Access to DG Participation Options .................................................... 86

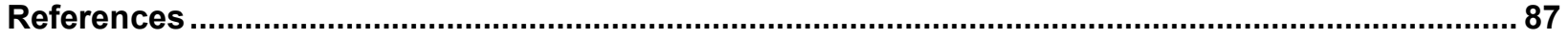




\section{List of Figures}

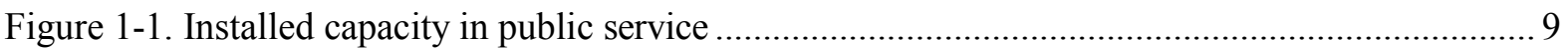

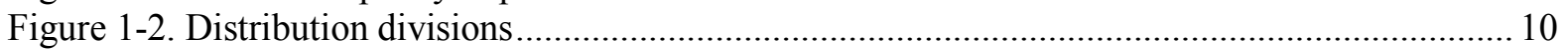

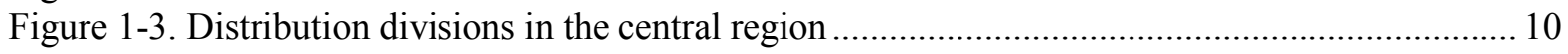

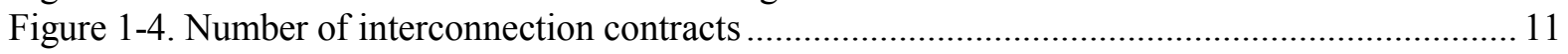

Figure 1-5. Installed capacity through interconnection contracts .................................................... 11

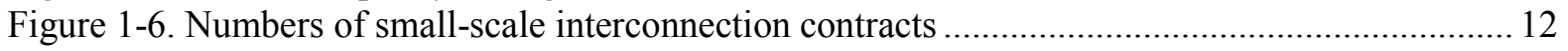

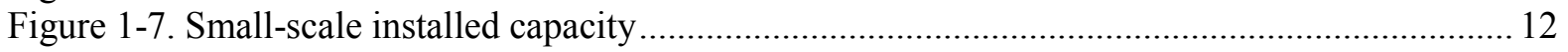

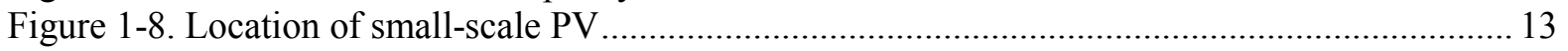

Figure 1-9. Numbers of medium-scale interconnections contracts, 2014 ...................................... 13

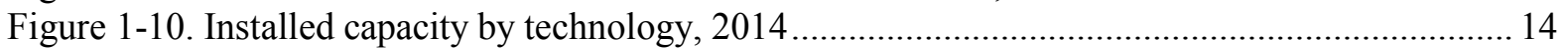

Figure 1-11. Locations of installed capacity, medium-scale ............................................................ 14

Figure 1-12. Viability of renewable DG in Mexico (US\$ per kilowatt-hour)................................. 15

Figure 1-13. Levelized cost of energy for selected DG technologies in the United States ................. 16

Figure 1-14. Reported, bottom-up, and analyst-projected average U.S. PV system price over time ... 17

Figure 1-15. Clean generation share targets for a 20-year horizon .................................................... 19

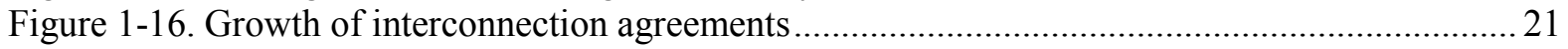

Figure 1-17. Percent decrease in electricity bills of net-metered consumers ..................................... 21

Figure 3-1. "Duck curve" showing net system demand on system with high levels of solar and

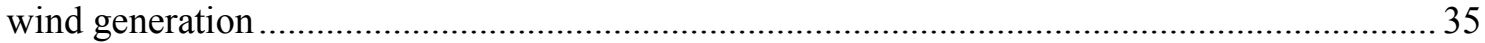

Figure 3-2. U.S. states with mandatory NEM or FIT requirements …........................................... 40

Figure 3-3. U.S. states allowing third-party ownership of solar PV systems ................................... 41

Figure 3-4. U.S. states allowing meter aggregation for net metering .............................................. 42

Figure 4-1. The typical PV owner as customer, self-provider, and exporter ..................................... 49

Figure 5-1: "Value of Solar" studies and U.S. residential rates ......................................................... 57

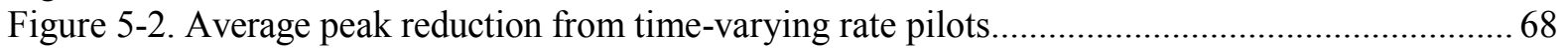

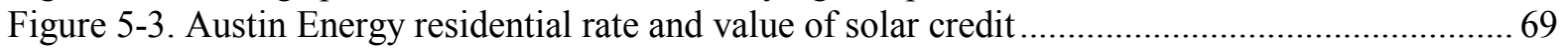

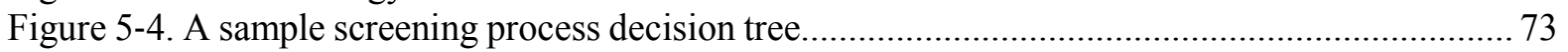




\section{List of Tables}

Table 1-1. Additional Capacity Status by Project and Technology, 2015-2029 (MW)...................... 6

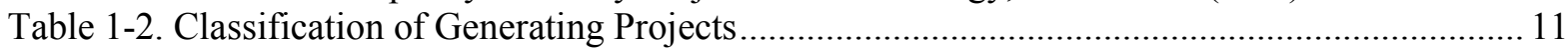

Table 1-3. Levelized Cost of Energy for Solar PV in 2015 and 2030 ........................................... 17

Table 1-4. Forecasts of Generation Costs for Some Technologies, 2022 and 2040......................... 18

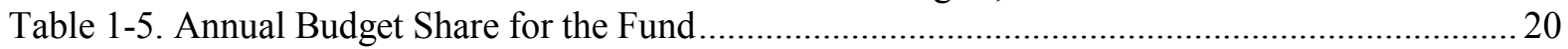

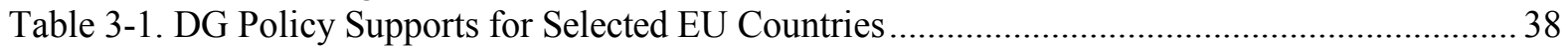

Table 4-1. The Purpose of Stakeholder Perspective Tests ............................................................ 47

Table 4-2. Benefits and Costs in the Program Administrator Cost Test............................................ 48

Table 4-3. Benefits and Costs in the Total Resource Cost and Societal Cost Tests ........................... 50

Table 5-1. A Typical Rate Design and Three Alternatives .......................................................... 59

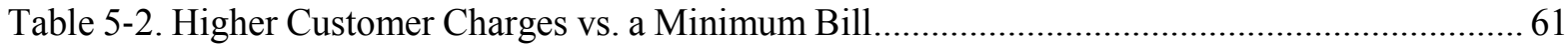

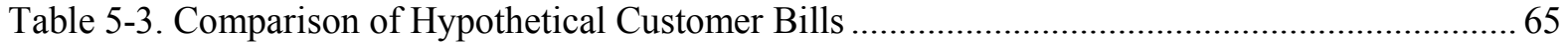

Table 5-4. PV Customer Bill Breakdown under Each Rate Design .................................................. 66

Table 5-5. Gainesville, Florida, FIT for Systems Energized in 2013 …........................................... 70

Table 5-6. Rate Design Options Taken from "Smart Rate Design for a Smart Future"........................ 74

Table 5-7. Conventional Areas of Performance Measurement ........................................................... 77

Table 5-8. Emerging Areas of Performance Measurement................................................................. 78

Table 5-9. Customer Engagement Performance Metrics.................................................................... 79

Table 5-10. Network Support Services Performance Metrics ........................................................... 80 


\section{List of Text Boxes}

Text Box 1. The Local Integration Challenge of High Solar DG Penetration .................................... 35

Text Box 2. The State of DG Development in Key Emerging Markets............................................ 37

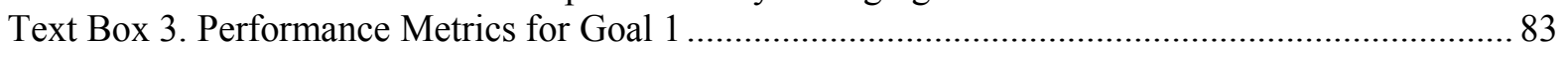

Text Box 4. Performance Metrics for Goal 2 ........................................................................... 84

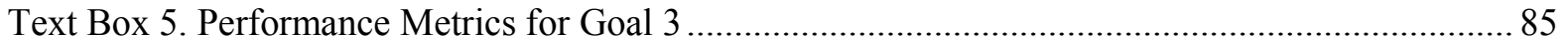

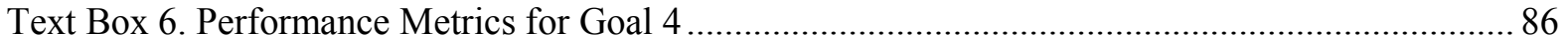

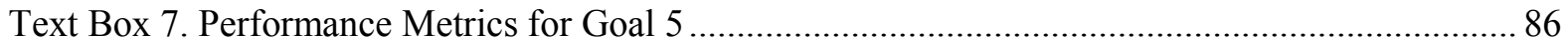




\section{Introduction: Mexico's Energy Reform and Distributed Generation Policy Goals}

Mexico's energy reform will have far-reaching effects on how people produce and consume electricity in the country. Market liberalization will open the door to an increasing number of options for Mexican residential, commercial, and industrial consumers, and distributed generation (DG), which for Mexico includes generators of less than 500 kilowatts (kW) of capacity connected to the distribution network. Distributed generation is an option for consumers who want to produce their own electricity and provide electricity services to others. The Smart Grid Regulatory Framework of Mexico (the Smart Grid Framework) ${ }^{1}$ declares that customer empowerment is the first of four framework pillars, and one can argue that customer-sited DG is perhaps the most literal embodiment of that pillar. At the same time, Mexican governmental officials understand that selecting economic and regulatory policy supports wisely and implementing them well is essential to create maximum societal benefits. This report was commissioned to provide guidance to Mexican officials on designing DG economic and regulatory policies.

The first five sections of the report summarize the current energy policy context in Mexico, describe opportunities and barriers for DG in Mexico, survey DG policies that have been implemented in other countries, describe the sources of value that should be considered in evaluating mature DG 2.0 policies, including their cost effectiveness and alternative rate designs, and describe the central role of rate design and pricing in developing a set of policy options to encourage expanded and cost-effective DG adoption.

Section 1 presents the recent history of DG in Mexico and looks at where DG could be in the coming years as regulatory reform of the power sector takes hold. The section describes the overall policy direction of Mexico and describes how DG deployment is reflected in broader policy goals.

Section 2 builds on the Section 1 situation analysis and applies the research from the Smart Grid Framework to summarize the economic, regulatory, and technical barriers that Mexican officials feel need to be addressed in order for DG to take off in the coming decade.

Section 3 takes stock of the barriers identified in Section 2 and then looks to international examples of DG economic, regulatory, and market development policies that might help overcome those barriers. The examples include a survey of emerging markets, the European Union (EU), and U.S. policy supports. The challenge faced by Mexican officials is to choose the portfolio of policies that best address the barriers they see and move DG growth onto a trajectory consistent with their goals for the Mexican power sector.

Section 4 lays a foundation for selecting the best policy portfolio for Mexico by taking on the complex subject of the "value of DG." The fundamental truth is that there is not one "value of

\footnotetext{
${ }^{1}$ The Smart Grid Regulatory Framework of Mexico is a 2014 report prepared for the Comisión Reguladora de Energía (CRE) that outlined a regulatory framework for Mexico to develop a path to regulate the electric sector in the presence of a smart grid. See http://cre.gob.mx/documento/3979.pdf.
} 
DG" but several values. This value is in the eye of the beholder, and Section 4 attempts to convey differences in the value proposition depending on whether the "beholder" is DG adopters, consumers who are not DG adopters, all power sector participants in aggregate, or Mexican society as a whole. While some sources of value (costs and benefits) are relevant to more than one perspective, the combinations of factors that play into the value of DG from each perspective are different.

Section 5 describes how Mexico can leverage the Smart Grid Framework to transition from DG basic policy options typically introduced when DG adoption is low (DG 1.0 policies) to a series of more complex policies typically found in areas where the sector is more mature (DG 2.0). Section 5 describes how DG tariffs and rate design need to evolve to maximize rapid costeffective DG adoption. The section first takes on the issues of net energy metering, feed-in tariffs, and other tariff structures. It then examines rate design approaches to support a DG value proposition that promotes fairness among different interests. While selecting a tariff and rate design approach is central to a DG 2.0 future that overcomes economic and regulatory barriers, a broader range of DG 2.0 policies is needed to address the full range of regulatory and technical barriers. The remaining sections of Section 5 describe the DG 2.0 policies.

Section 6 proposes 5 DG policy goals and sorts the DG 2.0 policy options into the relevant goals. The 5 goals are:

1. Ensure retail DG Resource compensation is fair

2. Ensure wholesale DG has access to markets

3. Improve the interconnection process

4. Improve DG access to capital markets

5. Expand customer access to DG participation options.

The primary purpose of this report is to provide Mexican officials with options for specific policy action items to expand the adoption of DG cost-effectively in Mexico. Section 6 summarizes the set of 14 policy action items within the context of the 5 proposed DG policy goals and provides sample performance metrics that could be tracked to ensure progress toward meeting the goals over time. 


\section{Distributed Generation Policy and Deployment in Mexico}

\subsection{Legal Framework for the Electric Sector: Before and After Energy Reform}

\section{Former Legal Framework}

Prior to the passage of energy reform in Mexico at the end of 2013 (see Section 1.2), the legal framework in place called for electric public service to be carried out by the Comision Federal de Electricidad (CFE) (Federal Electricity Commission), Mexico's state-owned utility. The framework stated that private investors could participate in the generation of electricity under various schemes: self-supply, cogeneration, independent power production, small production, export, and import. By the end of 2014, more than 40\% of Mexico's total electricity generation came from privately owned projects.

At the end of 2008, Mexico's Congress passed the Law on Renewable Energy Development and Energy Transition Financing (RE Act for short, or LAERFTE by its Spanish acronym). Over the several years prior to the law's passage, the Energy Regulatory Commission (CRE) issued a number of regulatory instruments to incentivize private investment in this field. These instruments were designed under the assumption that no subsidies, such as feed-in tariffs at premium prices, would be available, thus making it necessary to look for alternative measures to promote renewable energy. The underlying logic was to implement policy instruments that would level the field for these kinds of technologies by recognizing the special characteristics of variable sources of renewable energy, such as wind and solar. Therefore, the regulation implied that CRE was seeking to explicitly coordinate regulation with energy policies intended to support renewable energy. For example, a policy of allowing northern Mexico businesses to pay for transmission from southern Mexico wind resources facilitated direct contracting that led to wind and transmission development in Mexico (Center for Clean Air Policy 2011). These types of policy instruments were successful because of support from all relevant players: the Ministry of Energy (SENER), CFE, financing entities, developers, permit holders, and investors. With the passage of the RE Act, however, the Congress conveyed a clearer political will to set Mexico on a path away from its dependence on fuel oil and natural gas for the generation of electricity.

The RE Act, first published in October 1995 and reformed in 2008, established powers to regulate the electricity and hydrocarbons sectors and aimed to achieve efficient markets whenever possible. CRE was responsible for issuing permits for the generation or import of electricity, modeling contracts for backup power, wheeling, the sale of excess energy to CFE, and other technical, economic, and legal conditions that regulated the relationship between CFE and permit holders. CRE has also issued methodologies to calculate charges for services rendered between the parties. Project developers had used this regulation since the late 1990s to get all needed financing for their generating plants, regardless of energy source, and to clarify their day-to-day operations. Once the RE Act went into effect, CRE produced specific regulation for renewable energy and cogeneration projects.

For some years, the Electricity Act reforms of 1992 served as the legal framework on which $\mathrm{CRE}$ regulation was based. Once the RE Act went into effect, specific powers and responsibilities were given to both SENER and CRE for the sake of promoting renewables and 
cogeneration. One new requirement was that SENER must produce and publish, with the Senate's approval, a national energy strategy and a program for the use of renewable energy. The renewables program must define compulsory goals for the penetration of renewable energy and cogeneration in the generation mix and guide the pace at which renewable energy projects should enter commercial operation, in the same manner as a renewable portfolio standard. In addition, SENER was tasked with publishing a methodology to calculate the value of environmental externalities and consider this value when approving the expansion of public utilities' generating capacity.

The RE Act granted CRE the following authorities:

- Issue standards, orders, methodologies, model contracts, and all other rules to regulate the generation of electricity with renewable energy and cogeneration

- Issue regulatory tools to calculate payments for services rendered between CFE and investors

- Verify and approve technical requirements for interconnection into the national grid

- Require the system operator to modify its dispatching rules to guarantee that no undue barriers are imposed on renewable energy and cogeneration projects

- Issue the methodology whereby capacity credits are granted to renewable energy and cogeneration projects

- Set maximum payments to be paid in renewable energy projects that CFE may contract

- For projects below 20 megawatts (MW), set the payment CFE shall remunerate private projects and the rules for contract allocation, following the goals established by SENER in the program

- Calculate payments that include the value of externalities when the goals set by the program may not be reached.

Based on the requirements outlined above, two guiding documents were developed by SENER: the National Strategy for Energy Transition and Sustainable Use of Energy (ENTEASE) and the Special Program for the Development of Renewable Energy (PEAER) (SENER 2014a; SENER 2014b).

ENTEASE is the public policy mechanism by which the state promotes policies, programs, actions, and projects to promote and encourage the use and application of clean and renewable technologies.

PEAER, which will be updated annually, analyzes the integration of renewable energy in the country within the context of the energy transition. It establishes specific goals and objectives for the use of renewable energy technologies, defines strategies and actions to achieve them, and sets goals for the participation of renewables in electricity generation.

Furthermore, the National Energy Strategy of 2010, developed by SENER, states that the minimum participation of generation based on clean energy should be at least $35 \%$ by 2024 . SENER introduced the Renewable Energy Prospective (PER by its acronym in Spanish) as a 
complementary effort to the PEAER. The PER estimates that DG will constitute more than 2,200 MW by 2028. The total is expected to be distributed as follows: 1,273 MW of solar photovoltaic (PV), $402 \mathrm{MW}$ of bioenergy, $395 \mathrm{MW}$ of wind power plants, $150 \mathrm{MW}$ in water projects, $57 \mathrm{MW}$ of geothermal, and $1 \mathrm{MW}$ of solar thermal technology. While the PEAER establishes specific objectives, goals, strategies, and actions for the development of renewables in Mexico, the PER is intended to inform society in general regarding the current and projected state of renewable development in the country.

The Development Program of the National Electricity System (PRODESEN) is a reference and consultation document that includes the development program for generation, transmission, and distribution of electrical energy in Mexico (SENER 2015a). The PRODESEN is the responsibility of SENER and replaces the former Program for Construction Development and Investment of the Electric Sector (POISE). The first PRODESEN, covering the 2015-2029 period, was published on June 30, 2015. The goal of the PRODESEN is to guide productive investment in infrastructure to meet demand and in accordance with the provisions and regulations in the new Electricity Industry Act.

The PRODESEN includes current generation facilities and future power plants that appear on record. Currently, the document covers only utility scale projects, but future PRODESEN reports are expected to include expectations of future DG by technology. The PRODESEN also includes expansion and modernization projects for the national transmission and distribution networks. The document represents a new approach to comprehensive power sector planning, encompassing projects planned by both CFE and the private sector.

The expansion and modernization of the transmission network proposed in the PRODESEN is under the jurisdiction of the National Center for Energy Control (CENACE). The project aims to address congestion, reduce losses, encourage the use of more efficient technologies such as high voltage direct current transmission, and begin work to interconnect Baja California with the National Interconnected System. The PRODESEN incorporates the growth of clean energy technologies to promote a more diversified and efficient electricity grid, helping to meet the goal of $25 \%$ clean generation by 2018. Table 1-1 was taken from the PRODESEN (SENER 2015a). 
Table 1-1. Additional Capacity Status by Project and Technology, 2015-2029 (MW)

\begin{tabular}{|c|c|c|c|c|c|}
\hline Technology & $\begin{array}{c}\text { New } \\
\text { projects }\end{array}$ & $\begin{array}{l}\text { Under } \\
\text { construction } \\
\text { or tender to } \\
\text { begin work }\end{array}$ & $\begin{array}{l}\text { Work finished, } \\
\text { ready to begin } \\
\text { operations, or in } \\
\text { operation }\end{array}$ & $\begin{array}{l}\text { Rehabilitation } \\
\text { and } \\
\text { modernization }\end{array}$ & Total \\
\hline Clean & 20,379 & 11,291 & 662 & 220 & 32,552 \\
\hline Bioenergy & 0 & 63 & 45 & 0 & 108 \\
\hline Wind & 5,421 & 6,364 & 168 & 0 & 11,952 \\
\hline Geothermal & 1,290 & 275 & 53 & 0 & 1,618 \\
\hline Hydro & 4,064 & 1,385 & 0 & 0 & 5,450 \\
\hline Nuclear & 3,850 & 0 & 0 & 220 & 4,070 \\
\hline Solar & 483 & 1,325 & 15 & 0 & 1,822 \\
\hline $\begin{array}{l}\text { Efficient } \\
\text { cogeneration }\end{array}$ & 5,271 & 1,880 & 382 & 0 & 7,533 \\
\hline Conventional & 12,573 & 12,381 & 1,653 & 826 & 27,433 \\
\hline Coal-fired & 0 & 0 & 0 & 120 & 120 \\
\hline $\begin{array}{l}\text { Combined- } \\
\text { cycle }\end{array}$ & 12,349 & 12,148 & 1,570 & 376 & 26,443 \\
\hline $\begin{array}{l}\text { Internal } \\
\text { combustion }\end{array}$ & 1 & 111 & 19 & 0 & 131 \\
\hline $\begin{array}{l}\text { Conventional } \\
\text { thermoelectric }\end{array}$ & 0 & 0 & 0 & 330 & 330 \\
\hline Gas turbine & 220 & 120 & 63 & 0 & 403 \\
\hline Imports & 3 & 3 & 0 & 0 & 6 \\
\hline Total & 32,952 & 23,673 & 2,315 & 1,046 & 59,986 \\
\hline
\end{tabular}

The LAERFTE, the rules promulgated to support LAERFTE, the guiding documents, and the clean energy targets identified in the PEAER and PER prevail where no other document regarding the energy transition indicates otherwise.

\section{Energy Reform in Mexico, 2013-2014}

In December 2013, Mexico's Congress passed broad energy reform legislation that included amendments to Articles 25, 27, and 28 of the Mexican Constitution. The Energy Reform Act has broad implications for the energy sector and its stakeholders in Mexico. With this ratification, Mexico overturned the 1938 nationalization of its oil industry and opened its energy sector to outside investment. This is expected to rejuvenate Mexico's energy sector, stimulate economic growth and job creation, and, in time, attract substantial new resources to the energy market.

According to the law, secondary legislation and norms associated with the energy reform were completed within the first 120 days of 2014. In August 2014, the Congress approved 21 transitional articles (secondary legislation) proposed by the federal government through SENER with assistance from other government agencies. This legislation is intended to clarify stakeholders' roles in shaping policy and stimulate investment in renewable energy to promote the country's sustainable development and honor its commitment to mitigating climate change. As a result of this landmark reform, CRE's regulatory role will be considerably expanded and strengthened to effectively oversee a newly competitive energy market.

With this new legislation in place, Mexico foresees some important changes:

The public sector will be responsible, exclusively, for the strategic areas identified in Article 28, Paragraph 4 of the Constitution, the federal government should maintain the ownership and control over productive agencies and state enterprises 
which in their case are going to be established. In regards of the planning and control of the national electricity power system, and of the public service of transmission and distribution of electricity, as well as the exploration and extraction of oil and other hydrocarbons, the nation shall conduct these activities in terms of the provisions of the sixth and seventh paragraphs of Article 27 of this Constitution.

In these activities the law will establish the rules for the administration, organization, operation, procurement procedures and other legal acts that celebrate productive state enterprises, as well as the pay of their staff, to ensure effectiveness, efficiency, honesty, productivity, transparency and accountability, based on best practices, and identify other activities that may be performed.

These new mandates redefine some of the powers and responsibilities of SENER, CRE, CFE, and all stakeholders in the electric sector.

The separation of CENACE from CFE to become an independent national control center responsible for operating the grid and ensuring electric system reliability is another important change. CENACE is independent from CFE and is owned and controlled by the federal government. Other relevant modifications include establishing an open wholesale market for electricity, which is in progress, and increasing the use of clean energy sources. The new Electric Industry Act empowers CRE to issue rules, guidelines, and other administrative provisions on DG, based on the policy established by SENER.

\subsection{Definition of Distributed Generation in the Scope of This Report}

The definition of distributed generation, established in the Electric Industry Act and in the electric market rules, includes all clean generation that meets the following criteria:

1. Electricity must be generated by an electric power plant that does not require a generation permit (exempting generators where capacity is less than $500 \mathrm{~kW}$ ).

2. Electricity must be generated by an electric power plant directly connected to a distribution network with "high load concentration," which in turn is defined as:

A. The electric installed capacity must be smaller than the expected demand in the distribution network to which the electric power plant is connected, and the power plant must reduce or not have an impact on the maximum load of each element of the distribution circuit.

B. All electric power plants with installed capacity lower than $500 \mathrm{~kW}$ connected to a distribution network must observe the point (i) criteria, unless the independent system operator (CENACE) concludes the opposite.

3. Electricity must be generated by clean energies.

In the same act, the term "clean generation" is defined as those energy sources and electricity generation processes whose emissions or wastes do not exceed the limits established in regulations and guidelines. 
The following are considered clean energy sources:

- Wind

- Solar radiation in all its manifestations

- Oceanic energy in all its manifestations: tidal power, wave power

- Geothermal field's heat

- Bioenergy

- Energy generated through the use of biogas

- Energy generated through the use of hydrogen; either by its combustion or its use in fuel cells in terms defined by CRE and the environmental authority criteria

- Hydroelectric power

- Nuclear power

- Solid wastes and agricultural organic material in terms of the environmental authority criteria

- Energy generated by efficient cogeneration in terms of CRE's efficiency criteria

- Energy generated in sugar mills

- Energy generated in carbon dioxide $\left(\mathrm{CO}_{2}\right)$ capture technology power plants

- Technologies considered to produce low $\mathrm{CO}_{2}$ emissions according to international standards

- Other technologies approved by the Ministry of Environment based on efficiency and emissions standards and guidelines.

\subsection{Capacity and Potential for Distributed Generation}

By the end of 2013, total installed capacity in Mexico was 64,456 MW. Of this capacity, 83.8\% $(54,034 \mathrm{MW})$ was for public service, of which 39,656 MW relied on fossil fuels (mainly natural gas and fuel oil, with some coal) and the rest on clean energy sources. Figure 1-1 shows that as of 2013, Mexico was still relying heavily on fossil fuels, with coal having a much smaller presence than all other fossil-fueled capacity combined. This indicates the great potential to reduce all fossil fuel dependence and increase the use of renewable energy. Solar and small hydro have been the predominant DG technologies in Mexico. Public service had more than 599 MW of wind power capacity and 5.4 MW of solar power capacity. 


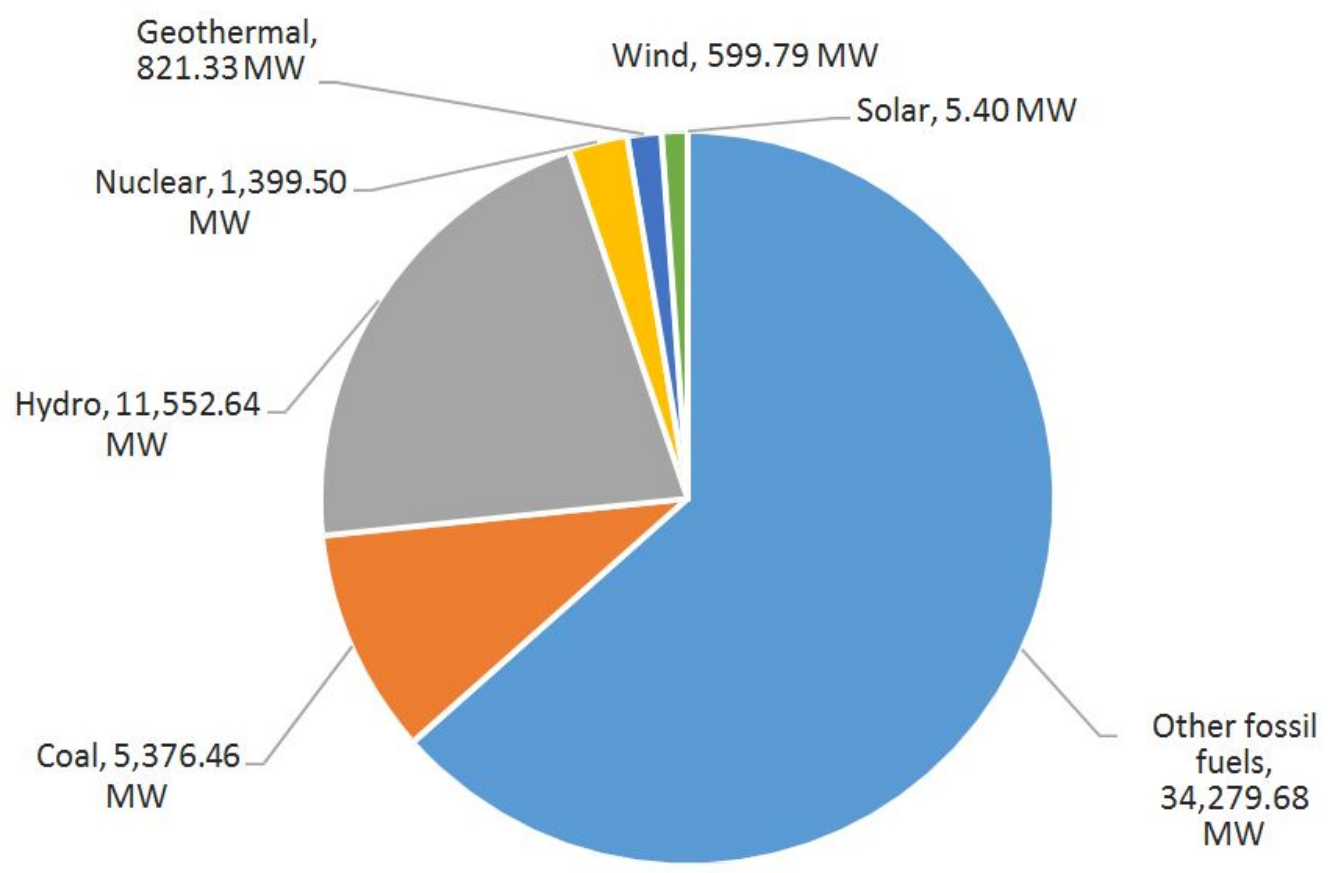

Figure 1-1. Installed capacity in public service

\section{Distribution Network}

For operation and planning purposes, CFE separated the country into 16 distribution divisions (Figure 1-2), which are further subdivided in the central region (Figure 1-3). 
12.- Sureste

13.- Peninsular

14.- Tres Divisiones de Distribución:

Valle de México Norte

Valle de México Centro

Figure 1-2. Distribution divisions

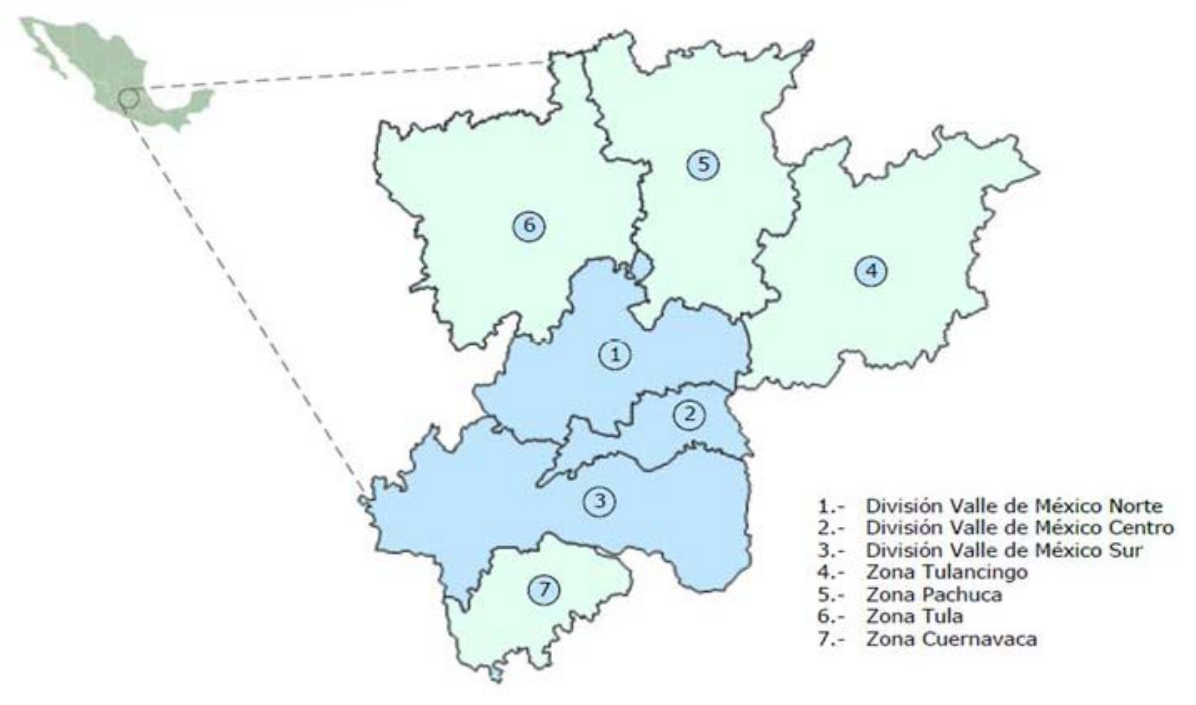

Figure 1-3. Distribution divisions in the central region 


\section{Medium and Small Generation Interconnection Applications}

In Mexico, all electricity generation projects require an interconnection contract. The process of securing such a contract begins with a request to the supplier. Projects with a capacity of more than $500 \mathrm{~kW}$ require an interconnection study be performed by CENACE that provides technical information about the project. The supplier makes technical comments on the draft, which must be addressed by the generator/owner. After it is finalized, the generator/owner can sign the interconnection contract based on the models used by CRE.

According to the former regulatory framework, projects below $500 \mathrm{~kW}$ may be classified within three different categories as shown in Table 1-2.

Table 1-2. Classification of Generating Projects

\begin{tabular}{ll}
\hline Installed Capacity & Classification \\
\hline Up to $10 \mathrm{~kW}$ & Residential small scale \\
Up to $30 \mathrm{~kW}$ & Commercial small scale \\
Up to $500 \mathrm{~kW}$ & Medium scale \\
\hline Source: CRE &
\end{tabular}

During the first half of 2014, the installed operating capacity for medium- and small-scale renewable generating projects was $36,088 \mathrm{~kW}$, which corresponded to a total of 5,475 interconnection contracts, as shown in Figures 1-4 and 1-5.

Number of contracts

$(5,475$ total)

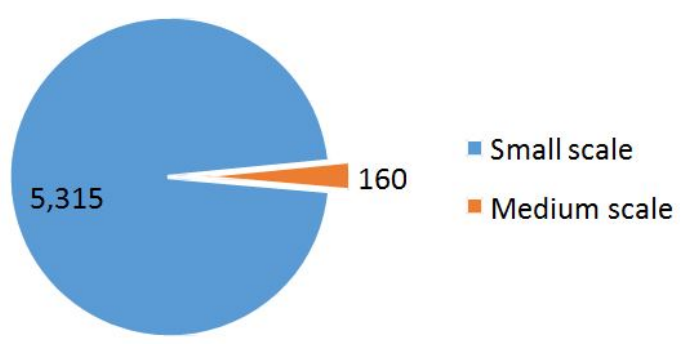

Figure 1-4. Number of interconnection contracts
Installed capacity through

interconnection agreement $(36,088 \mathrm{~kW})$

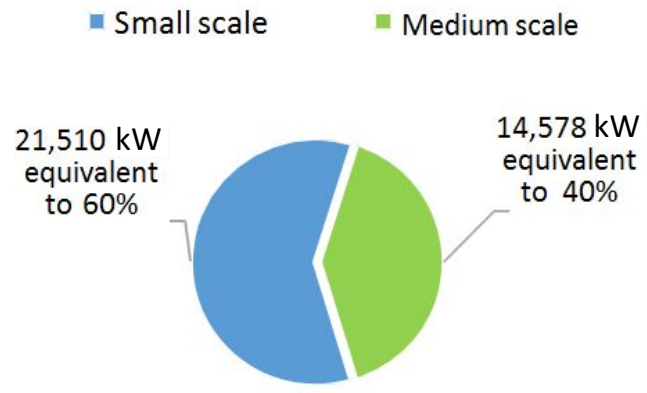

Figure 1-5. Installed capacity through interconnection contracts 


\section{Small-Scale Deployment}

During the first half of 2014, 5,315 small-scale interconnection contracts were operating. Figure 1-6 shows that 5,301 of those corresponded to solar PV projects; the rest were small-scale biogas, small-scale wind, and small-scale "solar-wind" hybrid projects.

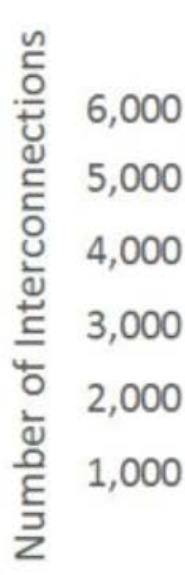

Technology

Number

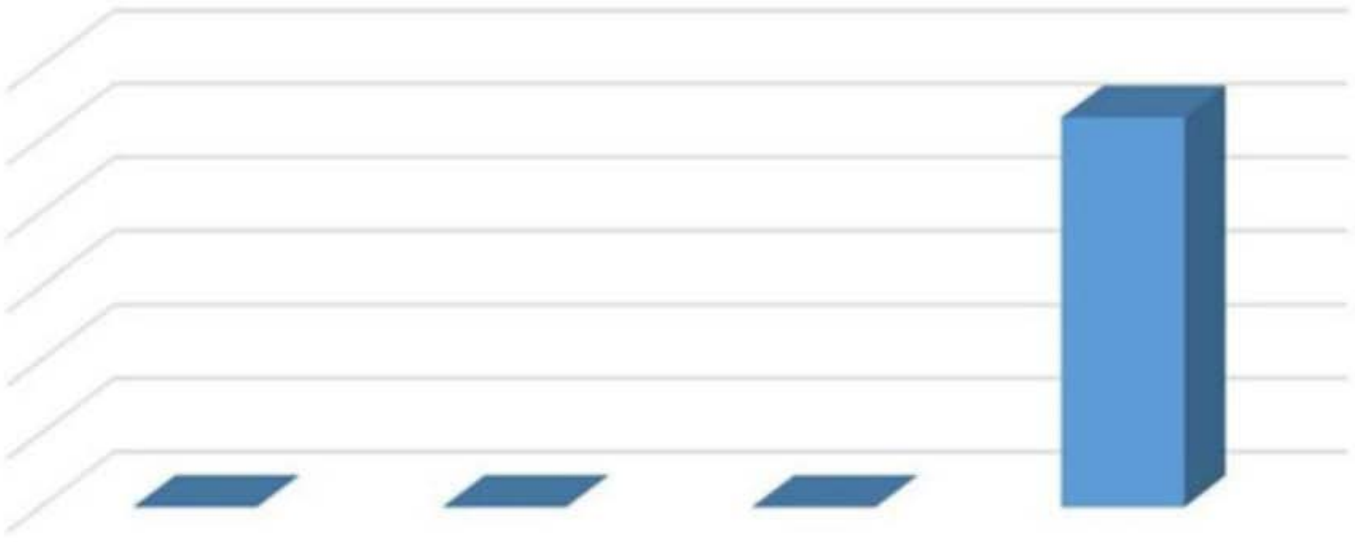

Small-scale
biogas

5
Small-scale wind

5

\section{Small-scale solar-} wind

4
Small-scale
solar

5,301

Figure 1-6. Numbers of small-scale interconnection contracts

Figure 1-7 shows that solar technology had an important contribution, with $21,396 \mathrm{~kW}$ of the total installed capacity of $21,510 \mathrm{~kW}$ :

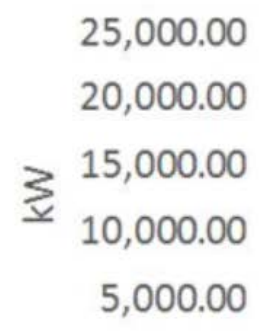

Technology

$\mathrm{kW}$
Small-scale biogas

74.34

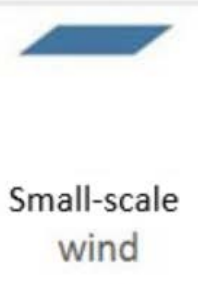

20.00

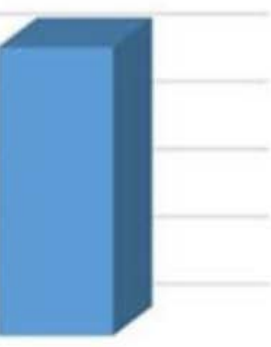
Small-scale solar-wind

Small-scale

18.50

21,396.97

Figure 1-7. Small-scale installed capacity 
According to CFE, the distribution divisions with the highest levels of small-scale solar penetration are Jalisco, with 5,831 kW, and Golfo Norte, with 5,211 kW (see Figure 1-8).

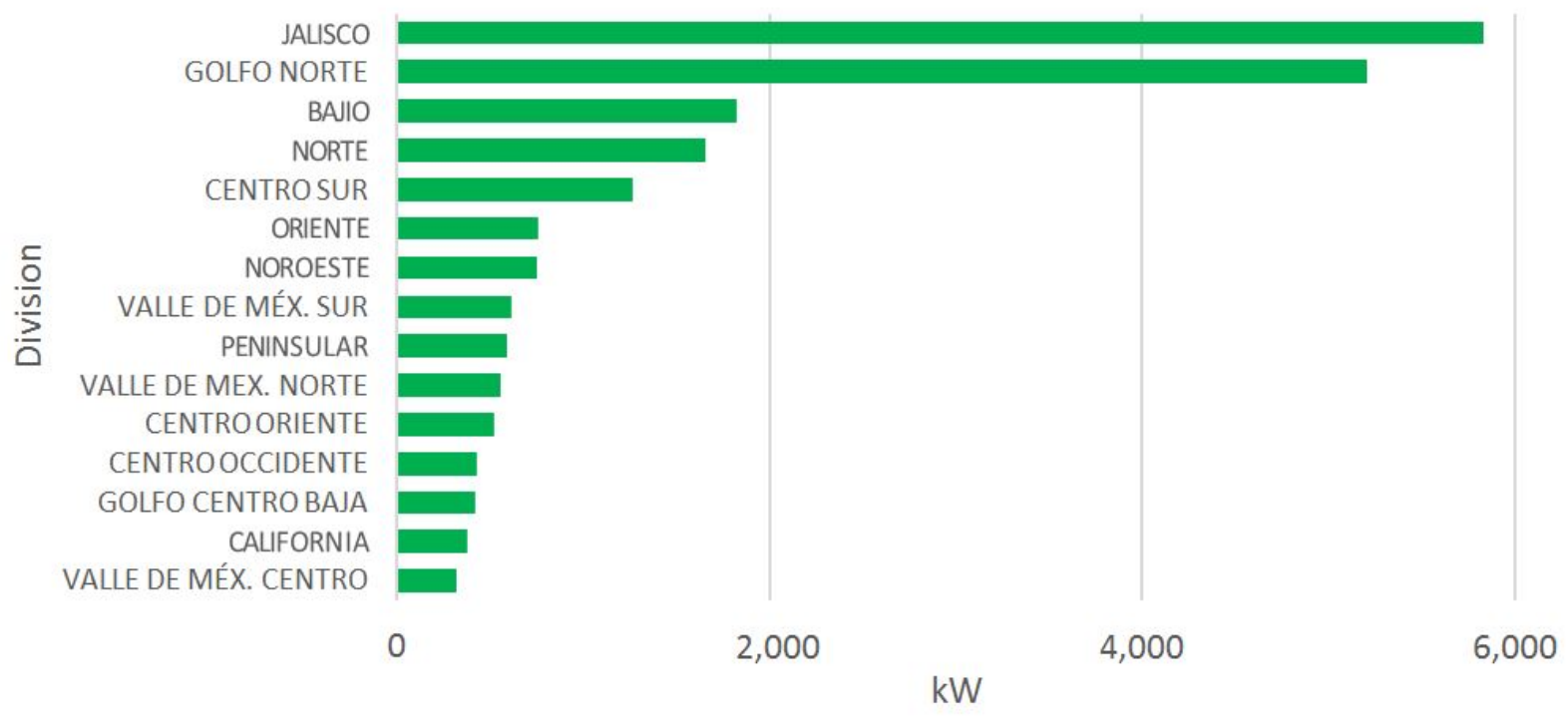

Figure 1-8. Location of small-scale PV

\section{Medium-Scale Deployment}

Figure 1-9 shows that during the first half of 2014, there were 160 medium-scale interconnection agreements with 138 medium-scale solar projects in operation.

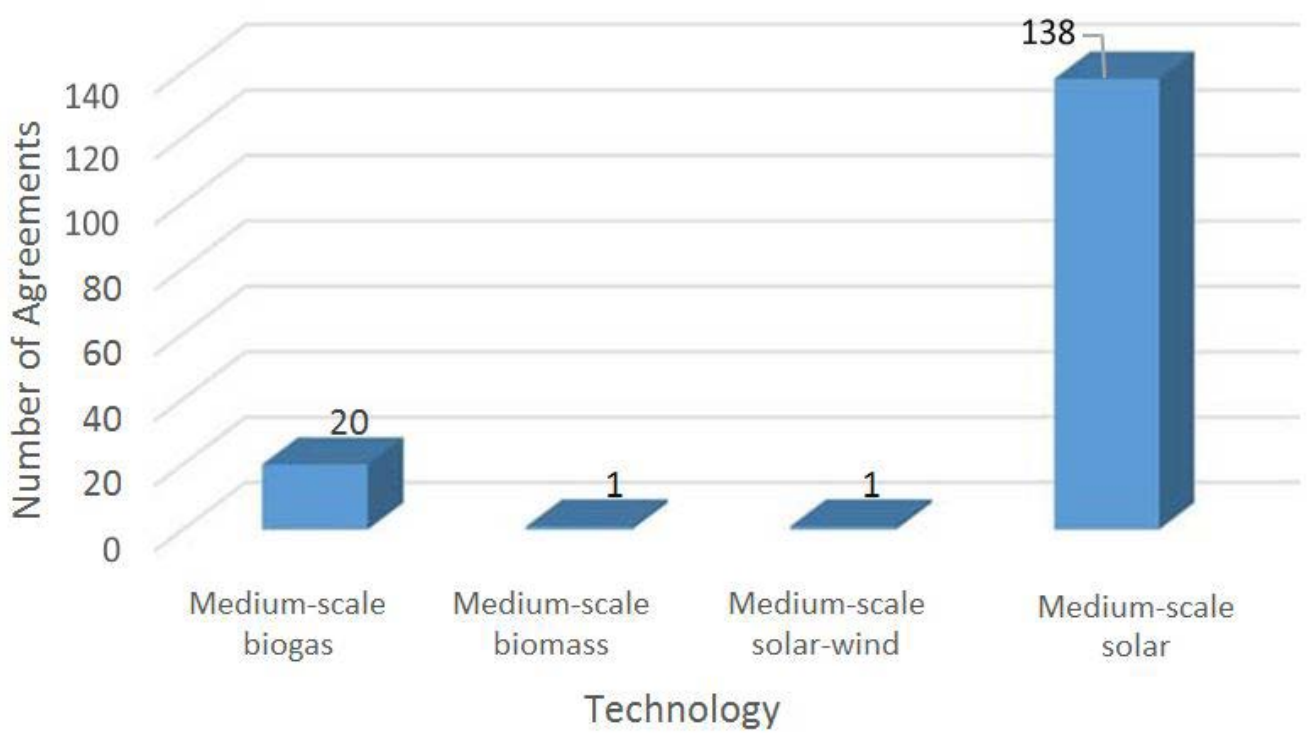

Figure 1-9. Numbers of medium-scale interconnections contracts, 2014 
By the first half of 2014, medium-scale installed capacity was $14,577 \mathrm{~kW}$. Figure 1-10 shows that solar technology accounted for $11,481 \mathrm{~kW}$ of that capacity.

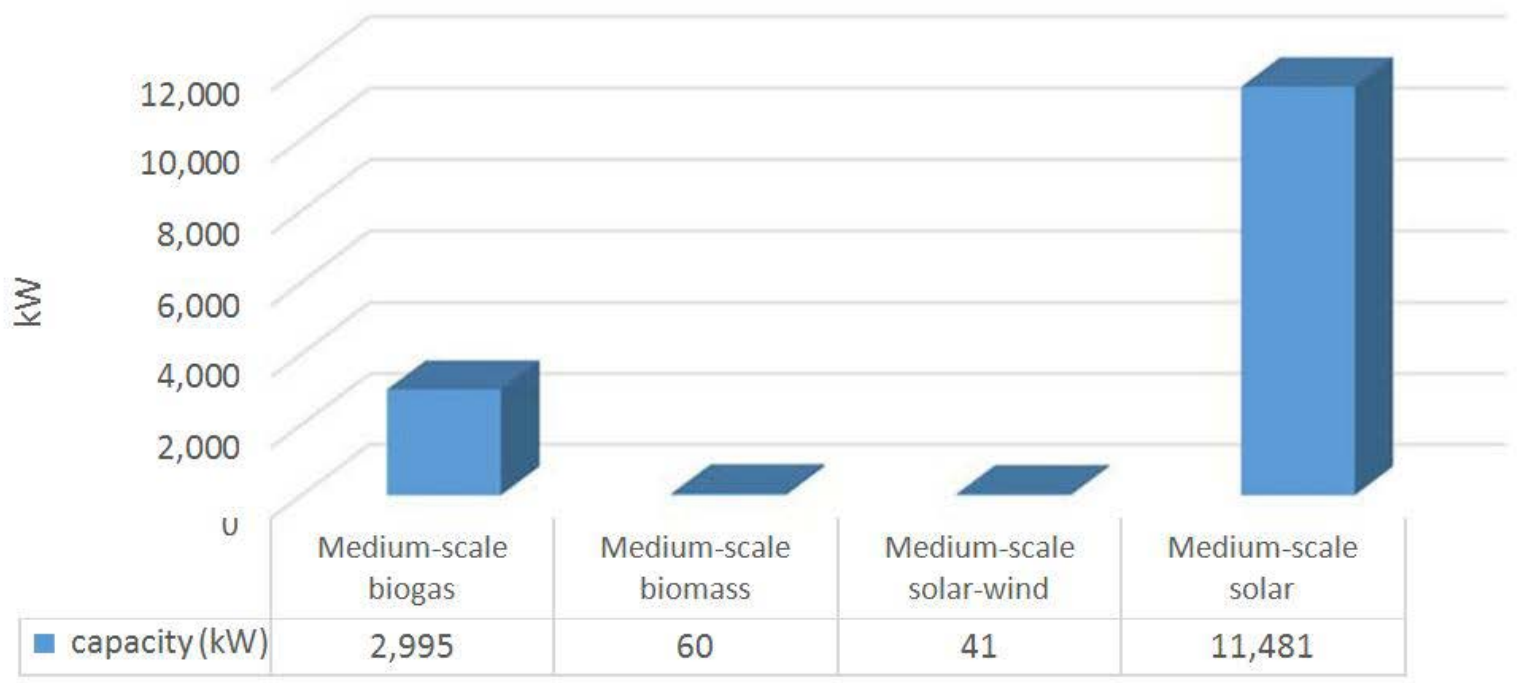

Figure 1-10. Installed capacity by technology, 2014

Figure 1-11 shows that medium-scale installed capacity is concentrated in Golfo Norte (2,523 $\mathrm{kW})$, Jalisco $(1,867 \mathrm{~kW})$, Norte $(1,507 \mathrm{~kW})$ and Golfo Centro $(1,369 \mathrm{~kW})$.

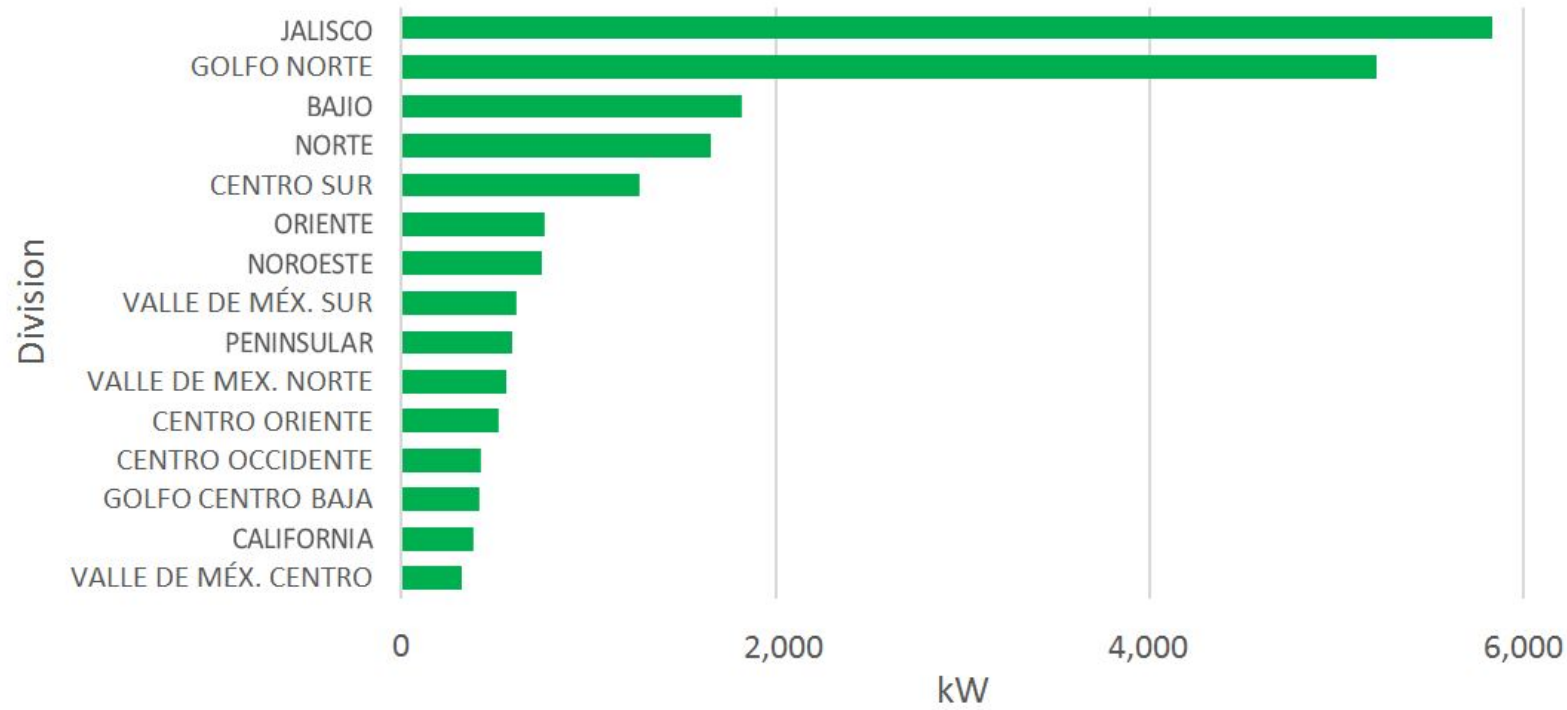

Figure 1-11. Locations of installed capacity, medium-scale

\section{Evolution of the Distribution Network as DG Adoption Grows}

CFE, in its 2014 expansion plan, states that it is putting more effort into DG impact studies as the penetration of clean DG grows. A significant adjustment in the distribution networks' planning and operating criteria will be needed so that reliability and security in protection and in operations and maintenance (O\&M) systems can be guaranteed. 
CFE suggests that protection systems must include bidirectional functions that can consider reverse power flows. Also, protections against voltage and frequency variations produced by clean technologies are needed.

\subsection{Evolution of Photovoltaic Distributed Generation Costs}

Solar cost estimates, including DG, have been declining steadily since 2010 in the United States and around the world. The most recently available study of Latin American DG costs was published in 2011. The Inter-American Development Bank (IDB) published Perspectives for Distributed Generation with Renewable Energy in Latin America and the Caribbean (Gischler and Nils Janson), which argued that renewable DG units were economically feasible only on the medium scale and not on the small scale (see Figure 1-12). The IDB's view in this study was that generation costs for these technologies were greater than natural gas generation costs and also higher than residential electricity rates, based on data from 2009 to 2011.

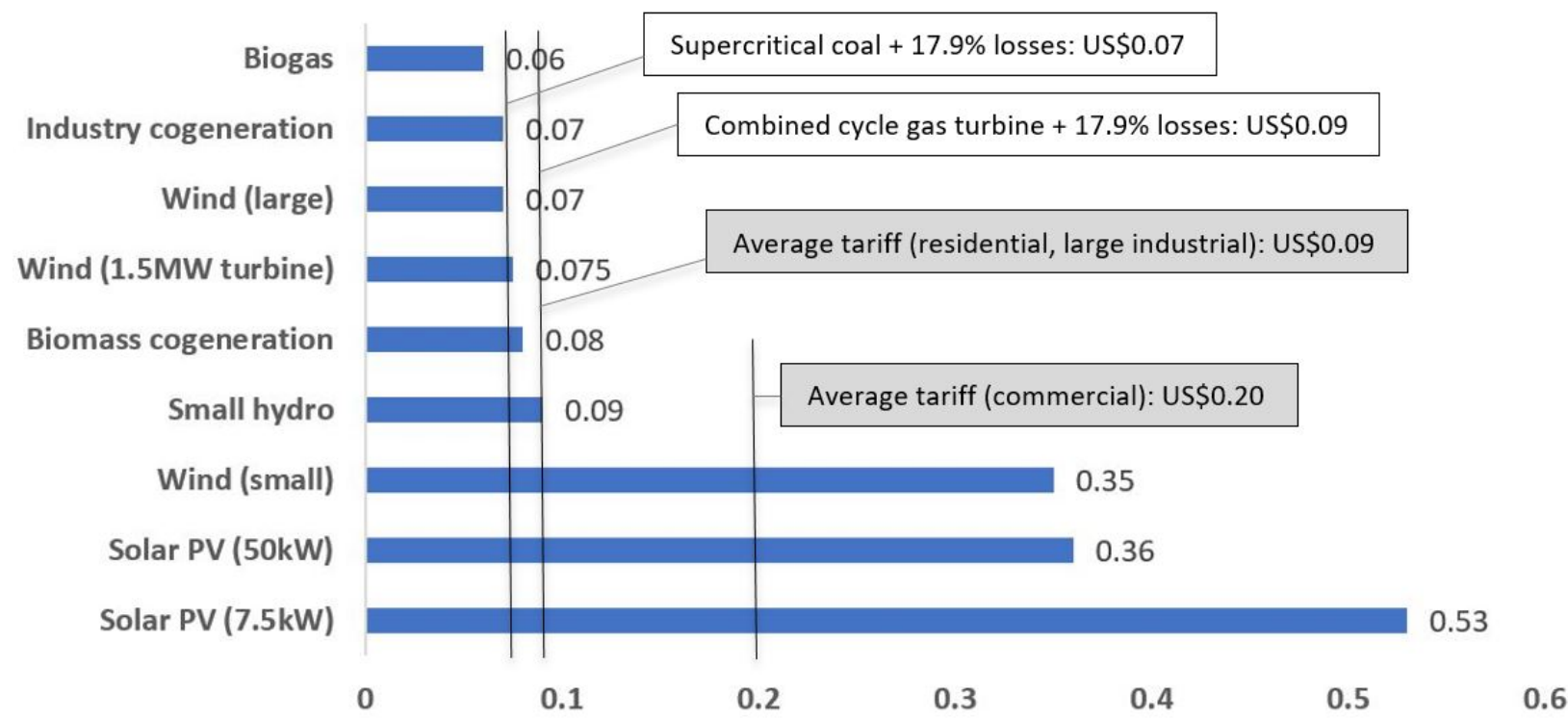

Figure 1-12. Viability of renewable DG in Mexico (US $\$ 2$ per kilowatt-hour) ${ }^{3}$

The IDB study is a useful snapshot for the region, but since it was published, its cost conclusions have been superseded by global and U.S. data that have consistently shown reductions in cost for solar.

In 2010, the International Energy Agency's World Energy Outlook projected that the cost of solar PV would fall by almost half between the current decade (2010-2020) and the period of 2021-2035. As significant as that prediction seemed at the time, it has already been outstripped by real-world reductions in cost that are even sharper. Salvatore (2013) presents levelized cost of energy (LCOE) estimates, a common metric for comparing generation costs of different

\footnotetext{
${ }^{2}$ All currency amounts shown in this paper are U.S. dollars.

${ }^{3}$ Small wind assumed $\$ 6,000 / \mathrm{kW}$, a $30 \%$ capacity factor, and a $12 \%$ discount rate. The source for fossil fuel technologies, biogas, industry cogeneration, wind (large), biomass cogeneration, and small hydro is Johnson et al. (2009). For solar PV, information is from Mexican system providers. For a 1.5-MW wind turbine, the source is IDB (2011).
} 
technologies, and estimates for DG technologies in 2013 in the United States show that further cost reduction beyond the 2010 IEA projections is already occurring (Salvatore 2013). ${ }^{4}$ In many cases, the LCOE for DG technologies is now close to, or even less than, the retail cost of delivered electric power in the United States, as indicated in Figure 1-13.

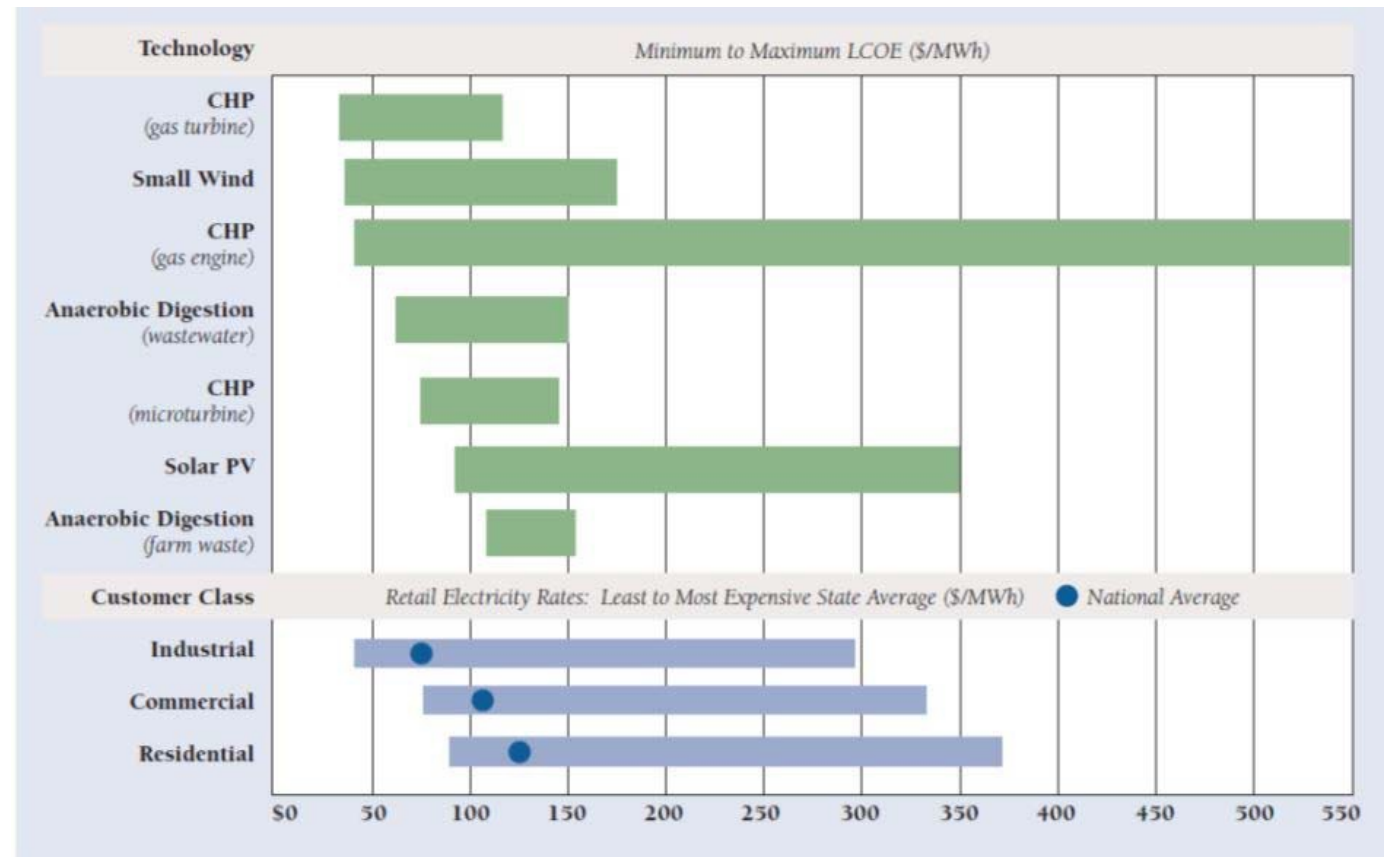

Figure 1-13. Levelized cost of energy for selected DG technologies in the United States

Sources: Linvill et al. 2013

LCOE data are based on Salvatore 2013. Retail rates data are from EIA 2013.

The decline in the cost of solar PV in the United States has been especially dramatic in the last few years, as shown in Figure 1-14, and there are reasons to believe that prices will continue to decline in the U.S. Feldman et al. (2015) report that the installed cost of solar PV in the United States is roughly double the installed cost in Germany, and they attribute the disparity to differences in balance-of-system costs. ${ }^{5}$ These sustained cost declines in the United States and Germany are an indication of the kind of cost levels and cost declines that can be expected in Mexico as penetration levels increase. Lazard's most recent study provides further evidence that solar costs continue to decline. For example, Lazard's most recent LCOE analysis found that from 2010 to 2016, the cost of commercial and industrial rooftop solar dropped by half, from $\$ 300$ per MWh to $\$ 150$ (Lazard, 2016).

\footnotetext{
${ }^{4}$ LCOE reflects the anticipated average cost per unit of electricity that will be generated over the financial life and duty cycle of a typical generator; it includes both capital costs and operation and maintenance costs.

${ }^{5}$ Balance-of-system costs refer to all costs of installing a DG system other than the cost of the generation equipment itself. For example, balance-of-system costs for a PV system include the cost of an inverter, any incremental metering expense, and the cost of framing and installing the system.
} 


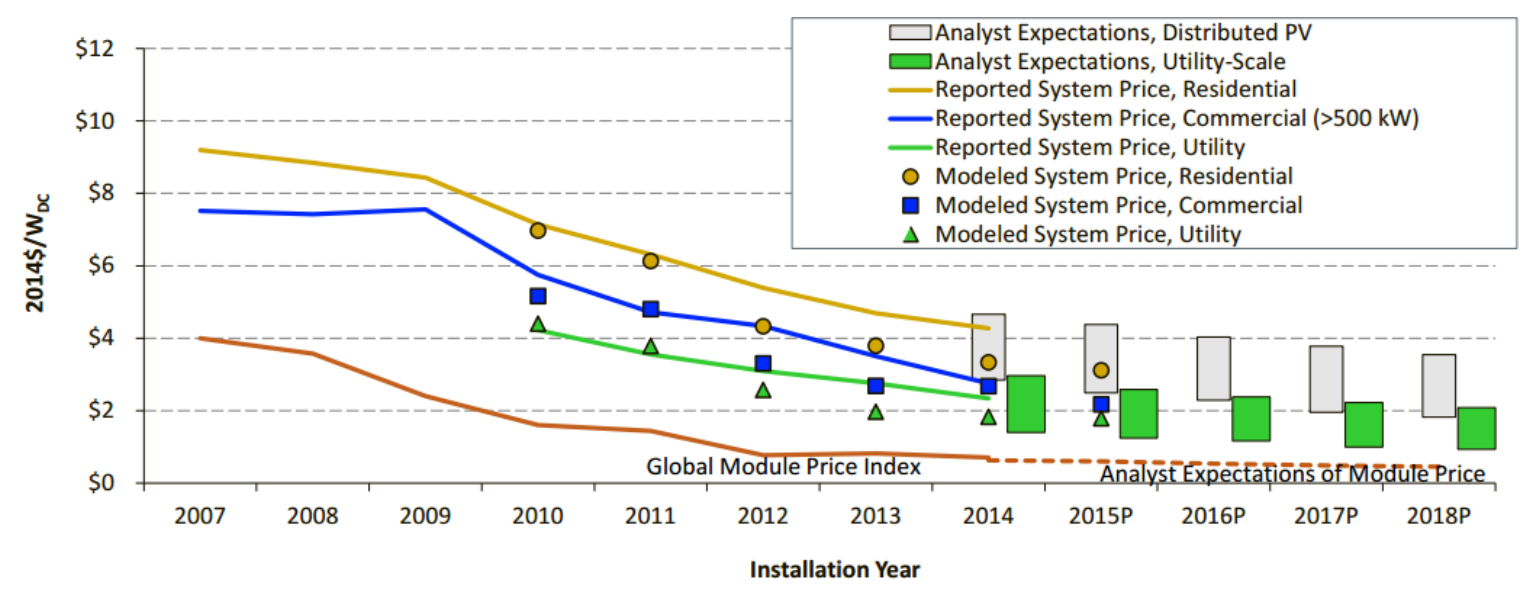

Figure 1-14. Reported, bottom-up, and analyst-projected average U.S. PV system price over time

Source: Feldman et al. 2015

These trends are forecast to continue in the medium to long term. Table 1-3, based on data from the International Energy Agency, shows that PV technology globally is expected to fall significantly in cost over the next 15 years. Utility-scale solar's levelized cost is projected to fall by $\$ 81 / \mathrm{MWh}$, a reduction of almost half, while rooftop systems' cost is projected to fall by $40 \%$.

Table 1-4, based on data from the U.S. Energy Information Administration (EIA), looks further out to show that while the pace of falling costs will slow over the next 20-25 years, solar's cost reduction (15\% between 2022 and 2040) will still outpace that of wind (8\%) and hydro (3.6\%) over the same period.

Table 1-3. Levelized Cost of Energy for Solar PV in 2015 and 2030

\begin{tabular}{|c|c|c|c|c|}
\hline Scenario & Technology & $\begin{array}{l}\text { LCOE } 2015 \\
\text { (USD/MWh) }\end{array}$ & $\begin{array}{l}\text { LCOE } 2030 \\
\text { (USD/MWh) }\end{array}$ & $\begin{array}{c}\text { Capacity } 2030 \\
\text { (GW) }\end{array}$ \\
\hline \multirow{2}{*}{ 2DS } & Utility-scale systems & $\begin{array}{c}110-294 \\
\text { (164 global average) }\end{array}$ & $\begin{array}{c}68-173 \\
\text { (83 global average) }\end{array}$ & \multirow{2}{*}{841} \\
\hline & Rooftop systems & $\begin{array}{c}125-499 \\
\text { (186 global average) }\end{array}$ & $\begin{array}{c}77-389 \\
\text { (110 global average) }\end{array}$ & \\
\hline \multirow{2}{*}{ 2DS hi-Ren } & Utility-scale systems & $\begin{array}{c}110-294 \\
\text { (164 global average) }\end{array}$ & $\begin{array}{c}52-129 \\
(75 \text { global average) }\end{array}$ & \multirow{2}{*}{1920} \\
\hline & Rooftop systems & $\begin{array}{c}125-499 \\
\text { (186 global average) }\end{array}$ & $\begin{array}{c}59-214 \\
\text { (94 global average) }\end{array}$ & \\
\hline
\end{tabular}


Table 1-4. Forecasts of Generation Costs for Some Technologies, 2022 and 2040

\begin{tabular}{|l|c|c|c|c|c|c|}
\hline \multirow{2}{*}{ Technology } & \multicolumn{5}{|c|}{ Range for Total System LCOE for New Resources (2015 US\$/MWh) } \\
\cline { 2 - 7 } & \multicolumn{7}{|c|}{2022} & Min & Max & $\begin{array}{c}\text { Non- } \\
\text { Weighted } \\
\text { Average }\end{array}$ & Min & Max & $\begin{array}{c}\text { Non- } \\
\text { Weighted } \\
\text { Average }\end{array}$ \\
\cline { 2 - 7 } & 59.0 & 78.1 & 67.8 & 60.0 & 72.5 & 65.3 \\
\hline Hydroelectric & 81.5 & 115.6 & 96.1 & 62.4 & 105.5 & 78.7 \\
\hline Biomass & 43.0 & 78.5 & 64.5 & 39.0 & 70.1 & 58.8 \\
\hline $\begin{array}{l}\text { Onshore } \\
\text { wind }\end{array}$ & 65.6 & 126.2 & 84.7 & 55.3 & 105.3 & 71.2 \\
\hline Solar PV & &
\end{tabular}

\subsection{Support-Building}

The Consumers (Residential, Commercial, Industrial, Government)

In 2014, there were 38,433,775 electricity users in Mexico. Of that total, 88.6\% were domestic users, 9.8\% were commercial users, and the rest were industrial and government users (SENER 2015b).

In 2014, the annual total subsidy for residential electricity service was over \$6 billion (IEA 2016). One proposal is that that subsidy should cover PV systems deployment, rather than electric service. In this way, the electricity user gets the benefit of self-generating energy, reducing electricity cost.

\section{The Role of Private Generators}

Private generators play an important role in DG deployment and are finding more attractive opportunities for investment. One of the aims of the energy reform is to encourage the private sector to develop DG projects through an open generation market, renewable generation policies, simplified procedures, and improved access to distribution networks.

\section{The Role of Third-Party Installers and Financiers of Distributed Generation Projects}

Third-party financing is essential for DG projects development. In Mexico, as in other countries, there are energy services companies that offer a wide variety of services including design, development, financing, O\&M, and monitoring of DG systems.

The Solar Energy National Association has 72 members representing solar project developers, suppliers, and financiers that operate across the country. This association promotes the use of solar energy through courses, congresses, and consultancies.

The Wind Energy National Association promotes the development of wind power generation projects and gathers construction, installation, and operation industry participants. It has 58 members, including developers, manufacturers, and suppliers. 


\subsection{Policies That Have Led to Distributed Generation Adoption}

The LAERFTE law established a sliding scale of limits for fossil fuel generation over a 20-year horizon; no more than $65 \%$ of total generation is allowed in 2024 , and that falls to $60 \%$ in 2035 and $50 \%$ in 2050 . The remainder of the generation mix must be covered by clean fuels (including nuclear and hydro), as shown in Figure 1-15 (IEA, 2014).

\section{National goals for clean generation (\% of total generation)}

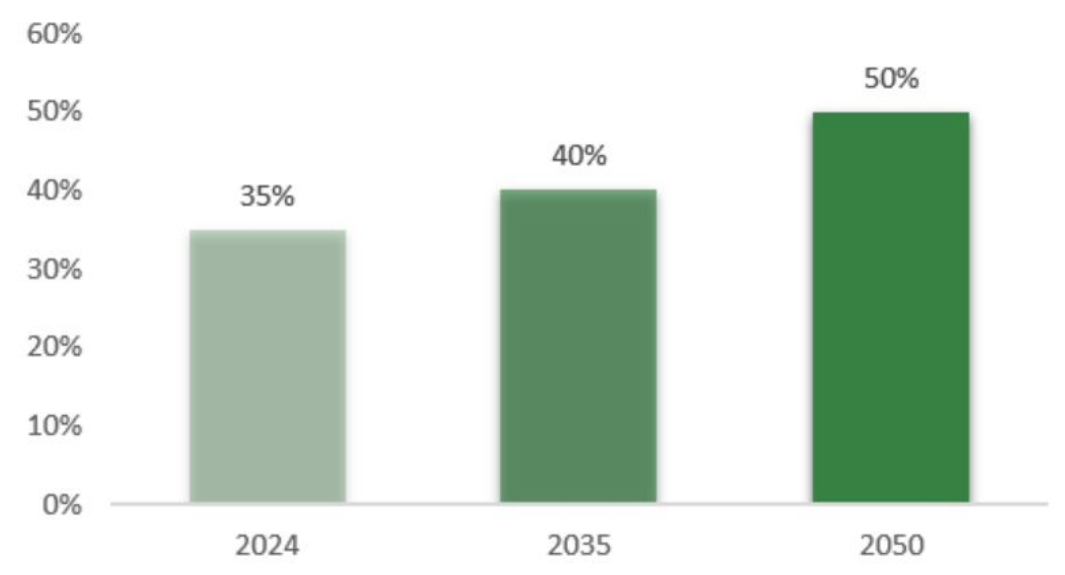

Figure 1-15. Clean generation share targets for a 20-year horizon

To reach these goals, renewable technologies must play an increased role. The Ministry of Energy promotes their development through the following energy sector funds.

Fund for Energy Transition and Sustainable Utilization of Energy_Fondo para la Transición Energética y el Aprovechamiento Sustentable de la Energía (FOTEASE)

This fund is operated by SENER. It was created in observation of Article 27 of LAERFTE with the aim to finance projects related to:

- Deployment of technology for renewables and clean generation

- Promotion of efficient energy use in residential, commercial, and industrial sectors

- Diversification of energy sources. 
Since 2009, this fund has financed 26 projects with a total of $\$ 577$ million. The national annual budget has included the following funding for FOTEASE since the fund's creation (Table 1-5).

Table 1-5. Annual Budget Share for
\begin{tabular}{|rr}
\hline Year & \$US \\
2009 & $43,178,666$ \\
2010 & $198,180,000$ \\
2011 & $123,008,000$ \\
2012 & $91,933,333$ \\
2013 & $20,000,000$ \\
2014 & $66,666,666$ \\
\hline
\end{tabular}

Projects that apply for financing are evaluated by a committee that includes representatives of CFE, the ministries of energy, finance, environment, and agriculture, the National Science and Technology Council, the Mexican Oil Institute, and the Instituto de Investigaciones Electricas.

\section{Electric Power Saving Trust-Fideicomiso para el Ahorro de Energía Eléctrica (FIDE)}

The Electric Power Saving Trust (FIDE) was created in 1990 with the support of CFE to promote efficient energy use and energy savings in all economic sectors. The trust finances PV, wind, and biogas generators with a capacity of $500 \mathrm{~kW}$ and lower.

\section{Shared Risk Trust-Fideicomiso de Riesgo Compartido (FIRCO)}

The Shared Risk Trust (FIRCO) is a trust that finances on-grid PV, biomass, and solar pump systems for the rural sector. The financing share of each project is $50 \%$. The upper financing limit is $\$ 133,333$ for $\mathrm{PV}$ and solar pump systems and $\$ 1$ million for biomass technologies.

\subsection{Regulatory Mechanisms That Have Supported Adoption}

Mexico has several available mechanisms to encourage the use of renewable energy, including regulatory and economic incentives. The support mechanisms that have been implemented in Mexico are described in this section. The instruments described were conceived in the former legal framework; new regulatory instruments will be developed within the context of the energy reform.

The goal of the new regulatory framework is to preserve previously successful mechanisms and improve them by taking into account the new opportunities brought by the energy reform.

\section{Net Energy Metering}

Net energy metering (NEM, otherwise known simply as net metering) is a regulatory instrument to promote small-scale power systems using renewable energy interconnected to the electrical grid. These small-scale power systems are installed in residential, commercial, and industrial sectors (Instituto de Investigaciones Electricas 2007).

${ }^{6}$ Data provided by CRE. 
Net metering consists of measuring the electrical energy fed to the electrical system that is generated by renewable energy sources and is not consumed (surplus energy) by an owner. Energy billing is based on the difference between energy fed to, and consumed from, the distribution network.

In 2007, CRE issued an order to implement a net metering mechanism for small- and mediumsized PV systems intended for self-supply. Since the implementation, the number of interconnection agreements has grown, as shown in Figure 1-16.

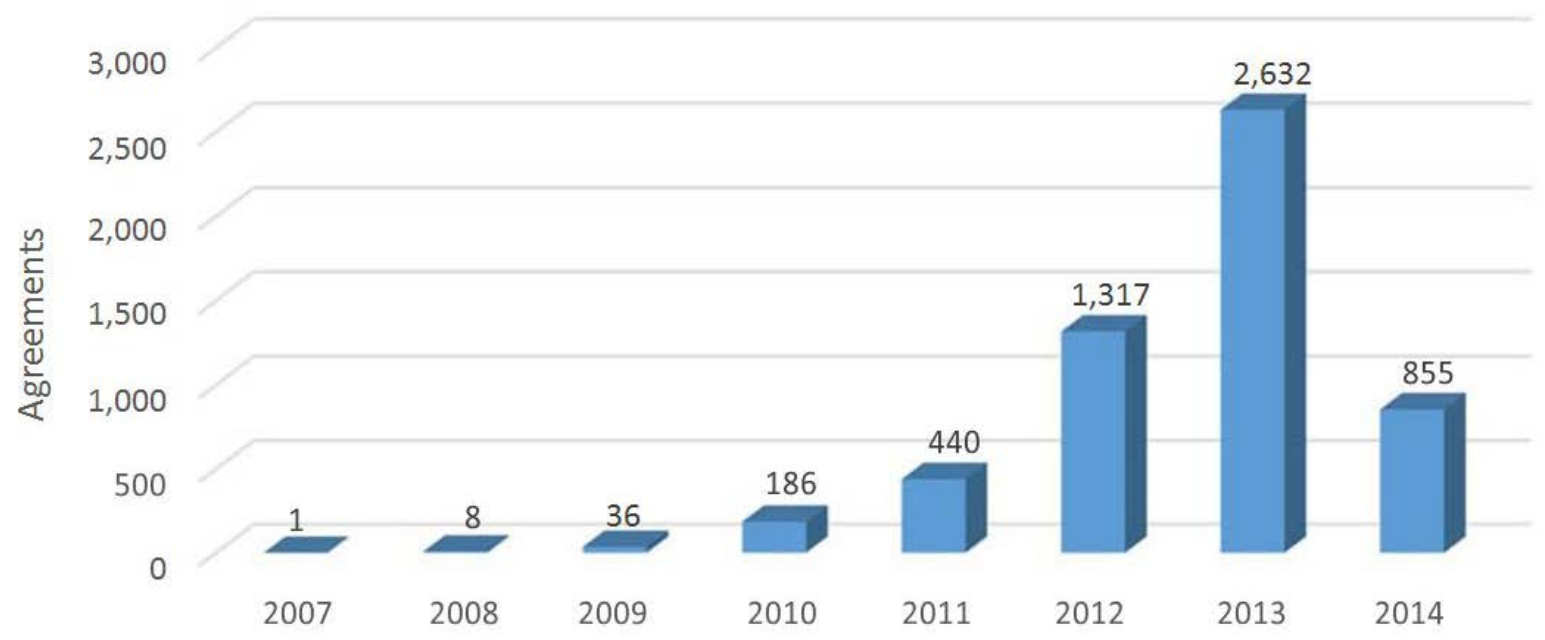

Figure 1-16. Growth of interconnection agreements

(2007 to first half of 2014. Data provided by CRE.)

Studies performed by CRE showed that net metering, under certain conditions, enables the reduction of energy bills by up to 100\%, as shown in Figure 1-17.

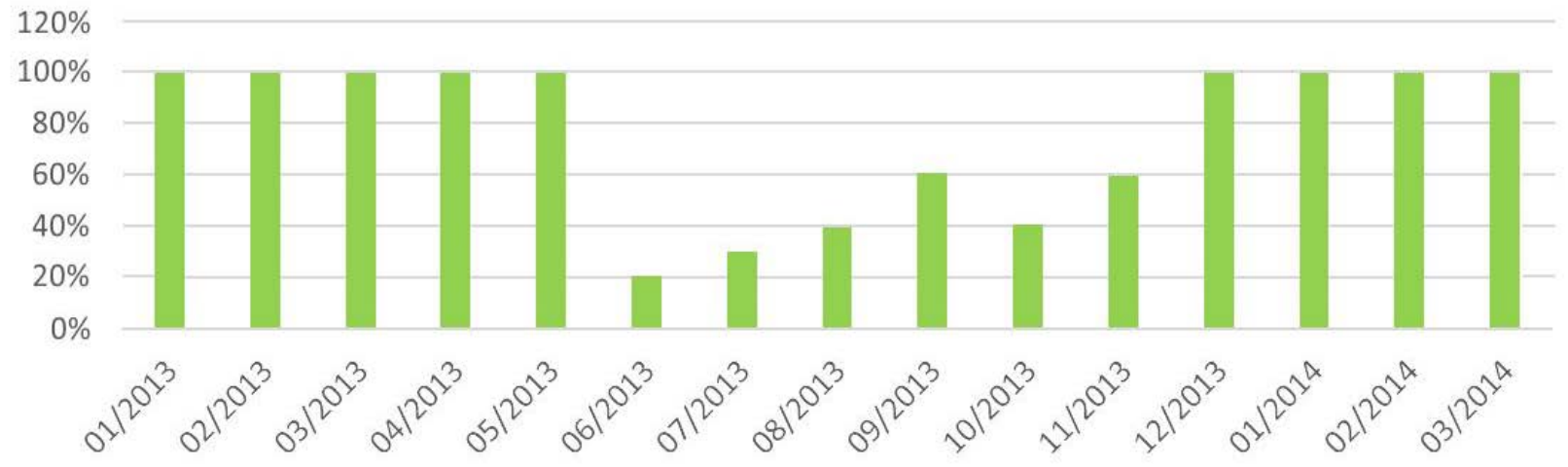

Figure 1-17. Percent decrease in electricity bills of net-metered consumers (Data provided by CRE.)

\section{Accelerated Depreciation of Fixed Assets}

In 2005, a financial policy was implemented to promote renewable energy in Mexico. The policy allows $100 \%$ depreciation of investments over one year "for machinery and equipment for power 
generation from renewable sources" (Article 34, Section XIII of Ley del Impuesto Sobre la Renta). This mechanism enables investors to gain greater economic benefit and in less time.

\section{Interconnection Rules}

The rules for interconnection provide generators with the technical, administrative, and legal requirements to be able to interconnect to the power system reliably and safely.

\subsection{Impact of the Energy Reform on the Deployment of Distributed Generation}

The energy reform described in this section includes structural changes for supporting renewable energy and particularly for encouraging investment in DG. The changes are based on the Electric Industry Act, which in turn has informed the National Plan for the Sustainable Use of Energy and the Coordinated Regulatory Entities Act, with its by-laws for covering DG themes. The Electric Industry Act establishes the criteria for setting a universal and inclusive access for DG:

- The National Electric Grid development program will consider the expansion and update of the general distribution networks needed for DG interconnection.

- CRE will issue guidelines, standards, and other administrative mandates for DG themes. The commission will also issue regulation for reliability, security, quality, and continuity in distributed clean generation.

- The criteria for using distribution public service or the wholesale electric market rules will ensure the deployment procedures for DG integration. 


\section{Challenges of Distributed Generation Integration in Mexico}

To ensure the adequate and successful deployment of renewable DG, it is imperative to identify and remove the potential barriers to DG deployment, from the perspective of the distribution network as well as perspective of the customer and developer's perspective, considering the current Mexican legislation in the matter. The main potential barriers, which are identified in this section, are economic, regulatory, and technical in nature.

\subsection{Economic Barriers}

\section{Rate Structure}

According to a study by the U.S. Department of Energy (DOE) ${ }^{7}$ rates have a great impact on the practicality of DG, as they have a direct impact on the payback rate. Furthermore, the most common issues related to rates that affect customers and operators include the potential for loss of revenues.

Rate structures determine how a distribution company (or a utility) charges a customer for electricity usage. For residential customers in Mexico, there are basically two rates: domestic rate and domestic rate for high consumption. For the latter rate, customers pay much more per kilowatt hour (kWh). The high-usage customers therefore have greater economic incentive to pursue DG options. Considering the current rate structure, even if customers paying the lower rate are interested in installing DG, they will be unable to justify such an investment given their low per$\mathrm{kWh}$ rate.

Commercial and industrial customers can pay a "demand charge" in addition to the per-kWh energy charge that is based on the individual customer's peak demand. The demand charge applies to customers with demands above $100 \mathrm{~kW}$. This charge considers the maximum demand measured during base, intermediate, and peak periods, according to officially established schedules. The charge is meant to cover some of the costs of the infrastructure used to serve larger customers; it is also used to give these customers a price signal that communicates the value of reducing their peak demand.

The impact of rate structure on customer choice and the recovery of distribution network costs can be illuminated with an example. High-consumption customers face a high electricity price, so a DG system investment can reduce volumetric consumption enough to avoid higher-priced rates. At the same time, lower consumption reduces the DG adopter's contribution to distribution network costs of service (e.g., the costs related to infrastructure that allows DG customers to reliably consume electricity from, and export to, the utility grid). If utility system benefits generated by the private investment are low, a net cost may be transferred to non-participating customers. Whether nonparticipants receive a net benefit or incur a net cost depends on several factors; that trade-off is discussed in Section 7. An E3 study (E3 2013) evaluating Net Energy Metering in California found that very high tiered rates in utilities like San Diego Gas and Electric (SDG\&E) would induce very high DG adoption, which would in turn exacerbate cross-

\footnotetext{
7 “The Potential Benefits of DG and Rate-Related Issues That May Impede Their Expansion" (DOE 2007).
} 
subsidization of NEM customers by non-NEM customers. It should be noted that the California Public Utilities Commission (CPUC) recently voted to decrease the highest-consumption tier's rates in order to prevent an unsustainable feedback loop (CPUC 2016).

The potential magnitude of rate-related impacts can vary substantially depending on the technology chosen, the size of the generator, charges for distribution feasibility studies, interconnection application fees, and specifics of the distribution network's rate structure. Therefore, Mexico's current rate design of offering very low subsidized rates for low levels of consumption and high rates for higher levels of consumption may need to be addressed in some fashion to ensure DG customers do not impose an undue cost burden on non-adopting customers. This issue is discussed more fully in Section 5.

\section{Lack of Financial Incentives}

Generally, the cost of renewable DG is primarily an upfront capital cost. For most customers, self-financing the investment is a barrier, and many projects that would have positive net present value are not built due to the absence of financing mechanisms and incentives.

In Mexico, the current mechanisms established to support the deployment of small-scale DG consider several financing schemes; however, the only currently established financial incentive is net metering. This leaves DG developers with the task of identifying potential residential and commercial customers who can afford to finance the investment, and thus the size of the market is limited by the absence of financing and incentives.

Financial incentives are the most immediate and direct method to reduce the cost of DG and increase deployment. Yet, such incentives will finally be absorbed by the ratepayers and taxpayers, whether or not they participate. Continued proliferation of DG may be affected if the benefits for non-participants do not exceed the costs paid or if there is concern that cost allocation is non-equitable.

An alternative to financial incentives is the implementation of financing schemes that can successfully alleviate the initial capital cost barrier for the consumer. For example, in California, the availability of third-party leasing and financing options for solar PV has allowed less-affluent customers to deploy solar PV (CPUC 2013). Such financing companies install solar PV equipment with little or no upfront investment by the consumer; the consumer pays a monthly charge that is less than his or her preexisting electric bill. The advantage of financing schemes is that they enable customers to install DG without having to pay for the high initial investment costs and with the benefit of paying a lower charge rate.

The lack of financial incentives or efficient financing schemes is one of the most important potential barriers for DG deployment, and it is also perhaps the most visible one to customers and developers.

\section{Required Upgrades to the Distribution Network}

At low penetration levels of DG, the impacts to the distribution network may not be significant; however, as DG increases, the complexity of the distribution system increases. To ensure reliable operation, the system operator will need to make sure the system becomes more flexible and upgrade the system as needed. 
Frequency, voltage control, and reverse power flow are among the main issues driven by renewable DG. For instance, a large accumulation of DG can increase the voltage at the point of interconnection, particularly if there is a high level of generation during off-peak conditions. Furthermore, voltage regulation can potentially become more difficult if an important level of variable DG is added on a feeder, as it could induce voltage fluctuations on the feeder. In those cases, capital investments will need to be made to ensure the grid operates in a stable manner.

In Mexico, the infrastructure required to enable the interconnection of DG projects has to be considered in the Program for the Development of the National Electric System, according to the Electric Industry Act. It has been established that such infrastructure has to correspond to the most economic technical solution; however, the process to allocate the costs for the infrastructure has not been clearly defined.

To avoid upgrades from becoming potential barriers to further cost-effective deployment of DG, it is important to adequately allocate the incurred costs.

\subsection{Regulatory Barriers}

\section{Rate Design}

As mentioned in Section 2.1, having an efficient rate design can greatly contribute to the increase of DG deployment.

Regulators try to establish rates that align with the economics of system planning and operations. Such rates are established based on specific load growth projections. The main objective of the rates is to recover the costs of serving the load from those loads causing the costs. If the load does not increase as projected, for instance, due to higher than expected DG installations, the distribution network may not recover sufficient revenue to cover the costs of capital investments. In this case, the regulator may have to recover the costs by increasing the rates charged to nonDG customers.

This scenario can be seen as an impediment to the development of DG; however, it is important to mention that although DG will reduce energy sales, DG deployment can also reduce the need for new infrastructure costs, thus offsetting the reduced sales revenue and producing profits even while reducing total revenues. The regulator has an important task in identifying an efficient rate scheme that promotes DG installation without affecting non-participant customers or the distribution network's revenues.

\section{Interconnection Process and Interconnection Requirements for Distributed Generation}

According to the CPUC, challenges in obtaining access to the distribution grid and completing the utility interconnection process are often cited as barriers to DG deployment.

In Mexico, the Electric Industry Act establishes that DG projects will have open and not unduly discriminatory access to (1) the general distribution networks and (2) the competitive market where they may sell their energy production. However, the process that will have to be followed in order to interconnect to the grid has not yet been established. The efficiency and speed at which interconnection applications are processed has been identified as a barrier by some, 
because the amount of DG installed is completely determined by how much DG is approved for interconnection by the distribution system operator. Therefore, making the interconnection process more timely, cost-effective, and transparent may directly impact DG deployment.

Other interconnection barriers are related to the requirements that the distribution companies may demand from the developers to ensure the reliability of the grid.

Distribution network operators have to perform feasibility studies to identify the needed infrastructure to effectively interconnect projects. For example, in the Mexican scenario, the National Center for Energy Control will establish the interconnection requirements along with the process that must be followed by a DG developer in order to be able to interconnect to the grid.

The Electric Industry Act establishes that the technical requirements to interconnect new generating projects must include specific conditions for DG, so that in typical cases, requests for interconnection of the power plants may not require studies to determine the specific characteristics of the required infrastructure.

If the interconnection requirements are too restrictive, the developer may need to make additional investments, which may lead the project to lose its economic feasibility. Therefore, it is important to distinguish those requirements that are actually necessary to ensure the stable operation of the grid from those that are unnecessary.

\section{Specific Standards for Distributed Generation}

The development of specific standards to re-define the current design criteria applied to distribution networks may need to be considered in order to deal with the complexities that renewable DG can create for the grid. This review or update of the standards can enable the identification of specific modifications to system design that could help increase the benefits of DG, or at least mitigate the impacts, so higher penetrations could be achieved at a lower overall cost.

If the currently applied standards are not modified to consider renewable DG (and its particular characteristics), deployment may be delayed, as additional investments may be required to efficiently integrate DG.

\section{Customer Education}

Customer education and acceptance has often been identified as an important barrier (Pyper 2015). Considering that DG installations are voluntary, customers must be aware of the potential benefits of DG in terms of costs, environmental impact, and energy independence, among others, to actually see it as an option for their electric needs.

Establishing specialized programs to let the customer know about the benefits and advantages of DG systems may increase the trust in the technology, which can be translated into more DG projects. 


\subsection{Technical Barriers}

\section{Changes in the Operation of the Distribution Networks}

Renewable DG units induce additional complexities to the operation of the system. Distribution network operators have to handle such complexities in order to maintain the stability of the grid.

One of the first such considerations is that the system operator will have to improve forecast methodologies for demand and generation in order to address the variability and uncertainty of DG sources. Stochastic and advanced methods for estimating electricity production will help the operator better optimize dispatch and reserve capacity.

The current requirements to interconnect DG projects to the distribution grid do not demand real time monitoring, but reliability risks mean the operator will have to monitor the interconnection points to avoid instability problems, especially voltage and frequency variations. Smart grid technologies will have an important role in this process.

Overall, the distribution network operator will have to consider new schemes in its operation of the system to incorporate DG.

\section{Flexibility of the Distribution Networks}

Grid flexibility is known as the ability of a power system to answer quickly and reliably to large fluctuations in demand and supply. With high levels of renewable DG, the system may need to have more flexibility for its operation in order to maintain the stability of the grid.

Flexibility is a concern for DG deployment because, according to the IEA, "if a power system is sufficiently flexible, in terms of power production, load management, interconnection and storage, the importance of the variability aspect is reduced" (IEA 2008).

Mexico may need to include flexibility aspects in its grid expansion planning to deal with DG technical issues that inhibit its efficient growth. To increase flexibility, the system may need to have either upgrades or entirely new equipment. Such upgrades can be translated into new transformers, voltage control equipment, and feeders, among others. The requirements to increase the flexibility of the distribution system are often considered as barriers, as they imply investment costs that otherwise would not be needed.

Importantly, in a radial distribution system that is connected to DG, the utility may have to disconnect the DG system and anything beyond it from the main source of generation to troubleshoot an issue with the distribution system. This limit on operational flexibility may reduce the reliability of the distribution system in some cases (CPUC 2013).

\section{Interconnection Requirements}

The easier and quicker the interconnection process is, the more effective DG deployment will be. The system operator has to avoid bottlenecks in the interconnection process that could become barriers for generators. At the same time, the operator must ensure a reliable and secure interconnection transition through certain technical requirements. 
System operator technical requirements for DG projects should include at least:

- Voltage regulation: A voltage variation limit should be set to ensure security in the distribution system.

- DG plant integration to a distribution grounding system: DG units should be tied to a distribution ground to avoid overvoltages in the grid.

- Disconnection in fault situations: The system inverter should be able to disconnect in grid fault situations.

- The DG unit should not exceed harmonics or direct current limits.

- The power factor should be as close as possible to the unit.

- Other technical specifications should follow international standards and guidelines, such as IEEE 1547 standard for interconnection (IEEE 2015). 


\section{International Survey of Economic and Regulatory Policies to Address Economic, Regulatory, and Technical Barriers}

The declining cost of solar and increasing adoption of solar DG have presented many of the same challenges internationally that Mexico faces today. Indeed, nations around the world continue to learn the right set of power sector incentives and reforms to facilitate the deployment of costeffective DG. In this section we catalog the policies implemented internationally to address economic, regulatory, and technical barriers. We then group the policies into three categories: rate and tariff design policies, subsidies and tax support policies, and market development policies.

Policies implemented internationally to overcome economic barriers to cost effective DG adoption have included tax policy supports, such as tax credits and accelerated depreciation; financing support, such as public financing; innovative financing mechanisms, such as third-party leasing; direct public support in the form of subsidies and shared public-private investment; and policy targets founded on concepts such as clean energy certificates and DG portfolio standards. Encouraging the accelerated deployment of cost-effective DG in Mexico requires choosing which of the options make sense for Mexico and then choosing the right combination to address the country's economic barriers and help achieve its goals.

Policies implemented internationally to overcome regulatory barriers include special tariff structures, such as net energy metering (NEM), feed-in tariffs, value of solar tariffs, and shared renewable tariffs; rate design approaches, including time-of-use rates, real-time pricing, two-way distribution tariffs, and minimum bill designs; and revenue stabilization approaches, such as deferred energy accounting and revenue decoupling. Policies to overcome regulatory barriers should be chosen to address current barriers, target high-value DG locations, and help Mexico achieve its power sector goals.

Policies implemented internationally to overcome the technical barriers often depend on determining where DG provides the most benefits to the economic and utility system. Distributed generation and other customer resources such as EE, demand response, and storage are most cost effective when they defer or obviate large capital investments in generation, transmission, and distribution. This means implementing the policies so that parts of the grid that are experiencing rapid growth, transmission congestion, high prices, or recurrent reliability problems are the first to install DG and take advantage of other customer resources. Furthermore, because an important component of the value of DG is the avoided transmission and generation capacity costs , targeting regulatory policies and building support infrastructure where the value of DG is highest is likely to overcome the most immediate technical barriers and produce positive value propositions for adopters, non-adopters, the utility, and society as a whole.

\subsection{Categories of Economic and Regulatory Policy Support}

Policies aimed at overcoming economic, regulatory, and technical barriers to promote the uptake of DG can be divided into three categories: (1) policies that address tariff and rate design, (2) policies that use subsidies and tax breaks, and (3) policies that support market development. This section explores these categories more fully. 


\section{Tariff and Rate Design}

There are two basic approaches to designing tariffs for DG customers: a net energy metering (NEM) tariff or a feed-in tariff (FIT) (Linvill et al. 2013).

The NEM tariff bills the customer based on net electricity consumption (i.e., the amount consumed minus the amount generated). Measurement of this net consumption can be done either (1) with a meter that can count both forward and backward, which has the advantage of simplicity, or (2) via separate metering and a calculation of net value. In the United States, the Public Utility Regulatory Policy Act of 1978 (PURPA) and the Energy Policy Act of 2005 (EPACT) require utilities to offer net metering service to consumers who request it. Almost all NEM tariff structures include a limit on the size of eligible DG systems. In the case of excess generation (i.e., when the customer generates more electricity than he or she buys), most U.S. states allow bill credit for that excess generation to roll over month by month. A few jurisdictions require the utility to make cash payments for its value, while in a few others, the customer forfeits this value. Seventeen U.S. states currently have policies that allow meter aggregation under a NEM tariff (in which the output of a single generator is allocated to all the participating meters and netted against the consumption measured on those meters). ${ }^{8}$

Net metering policies vary from place to place. Sources of difference include differences in which DG technologies are eligible for net metering, whether there is a cap on the total megawatt penetration of DG, how net excess generation is compensated, who retains ownership of any renewable energy credits or certificates, and whether aggregate NEM is allowed. Most of these differences are self-explanatory, but three require a bit of explanation, and we will illustrate them by referring to implementation differences among some U.S. states.

Jurisdictions differ on how net excess generation is compensated, and Mexico will have to consider this when designing a NEM tariff. In some U.S. states (e.g., Arkansas and Montana), the customer forfeits the value of this net excess generation to the utility. In a few others (e.g., Georgia and Minnesota), the utility makes a cash payment to the customer for the value of the excess generation, which is typically calculated based on the utility's avoided cost rate. But in most jurisdictions, credits for net excess generation may be rolled over indefinitely from one billing period to the next. This can be especially helpful for customers who own PV systems that produce significant excess generation in the longer daylight of summer months but produce less than the customer's consumption in other months. Finally, some tariffs place a time limit (e.g., 12 months) on how long a credit for net excess generation can be applied to the customer's bill. At the end of the designated time period, the utility may retire the value of the credit or make a cash payment to the customer, typically at an avoided cost rate.

Jurisdictions also differ on who retains ownership of any renewable energy certificates (RECs) that are created from DG production. Most either grant ownership of any RECs created under a net metering tariff to the customer, or they do not specify who owns the RECs. A few U.S. jurisdictions (e.g., New Mexico) grant REC ownership to the utility or require sharing of the RECs between the customer and the utility. Where REC ownership is not specified in state policy, it may or may not be specified in an individual utility's tariff. Some states also require

\footnotetext{
${ }^{8}$ National Conference of State Legislatures, 2016.
} 
customers to transfer RECs to the utility if state or utility subsidies were used to support the installation of the system.

Finally, jurisdictions differ on whether NEM is permissible for customers who aggregate meters and serve the meters jointly with a common DG project. Nearly 20 U.S. jurisdictions have adopted policies that allow for the aggregation of multiple meters under a net metering tariff. States vary in what they allow. Generally speaking, the output of a single generator is allocated to all of the participating meters and netted against the consumption measured on those meters as with other net metering tariffs. In its most limited form, meter aggregation applies only to a single customer who has a generator and multiple meters on the same property. In the broadest form, meter aggregation applies to a generator that may be owned by a utility, one or more customers, or a third party, the output of which is allocated to the meters of multiple participating customers on multiple properties (which need not be contiguous). This sort of arrangement is sometimes referred to as "group," "community," "neighborhood," or "virtual" net metering aggregation. We return to group net metering when we discuss DG 2.0 mechanisms in Section 5.

The FIT design entails the utility essentially entering into a long-term power purchase agreement with a customer, and it pays that customer for the electricity he or she generates on terms that are different from those for the energy the customer buys. Specifically, a FIT typically compensates the customer at a fixed price that exceeds the utility's avoided costs of procurement from other sources.

Most FITs are structured in such a way that the utility agrees to pay the customer a fixed price for every kilowatt-hour the customer generates over the duration of the contract. A less common structure is one in which the customer is offered a fixed premium for every $\mathrm{kWh}$ that is added to a base price that is more variable. For example, the "Cow Power" FIT offered by Green Mountain Power in Vermont offers to pay a guaranteed premium of four cents over and above a PURPA avoided cost price that may vary over time for every $\mathrm{kWh}$ of electricity generated from biogas systems on farms. Under either a fixed price or a fixed premium FIT structure, the customer continues to purchase electricity under a separate retail tariff. ${ }^{9}$

Eight U.S. states have FIT policies, some of which do not apply to all types of utilities. FITs are also offered by a small number of utilities that are not subject to a state policy. But, most U.S. utilities do not offer FITs. And, even where FITs do exist, the policies vary from state to state and the tariffs vary from utility to utility in some significant ways. We have already discussed how FITs vary in terms of whether they are expressed as a fixed price or a fixed premium. Beyond that fundamental difference in tariff structure, FITs vary in what technologies qualify, whether a megawatt cap is set on total FIT installations, the basis for setting FIT prices, and whether price stability mechanisms are in place. The final two of these differences among programs require some explanation.

\footnotetext{
${ }^{9}$ We do not discuss the retail tariff under which the FIT customer purchases electricity from the utility, but the level of the standby rates that the utility charges is critical for many CHP facilities. Standby rates are intended to compensate the utility for any costs associated with preparing for contingencies in which the CHP unit is unable to generate at a normal or expected level, as well as the costs of providing any supplemental power that the customer requires beyond what the CHP unit can produce. See Selecky et al. (2014) for an evaluation of the standby rate issue.
} 
The prices paid under a FIT can be determined through either of two procedural methods:

1. The most common method historically has been for the utility or the public utility commission (PUC) to set FIT prices through an administrative process, such as a normal tariff proceeding. In some of jurisdictions, FIT prices are based primarily on estimations of the generator's costs. If, for example, the cost of generating electricity from biogas on a dairy farm averages $12 \phi / \mathrm{kWh}$, the FIT rate for biogas might be set at or around $12 \phi$. In other jurisdictions using an administrative process, FIT prices are based on a premium added to the utility's PURPA-avoided cost rates or a market rate, or they are based on the value of the output to the wider electric grid, irrespective of the generator's costs. For example, a FIT might be set at a rate equal to the utility's PURPA-avoided cost rate plus a premium of, for example, $2 \phi / \mathrm{kWh} .{ }^{10}$ Because it is fairly standard for utilities to be granted ownership of any associated RECs as part of a FIT transaction, the estimated value of the RECs to the utility (for renewable portfolio standard compliance, for trading, or for sale under a "green power" program) may be explicitly or implicitly factored into these administratively determined prices or premiums.

2. An entirely different procedural method for setting FIT prices involves using a competitive procurement process. With this method, the utility establishes all the terms and conditions of the FIT except the price and then solicits price bids from potential participants through a request for proposals or a reverse auction. ${ }^{11}$ In the United States, there appears to be a trend toward this kind of process. Competitive procurement methods were recently adopted in California, Maine, Oregon, Rhode Island, and Vermont. ${ }^{12}$

Regardless of the method used to set prices (administrative or competitive), it is common for a state or utility FIT policy to have multiple categories of eligible systems, each receiving a different rate or premium. This is to be expected, because the generator's costs, the utility's avoided costs, and the system value of DG all vary with the generating technology, system size, production profile, and location.

FITs also vary depending on whether and how they provide for rate stability over time. FITs are structured to provide the participating customer with stable terms and conditions, including the rate or premium paid, over a long period. FIT policies vary in terms of how long that period lasts, but 5-20 years is the norm in the United States. A few U.S. jurisdictions have also adopted a rate adjustment policy called "degression" in which the FIT rates offered to newly participating customers decline over time in a predictable fashion. This means that each customer enjoys stable terms and conditions for the duration of his or her own contract, but a customer who enrolls today would be paid a higher price than one who enrolls in the future. An example of

\footnotetext{
${ }^{10}$ If the rate were set exactly equal to avoided costs, with no premium, it would be what we call a PURPA rate rather than a FIT.

${ }^{11}$ A reverse auction is an auction in which the bidders offer a price at which they are willing to sell electricity, rather than a price at which they are willing to buy. The utility selects the lowest-priced bids that meet its procurement needs. In some cases, all accepted bids are granted a "clearing price" (i.e., the price offered by the most expensive accepted bid).

${ }^{12}$ When prices are set through a competitive process, they could conceivably end up at a price that is less than the utility's avoided costs for unspecified energy and capacity. Using the terminology we have adopted for this report, the resulting tariff would technically thus be a PURPA tariff rather than a FIT.
} 
degression can be found in the FITs offered by the Los Angeles Department of Water and Power. Los Angeles Department of Water and Power announced before it launched its FIT program that it would reduce the base price paid to participating customers by $1 \notin / \mathrm{kWh}$ after total enrollment reached $20 \mathrm{MW}$, and reduce it by one more cent each time another $20 \mathrm{MW}$ of capacity were enrolled in the program. ${ }^{13}$

In addition to the NEM and FIT, a small number of jurisdictions are experimenting with designs such as a value of solar (VOS) tariff, under which customers buy electricity at the utility's retail rate but are compensated at a separate rate that takes into account sources of value specified by the jurisdictional regulator. The sources of value included vary, but they typically include longrun avoided costs associated with avoided energy costs and avoided capital costs (generation, transmission, and distribution), as well as other sources of benefits such as environmental and public health benefits. The avoided costs also typically reflect the fact that local generation enjoys reduced line losses relative to remote generation. ${ }^{14}$

\section{Subsidies and Tax Breaks}

There are a variety of options for designing tax incentives. U.S. federal tax credits, such as the solar investment tax credit and the residential renewable energy tax credit. In many U.S. states, renewable energy systems are exempt from sales and property taxes. The tax code is similarly being revised in countries such as Brazil, where as of September 1, 2015, installers of DG systems using net metering will be exempt from value-added tax in three states: Goias, Pernambuco, and Sao Paulo (Kenning 2015).

\section{Market Development Support}

Distributed generation that is owned and financed by customers represents a new industry, and thus the institutional infrastructure associated with its market is still under development. Financial constraints, supply chain constraints, and system integration constraints need to be addressed with institutional innovation.

Some examples of institutional innovations that have helped with market development internationally are described below.

- Solar leasing: Some U.S. states have adopted policies allowing third parties to offer solar PV systems for lease, in effect competing with utilities to sell retail electricity directly to customers. This has been a major factor in driving DG uptake in those jurisdictions.

- Shared ownership DG: Development of solar and wind "farms" includes cooperatives, municipal facilities, and private installations that sell shares of a new DG generation facility to customers. These facilities are typically larger than $100 \mathrm{~kW}$ and may be up to $10 \mathrm{MW}$, and they are typically located within the portion of the distribution network proximate to the subscribing customers.

\footnotetext{
${ }^{13}$ Outside the United States, some FITs also include an automatic adjustment to the rate based on inflation. The authors are unaware of any U.S. jurisdiction that has adopted this policy option.

14 "Value-of-Solar Tariffs," NREL (National Renewable Energy Laboratory), http://www.nrel.gov/tech_deployment/state_local_governments/basics_value-of-solar_tariffs.html
} 
- Certification and training: Most major EU markets have certification schemes and training programs for solar installers. In Germany, for example, where there is an emphasis on vocational education, the country's Chamber of Trades and Crafts administers the training. In the United Kingdom, customers must use products and installers certified under the Microgeneration Certification Scheme to be eligible for a FIT (see Table 3-1).

- Interconnection standards and policies: Some countries, such as Germany and Spain, have established priority grid access for renewables, and this first-in-line status adds investment certainty. Many places are evolving their interconnection standards in accordance with and moving beyond IEEE 1547 interconnection standards in ways that facilitate DG installation and ensure system reliability (e.g., California's Rule 21 amendments). Places where DG capacity is projected to grow beyond minimum circuit load in some hours of the year are improving situational awareness by investing in the ability to monitor flows on the distribution system in real time.

- Integration challenge solutions: Places where variable generation is significantly shifting net load on the distribution system (e.g., the "duck curve" in southern California described below and illustrated in Figure 3-1) are implementing local integration strategies to support still higher levels of DG adoption. High penetration may happen in Mexico at a particular circuit or a particular substation, but this issue is relatively easily dealt with by (1) ensuring the remuneration of solar generation is specified in both place and time (e.g., via location-based rates and time-of-use rates), and (2) addressing interconnection upgrades where flow back of electricity onto the system across the substation becomes a problem. 


\section{Text Box 1. The Local Integration Challenge of High Solar DG Penetration}

High levels of penetration of resources that are not controlled by system operators can create a situation in which the utility has more generation than load. Large renewable energy additions exacerbate this challenge because of their inability to be dispatched. SDG\&E has predicted that by 2020 they will be facing an extremely challenging situation in the late afternoon, as DG resources diminish, and the need for system generation to ramp up to meet demand will be faster than their resource mix is capable of providing. In a three-hour period (hours 15 to 18 in Figure 3-1), they will need to increase system generation from resources other than wind and solar from approximately 1,500 MW to approximately 3,500 MW. The ability to curtail output from distributed generators, even for short periods, may be important to system reliability.

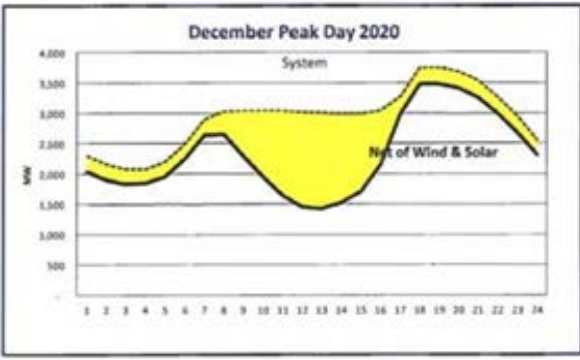

Figure 3-1. "Duck curve" showing net system demand on system with high levels of solar and wind generation

(Linvill et al. 2013)

Obviously, nonutility generators have the opposite interest (i.e., ensuring they get the maximum utilization from their resources and the maximum revenue from the utility).

This is a very real challenge. Maui Electric (MECO) now has approximately as much wind generation installed as it has night-time load. If all the wind turbines are operating at night, the utility would need to have its thermal plants operating at zero. But if they are completely shut down, they may not be able to start up and come up to full output fast enough to meet daytime loads. For this reason, they normally run the thermal plants at a reduced output at night to prepare for daytime loads. For a limited number of hours in 2012, MECO forced some wind turbines offline, reducing their revenue. The Hawaii PUC severely penalized MECO for this action in their 2013 rate decision. The experience in Maui is unlikely to be replicated by a mainland U.S. system any time soon simply because of the availability of transmission interconnections, but it provides an indication of the type of challenge that may be ahead for the industry.

Regulators would do well to strengthen linkages between DG and system benefits by encouraging stronger linkages between the timing and location of generation through rate and tariff design. The ability to curtail output for short periods will likely become increasingly essential. Regulators will need to address this as intermittent generation becomes a significant share of the utility resource base, but that treatment should be equitable. Utilities will need to maximize the flexibility of existing resources, acquire storage capacity, and improve interconnections in order to minimize the frequency and length of curtailment of DG output. For a set of strategies aimed at improving system operations that address the operational challenge of high penetration solar PV, see Linvill et al. (2013). 


\subsection{Examples of Policy Supports Around the World}

Policy support mechanisms have been implemented around the world, but the combination of policy supports vary. Section 3.1 referred to selected examples from around the world, but this section provides a more comprehensive overview of examples for Mexico to contemplate as it formulates the right set of policies for its current situation. Text Box 2 highlights support mechanisms in emerging markets. 


\section{Text Box 2. The State of DG Development in Key Emerging Markets}

\section{China}

China has been slow to adopt DG, and current installations are mostly on industrial sites. However, in September 2014, the National Energy Administration (NEA) announced several policies aimed at encouraging DG. One of these policies expanded eligible PV systems to include systems up to 20 MW in size, with local authorities providing incentives to install DG in public places, including at airports and train stations, sports stadiums, and public housing. Another policy sets up two subsidy schemes under which DG systems are fully connected to the grid will receive a FIT while those designated for "self-use" can sell surplus power to the grid. It should also be noted that a month before announcing its plans, the NEA revised downward its yearly DG installation target for 2014, from eight gigawatts $(\mathrm{GW})$ to five $\mathrm{GW}$, an indication of the difficulties of meeting the ambitious original goals.

\section{South Africa}

In South Africa, DG development is in the very early stages, and not much has happened beyond a few pilot programs by municipal utilities, which have had mixed success. In February 2015, the National Energy Regulator of South Africa (NERSA), the country's electricity regulator, issued a consultation paper outlining proposed rules for small-scale embedded energy generation. The rules propose, among other things, "appropriate" fixed charges to recover utility costs under a net metering scheme (which would include the option of time-of-use rates). Issuance of finalized rules was delayed into 2016.

\section{India}

Like that of South Africa, India's power sector has long been dependent on coal, and renewables development is likewise only in the early stages. Initiatives such as the Remote Village Electrification program and the Rajiv Gandhi Grameen Vidyutikaran Yojana scheme have sought to prioritize renewables and DG as part of their aim of bringing universal electricity access to the country. In February 2015, the National Institute for Transforming India (NITI) Aayog government think tank (a new agency that replaced the country's Planning Commission) published the Report on India's Renewable Electricity Roadmap 2030 with technical assistance from the Regulatory Assistance Project. Stakeholders consulted for the report called for small-scale and distributed renewables to be given equal priority to large-scale renewable energy, as well as a national renewables law that includes a mandatory net metering/FIT scheme.

\section{Chile}

Chile is the only country in Latin America where solar costs have reached grid parity, and the country accounted for more than three-quarters of the region's 625 MW of solar PV installation in 2014. However, Chile has been slow to implement policy supports. The solar development has come despite that, and almost all of it so far is at the industrial scale. A law passed in 2012 to institute a net metering scheme finally went into effect toward the end of 2014, and it applies to units of $100 \mathrm{~kW}$ or less. Other modest initiatives, such as a government plan to invest $\$ 13$ million in installing PV on the rooftops of public buildings, have also been put in place.

\section{Brazil}

Grappling with drought that is seriously stressing its vast hydropower systems, Brazil is seeking to encourage PV development through a series of tax breaks (see above). The country's energy regulator, Agência Nacional de Energia Elétrica (ANEEL), is also planning to revise its net metering regulations to allow people in multifamily dwellings, for example, to share benefits. 
Table 3-1 summarizes policy support mechanisms for DG in Europe, and Figures 3-2 through 3-4 show some of the key measures implemented in various U.S. states. While NEM and FIT are the most prominent support mechanisms shown, many other mechanisms exist to address DG adoption barriers. For example, training and certification programs are offered solar suppliers and installers to address the need to grow the cadre of professional installers, priority grid access policies are implemented in some places to expedite permitting and interconnection of renewable energy facilities, and low-interest loans and tax breaks are offered in some countries to support the need to accumulate a critical mass of financing for this infant industry.

Table 3-1. DG Policy Supports for Selected EU Countries

\begin{tabular}{|c|c|}
\hline Country & Policies \\
\hline Denmark & $\begin{array}{l}\text { - Premium tariff system based on bonus payments } \\
\text { - Net metering } \\
\text { - } \quad \text { ForskVE program provides subsidies for small renewable installations deemed to be } \\
\text { - } \text { Certification scheme } \\
\text { - Training for installers, including quality assurance scheme for PV installations } \\
\text { - Research \& development (R\&D) programs }\end{array}$ \\
\hline France & $\begin{array}{l}\text { - } \text { FIT } \\
\text { - Reduced value-added tax for PV installation } \\
\text { - Two training programs for installers, run by Qualit'EnR and Qualibat } \\
\text { - Certification schemes for renewable installations }\end{array}$ \\
\hline Germany & $\begin{array}{l}\text { - } \text { PIT } \\
\text { - Priority grid access for renewables } \\
\text { (fits with German focus on vocational training) } \\
\text { - R\&D: } 6 \text { th Energy Research Programme; } € 3.5 \text { billion from } 2011 \text { to } 2014 \\
\text { - Widespread development of community solar and wind }\end{array}$ \\
\hline Italy & $\begin{array}{l}\text { - FIT for plants under } 1 \mathrm{MW} \text {, but not PV } \\
\text { - "Ritiro dedicato," in which Gestore dei Servizi Energetici (GSE), a state-owned } \\
\text { company managed by Ministry of Economy and Finance, manages energy sales } \\
\text { in lieu of a classical FIT) }{ }^{15} \text { for } \\
\text { - all sources up to } 1 \mathrm{MW} \text { if they do not use other support schemes, or a limit of } 100 \\
\mathrm{~kW} \text { for PV } \\
\text { - if they do, choice can be made between minimum tariff and market price } \\
\text { - Wind and solar investments eligible for } 10 \% \text { reduction in value-added tax } \\
\text { - Net metering for capacity of } 20 \mathrm{~kW}-200 \mathrm{~kW} \\
\text { - Priority grid access for renewables } \\
\text { - Regional-level training for installers; installers must certify compliance. }\end{array}$ \\
\hline
\end{tabular}

\footnotetext{
${ }^{15}$ For more information about ritiro dedicato, see http://www.gse.it/it/Ritiro\%20e\%20scambio/Ritiro\%20dedicato/Pages/default.aspx
} 


\begin{tabular}{|c|c|}
\hline Country & Policies \\
\hline Netherlands & $\begin{array}{l}\text { - SDE+ (stimulering duurzame energie) premium feed-in scheme: phased admission to } \\
\text { the scheme with escalating base tariffs on a first-come, first-served basis } \\
\text { - Net metering for small-scale connections; grid usage charge is required } \\
\text { - Exemption from Environmental Protection Tax on electricity consumption if the } \\
\text { - } \text { electricity was generated by the consumer from renewable sources } \\
\text { - } \text { "Green fund" program for lending at reduced interest rates } \\
\text { - Certification programs and installer training } \\
\text { - R\&D: Public-private partnership }\end{array}$ \\
\hline Poland & $\begin{array}{l}\text { - } \quad \text { Quota/green certificate trading program } \\
\text { - } \text { low-interest loans and subsidies for small and micro installations. } \\
\text { - Renewables are exempted from consumption tax. } \\
\text { - Priority grid access for renewables } \\
\text { - Training qualification program for installers }\end{array}$ \\
\hline Spain & $\begin{array}{l}\text { - Priority grid access for renewables } \\
\text { - National system of training for installers } \\
\text { - Community solar development is fast-growing but seems private- and nonprofit-driven. }\end{array}$ \\
\hline Sweden & $\begin{array}{l}\text { - Quota/green certificate trading program } \\
\text { - Real-estate and energy tax breaks for wind } \\
\text { - Subsidies for PV installations } \\
\text { - R\&D for wind }\end{array}$ \\
\hline $\begin{array}{l}\text { United } \\
\text { Kingdom }\end{array}$ & $\begin{array}{l}\text { - FIT (for capacity less than } 5 \mathrm{MW} \text { ); government is considering doubling this to further } \\
\text { promote rooftop solar. } \\
\text { Microgeneration Certification Scheme: Certification required to participate in FIT; } \\
\text { website includes consumer database of certified installers and products. } \\
\text { - Department of Energy and Climate Change's Community Energy Strategy has } \\
\text { dedicated } € 12 \text { million to promote urban community generation projects. }\end{array}$ \\
\hline
\end{tabular}

Most information in this table was compiled from country reports on RES LEGAL Europe (www.res-legal.eu), the European Commission's database on support schemes, grid issues, and policies covering renewable energy. 


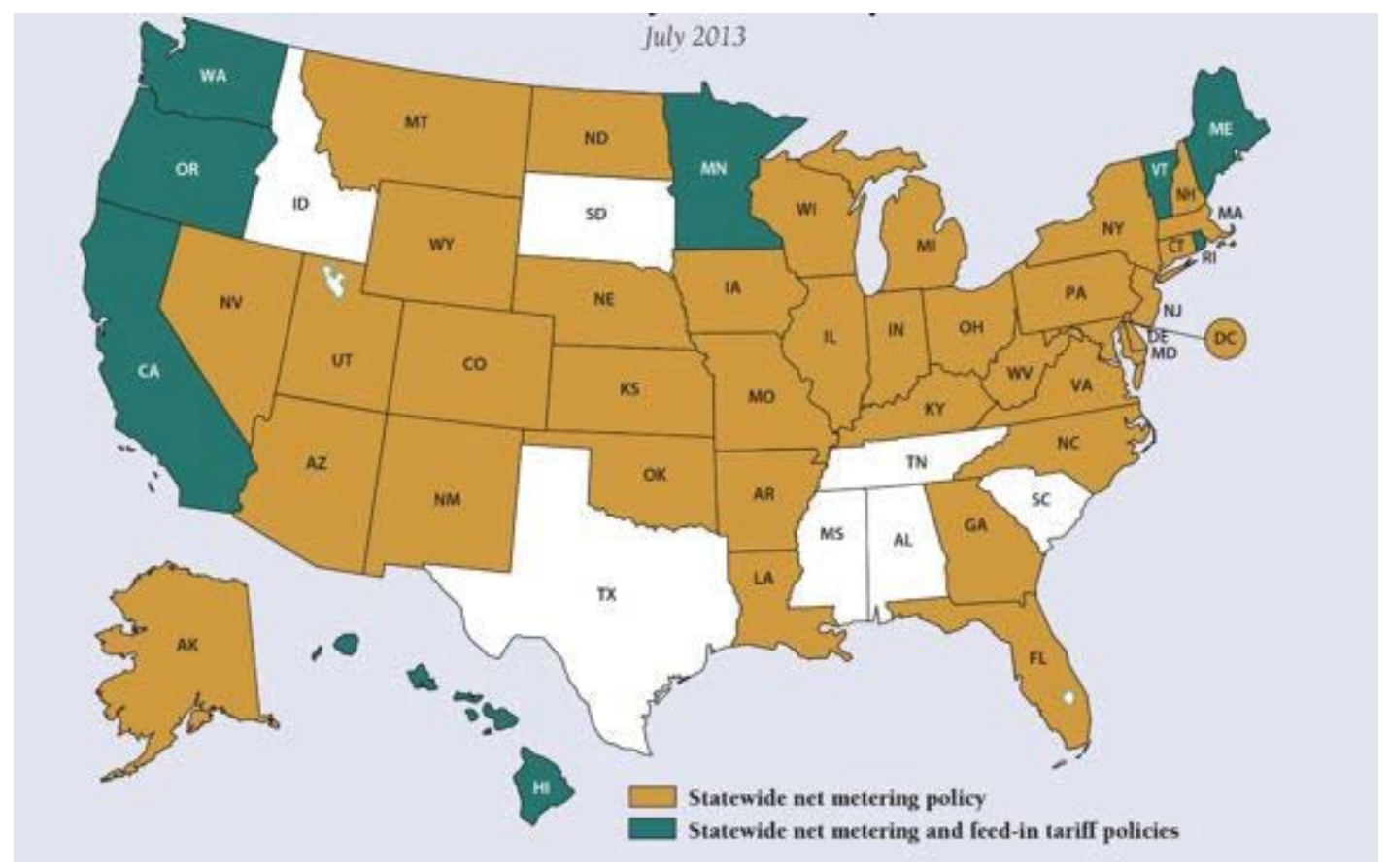

Figure 3-2. U.S. states with mandatory NEM or FIT requirements

As a policy innovation, third-party solar PV leasing options have had a great impact on DG uptake in the United States. New business models are arising that enable third parties to deliver DG options directly to customers in some states, in effect competing with the utility or loadserving entity to sell retail electricity. In particular, third-party ownership of solar PV systems has come to dominate the PV market in states where such arrangements are allowed, as shown in Figure 3-3. Industry reports indicate, for example, that third parties own more than $60 \%$ of the residential PV systems installed in California and Massachusetts, and more than $80 \%$ of the residential PV systems in Arizona and Colorado (GTM/SEIA 2014). 


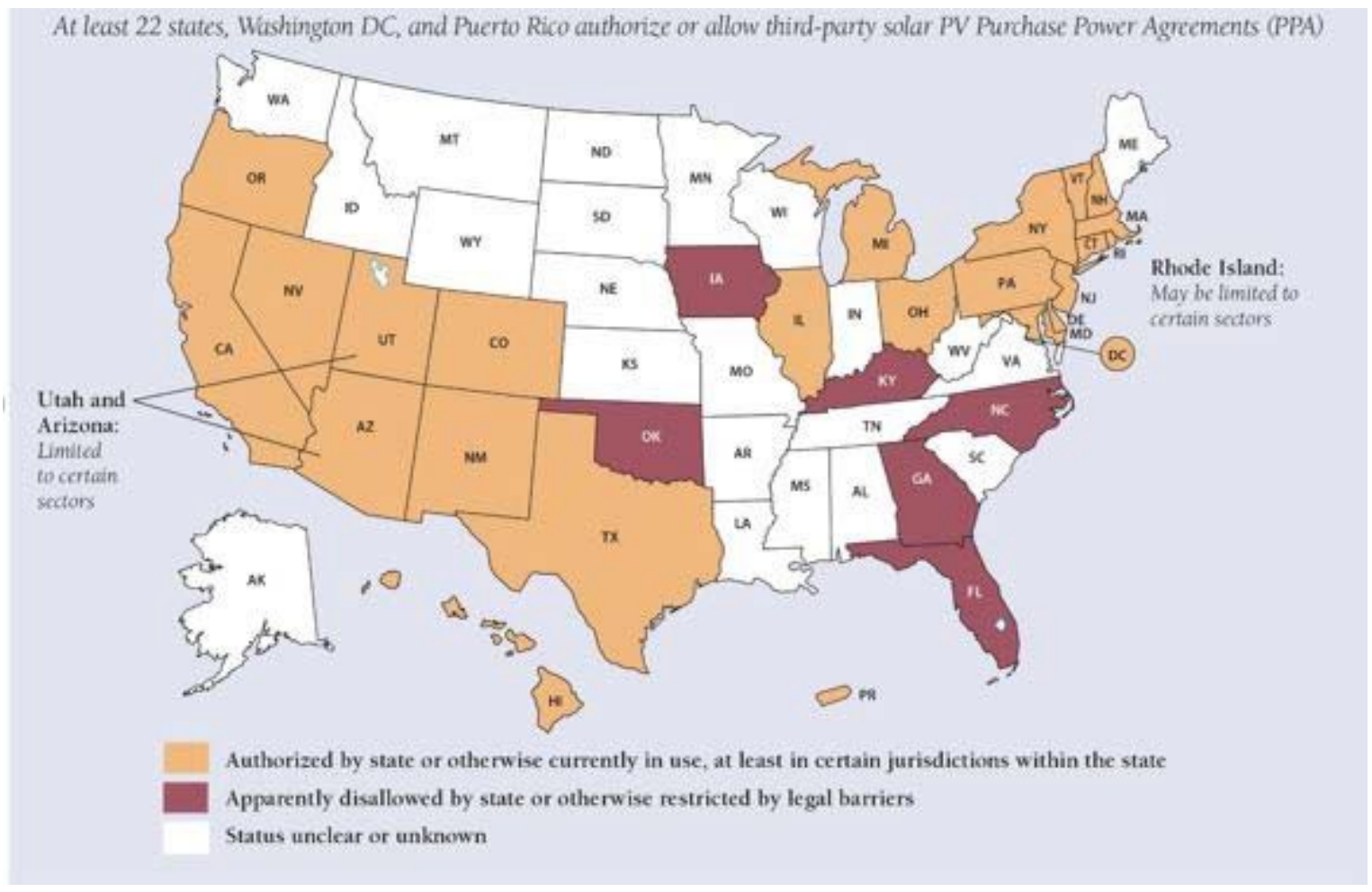

Figure 3-3. U.S. states allowing third-party ownership of solar PV systems ${ }^{16}$

A number of U.S. states (shown in brown in Figure 3-4) have also adopted policies that allow for the aggregation of multiple meters under a net metering tariff. This policy is beginning to take off in the United States and is worth considering in Mexico. Advocates for meter aggregation point to several benefits that this kind of policy provides to participating customers, including:

- Aggregation allows more customers to potentially benefit from net metering. Customers who rent a property normally cannot install DG, but they might be able to "buy a share" of the output of a generator and apply it to the home or commercial space they are renting. Similarly, customers who own a property that is ill suited for DG (e.g., they cannot install PV because their roof is shaded) can also participate and benefit.

- Larger DG systems can be installed that may benefit from economies of scale. For example, the cost of installing a $20-\mathrm{kW}$ PV system on one property will generally be less than the cost of installing two $10-\mathrm{kW}$ systems on separate properties.

- DG can be sited in optimal locations instead of always having to be sited on a single participating customer's property. For example, an aggregation of commercial customers could site a wind turbine on the property of the one customer with the best wind profile, so that the output is much greater than would be the case if each customer sited a smaller generator on his or her own property. Alternatively, a generator serving multiple net metering customers could be sited in where it alleviates (rather than exacerbates) a distribution system operational problem.

${ }^{16}$ http://ncsolarcen-prod.s3.amazonaws.com/wp-content/uploads/2014/11/3rd-Party-PPA.pdf 


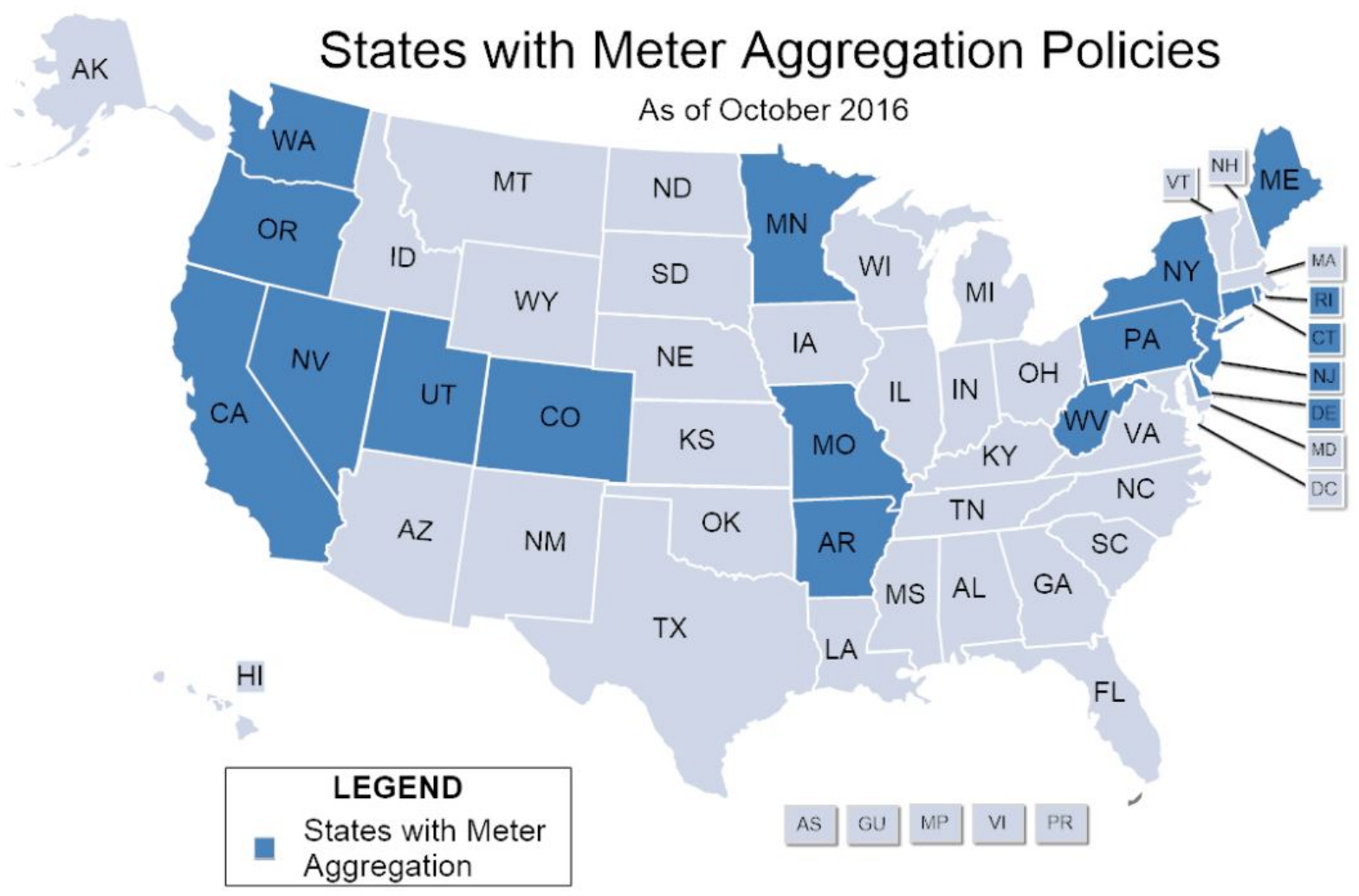

Figure 3-4. U.S. states allowing meter aggregation for net metering ${ }^{17}$

Detractors of meter aggregation policies point to the same concerns that arise with net metering in general, some of which can be exacerbated by aggregation. Although these policies will tend to promote even greater deployment of DG, they will also further erode sales of utility kilowatthours and, at least in the short term, increase the pressure to raise rates. In addition, these policies could potentially encourage the deployment of higher-capacity variable energy resources that add to the utility's challenge of balancing load, managing the distribution system, and providing reliable service.

Where meter aggregation is allowed, the costs and benefits of DG under a net metering tariff can be significantly different, especially from a participating customer's perspective. However, from the perspectives of utilities and non-participants, the changes will not always be as significant, assuming other restrictions and caps in the policy are unchanged. If a state allows meter aggregation but has a net metering program cap, aggregation may change who participates and how much they individually benefit without changing the cumulative amount of DG deployed or the impact on the utility and non-participants. Policymakers considering aggregation need to recognize that the design of the policy and ensuing tariffs will shape whether meter aggregation benefits all stakeholders or benefits some at the expense of others.

\footnotetext{
${ }^{17}$ Source: National Conference of State Legislators, data from DSIRE.org.
} 


\subsection{Identifying the Right Portfolio of Policies for Mexico}

The first pillar of Mexican power sector reform is to promote customer empowerment, and customer-sited DG is perhaps the most literal embodiment of this empowerment. At the same time, Mexico seeks to transition to much greater adoption of cost effective DG without the special subsidies or tax breaks that have been offered in some other countries. Instead, reform in Mexico is intended to motivate adoption of DG based on price signals that reflect the full and fair value of DG. NEMs, FITs, and shared renewable energy tariffs (like community solar garden tariffs) are vehicles for communicating value propositions to residential and small commercial consumers. At the same time, improving access to capital markets so that DG installations can be more cost effectively financed is important so that initiatives like third-party financing and on-bill financing are worth considering. Finally, for commercial, industrial, and shared renewable DG installations larger than $500 \mathrm{~kW}$, Mexico must ensure access to wholesale markets so that DG producers have a market for any net energy production.

Determining the portfolio of policies that fit Mexico's situation and tailoring policies for the Mexican context requires that we step back for a moment and consider the value proposition presented by DG. The policies selected and implemented by Mexico will be more sustainable if they are fair to adopters of DG, fair to all customers including those who do not adopt DG, fair to utility investors, fair to third-party participants in the market place, and beneficial to society as a whole. Fair policies that are in the public interest must consider the DG value proposition from each of these perspectives. Therefore, before we outline policy options for Mexico it is appropriate that we define the value proposition from each perspective. 


\section{Ensuring Equity and Fairness through Proper Valuation of Distributed Generation}

Energy reform in Mexico is bringing wholesale providers and market forces to the electricity sector, and consumers are suggesting that sector supports should be targeted to benefit consumers more directly. DG support policies are a means of delivering benefits directly to consumers, but international experience indicates DG policies that ensure fairness among DG-adopting and DG non-adopting consumers will be more durable. Durable DG policies are important because they support smooth growth of the sector rather than boom-bust cycles. Therefore, a foundational exercise that Mexico should undertake as it begins to implement favorable DG policies is the exercise of deciding how to ensure fair valuation of DG policies and regulations.

Valuation is especially important in implementing DG tariff policies such as NEM and FITs. Fair valuation requires that the value proposition be considered from the perspectives of several stakeholders, including energy producing customers, non-energy producing customers, the utility, and society. The purposes of this section are (1) to introduce the sources of DG benefits and costs and (2) to describe the net value proposition for DG adoption from each of the four perspectives. The description of the benefits and costs will focus on DG adoption behind a customer's meter in order to make the descriptions concrete, but the sources of benefits and costs can be adapted to situations where DG may be interconnected on the distribution system in front of the customer's meter.

\subsection{Specific Sources of Distributed Generation Benefits and Costs}

The specific sources of benefits and costs associated with DG can be broken down into five categories: DG program cost, utility system benefits, benefits to participants, non-energy benefits to participants, and societal non-energy benefits. DG program cost includes costs borne by utilities, participants, and non-participants. Many of these costs and benefits are similar to those provided by EE programs. The Regulatory Assistance Project's recent comprehensive study of EE costs and benefits (Lazar and Colburn 2013) should be consulted for detailed explanations of those sources of benefit or cost that are common to DG and EE. The sources of benefit and cost that are associated with DG but that are not with EE are separately summarized in this section.

Examples of program costs include the cost of administering a DG program, the installed cost of the DG system, and the costs associated with metering, interconnection, and system integration. The utility system benefits represent the largest category of benefits. The long-run marginal cost is the appropriate metric to use to represent the utility system avoided cost, because a DG investment by consumers should be considered a resource rather than merely a device to achieve short-term load reduction. For this reason, the utility system benefit should include all avoided marginal costs, including costs associated with avoided transmission, net avoided distribution and avoided generation, avoided line losses, and avoided reserve requirements. To the extent that DG construction affects compliance with a clean energy standard or renewable portfolio standard, any avoided cost of compliance should be included as well.

Benefits to customers who choose to adopt DG may include items such as reduced fuel consumption or reduced future energy payments. Non-energy benefits to participants may include items such as increased property value, comfort, enhanced energy reliability, and 
improved productivity. Societal non-energy benefits may include items such as air quality impacts, water quantity and quality impacts, enhanced energy system resiliency, and economic impacts.

\section{Distributed Generation Program Costs}

DG installed costs include both the cost of the DG equipment as well as the cost of all labor and other equipment that are required to enable a fully functioning DG system. The installed cost is paid primarily by the participant, but state and federal tax benefits and utility incentive payments may offset part of the installed cost. While Lazar and Colburn (2013) note that EE programs include "measure costs," which analogously are partially paid by the participant, DG also includes metering, interconnection, and system integration costs, which may be paid partially or entirely by the participant. Metering costs are sometimes paid exclusively by the participant, but in other cases, they may be shared by the utility or third parties. Interconnection and system integration costs are very low for low penetrations of DG and for smaller DG systems, but higher penetrations of DG and larger DG systems may include additional costs to interconnect incremental facilities or to accommodate facility operation with system resources. The larger the DG project, the more likely the project is to include a specific interconnection system impact study, additional interconnection hardware, and thus additional cost. ${ }^{18}$

\section{Utility System Costs and Benefits}

DG is likely to obviate the need for some energy, capacity, and ancillary services: DG reduces system demand and thus affects the quantity of resources that the utility must procure. ${ }^{19} \mathrm{In}$ addition, DG may provide incremental energy, capacity, and ancillary services to the system during those hours when the customer is a net generator of electricity. The incremental net generation further obviates the need for system resources and thus avoids additional costs.

Different types of DG have different operational capabilities and thus the value of capacity and ancillary services from an installation varies by technology type. Services that can be provided by some technologies include regulation service, reactive power service, load following service, and ramping service. The value of capacity and some ancillary services varies by location and time on the utility's system, with DG in some locations having high value and DG in other locations having low value.

Although EE can have avoided distribution cost benefits, DG is different in that it can either avoid utility distribution system expense or cause the utility to incur some incremental distribution expense. High penetrations of DG or large DG installations may cause distribution expense, whereas smaller and appropriately located DG facilities are likely to avoid incremental DG expenses and thus produce a net savings in distribution outlay. ${ }^{20}$

\footnotetext{
${ }^{18}$ For more information on the magnitude of the direct, metering, interconnection, and system integration costs in the case of high penetration solar DG, see Bird et al. (2013).

${ }^{19}$ Rooftop distributed PV also provides a shading benefit that can reduce temperature gain in structures, thus reducing the demand for electricity beyond the demand displaced by PV production.

${ }^{20}$ See Bird et al. (2013) for a detailed discussion of the potential for increased distribution system costs in situations where solar PV penetration is high and is concentrated in specific locations on the grid.
} 
For a thorough survey of how many of these benefits and costs have been applied in recent studies, see Newcomb et al. (2013), which describes the assumptions, data sources, and findings of 15 recent DG studies.

\subsection{Cost Testing from Various Stakeholder Perspectives}

Energy-producing consumers, non-energy-producing consumers, the utility, and society as a whole have different perspectives on translating the sources of benefit and cost into a net value assessment. Starting with California's Standard Practice Manual more than 30 years ago, EE programs have been evaluated from a number of perspectives. DG can likewise be reflected by these same measures with some adaptation to reflect the energy generation aspect of DG. The "Resource Valuation Framework" was introduced in 2014 to present an additional test that reflects a "public interest" perspective. ${ }^{21}$

The Program Administrator Cost Test (PACT, also known as the Utility Cost Test or UCT) represents a benefit-cost ratio from the administrator perspective. The Total Resource Cost (TRC) test and the Societal Cost Test (SCT) represent a benefit-cost ratio for society as a whole, wherein the TRC typically excludes non-energy benefits, and the SCT typically includes non-energy benefits. $^{22}$

Most utility commissions in the United States use the TRC test as the primary test for judging whether a utility EE program is cost effective. The PACT (UCT) is the second-most common test, and the still new Resource Value Test has not yet been implemented by a state utility commission. Each of the tests can be implemented well or poorly. Including all relevant sources of costs and benefits and estimating the value of each of the sources well are the two cornerstones of a well-implemented measure. Examples of TRC, SCT, and UCT implementation are included later in this section to demonstrate which sources of cost and benefit should be included.

Additional tests have been introduced to represent customer perspectives. The Participant Cost Test (PCT) represents a benefit-cost ratio showing the value of participating in an EE or DG program. The PCT is valuable for assessing whether a program is beneficial from the perspective of potential participants. The Ratepayer Impact Measure (RIM) test was introduced to reflect non-participant effects, but it fails to reflect net benefits for non-participants for several reasons. First, it is often narrowly defined to include the effect of reduced revenues on rates without including the benefits created by avoiding utility investment expense in transmission, distribution, and generation. Even if one includes all avoided costs in the RIM test, it does not

\footnotetext{
${ }^{21}$ While time-honored California Standard Practice Manual benefit and cost testing has served us well, some believe its application has certain fatal flaws. The Energy Efficiency Screening Coalition produced a methodology called the Resource Valuation Framework to overcome these perceived flaws. "Recommendations for Reforming Energy Efficiency Cost-Effectiveness Screening in the United States" (November 2013) describes the methodology and may be downloaded from http://www.nhpci.org/campaigns.html. An application of the methodology can be found in Woolf et al., "Unleashing Energy Efficiency," Public Utilities Fortnightly, October 2014.

${ }^{22}$ Each of the tests described here can also be represented as a net benefit value rather than a benefit-cost ratio. Similar tests have been developed to gauge the cost-effectiveness of demand response programs, as noted in A Framework for Evaluating the Cost-Effectiveness of Demand Response, prepared for the National Forum on the National Action Plan on Demand Response: Woolf et al. (2013), available at http://emp.lbl.gov/sites/all/files/napdrcost-effectiveness.pdf.
} 
reflect the full benefits accruing to non-participants, because it leaves out wholesale market price impacts of reduced demand and it leaves out non-energy benefits such as public health benefits, environmental benefits, and economic development benefits (Keyes and Rabago 2013).

Table 4-1 summarizes the purpose of these five tests when they are adapted to the context of DG evaluation.

Table 4-1. The Purpose of Stakeholder Perspective Tests

\begin{tabular}{|c|c|}
\hline Perspective & What Constitutes "Value" \\
\hline DG customer (PCT) & Will the DG customer's costs decrease? \\
\hline Other customers (RIM) & Will utility rates decrease? \\
\hline Utility (UCT or PACT) & Will the utility's costs (revenue requirement) decrease? \\
\hline Total resources (TRC) & Will the sum of utility costs and DG customer costs decrease? \\
\hline Society (SCT) & Will total costs to society decrease? \\
\hline
\end{tabular}

Note: $\mathrm{PCT}=$ Participant Cost Test, RIM = Ratepayer Impact Measure, $\mathrm{PACT}=$ Program Administrator Cost Test (also known as UCT or Utility Cost Test), TRC $=$ Total Resource Cost, SCT $=$ Societal Cost Test.

\subsection{The Utility Net Value Proposition from the Administrator Perspective}

DG that serves retail load directly, under any form of NEM or FIT, is a concern to utilities for a number of reasons, but two reasons are most commonly cited. First, in many states, the utility is providing an incentive to the customer in the form of credit at the retail rate for power received by the utility, whereas the utility arguably is avoiding only the power supply component of that rate. Second, the utility is losing revenue from the amount of power previously purchased by the consumer that is displaced by onsite generation. These two effects, plus several others indicated in Table 4-2, add up to a net value proposition for utilities associated with DG. It is important to note in reviewing the sources of benefit identified that the value of DG to the electric system varies by technology, location, and time. In particular, several of the utility system benefit attributes depend on the technology, location, and time of energy production, and thus the net value of a given DG project will vary based on these factors. 
Table 4-2. Benefits and Costs in the Program Administrator Cost Test

\begin{tabular}{ll}
\hline Cost or Benefit Category & Treatment in the Utility Cost Test \\
\hline DG program costs & $\begin{array}{l}\text { Program administration costs, any incentive costs paid to DG adopters } \\
\text { financed by utility rates and other DG costs assigned to the utility, as well as } \\
\text { any lost revenues to the utility }\end{array}$ \\
Utility system benefits & $\begin{array}{l}\text { Avoided energy, capacity, and ancillary service costs, avoided transmission, } \\
\text { net avoided distribution, and avoided costs associated with reduced line } \\
\text { losses, reduced reserves, reduced uncollected bills, and reduced service } \\
\text { terminations and other factors }\end{array}$ \\
Non-energy benefits & $\begin{array}{l}\text { Avoided unrecovered termination costs, and avoided unpaid bills } \\
\text { Net revenue impact }\end{array}$ \\
\hline $\begin{array}{l}\text { Net revenue impact depends on the quantifiable factors above and is } \\
\text { affected by tariff terms, rate design, and the presence or absence of } \\
\text { decoupling. }\end{array}$
\end{tabular}

\section{Program Costs}

Utilities incur administrative costs to enter into contracts with NEM and FIT generators. The level of cost depends on whether customers require meters of a type different from the type normally required, and utilities may incur incremental O\&M expenses to provide the metering, invoicing, and payment processing. Finally, some states provide for shareholder incentives for utilities that enter into contracts for renewable energy resources, including those procured through NEM or FITs.

Even in cases in which some investment is required on the part of the utility, the administrative and O\&M expenses are usually very minor, and cost recovery is left to general rate proceedings. But incentives are different, and most states where incentives are paid to DG adopters provide for timely recovery of these incentives through a tariff surcharge in which utilities are allowed to separately recover the incentive expenses. A public benefits charge is an example of such a tariff surcharge. It can be separately stated (rare), incorporated into a more general fuel and purchased power recovery mechanism (more common), or deferred for subsequent recovery, with accrual of interest during the deferral period.

\section{Lost Revenues in the Context of the UCT}

From the perspective of a program administrator, the lost revenues to the utility include the revenue lost from all kilowatt-hours of energy not sold because of DG. Decoupling is the tool designed to offset this quantity of lost revenues for investor owned utilities (Lazar, Weston, and Shirley 2011). For a publicly owned utility the issue of reduced revenues is dealt with through the rate setting and rate design process.

\section{Utility System Benefits}

Utility system benefits include all energy, capacity, ancillary services, transmission, and distribution costs that are avoided by the installation of the incremental DG facility. At high 
levels of penetration or for large DG facilities, there may be a net transmission, distribution, or ancillary service/integration service cost that counts against the avoided cost and thus reduces the avoided cost value of the DG facility to the utility. As discussed earlier, the value of DG is technology- and location-specific, so the avoided cost value to the utility will likewise be technology- and location-specific.

\subsection{The Three Roles of the Producing Consumer}

The consideration of net revenue impact on a public utility requires some background discussion. When considering the impact of DG on utility resources, the owner of DG may appear to have three different relationships with his or her utility. First, during times when the distributed system is not generating electricity, the customer's load will look just like that of any other customer. Second, when the system is generating electricity in amounts that are equal to or less than the customer's onsite consumption, the customers will have reduced load that is similar to what might happen if he or she had deployed EE measures. Third, when the customer generates more power than he or she consumes, the customer becomes an exporter of electricity to the system. Different customers are consuming electricity and exporting to the grid to varying degrees based on their consumption and production profiles. These changes have measurable impacts on electric utilities, and on the non-participating customers. All three relationships are illustrated in Figure 41 as they might happen for a typical customer with a PV system. The production profiles for other DG technologies and systems vary, but the DG owner as utility consumer, self-provider, and exporter are three roles common to most DG systems. Industrial customers who own combined heat and power (CHP) systems are an important example of a DG technology with a much different production profile from $\mathrm{PV}$.

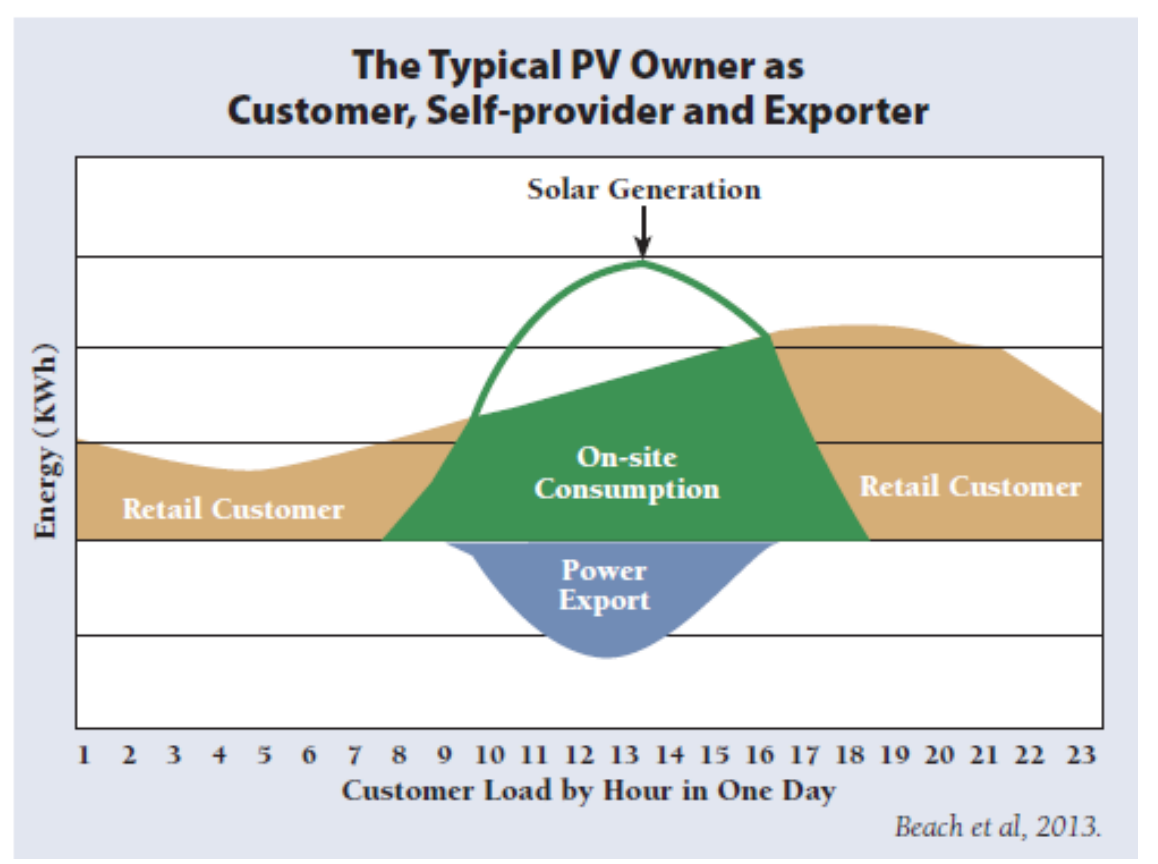

Figure 4-1. The typical PV owner as customer, self-provider, and exporter

Typical electric utility rates recover most of the cost of electric service through the per-kWh energy rate. Sales to larger commercial and industrial customers typically include a demand charge that is based on the customers' highest hourly usage, so the revenue decline from these 
customer classes will usually be small. On the other hand, small commercial and residential customers who may install NEM systems seldom pay a demand charge. The revenues a utility recovers from customers who choose to install PV may include payment for net energy purchases by customers, revenues from standby or fixed charges, and any revenues associated with special equipment (such as the customer's portion of smart meter costs, if any) purchased from the utility by customers.

\subsection{The Net Value Proposition from a Societal Perspective}

Higher penetration of DG resources produces benefits and costs for society as a whole. The TRC test evaluates the energy-related benefits and costs that are more readily quantified with expressed economic values. The SCT includes all of the quantified benefits and costs from the TRC, but it adds consideration of some non-energy externalities that are benefits or costs from a societal perspective but are not readily expressed in economic values at the present time. Citizens who value all of the resource benefits as well as the non-energy benefits of DG programs are likely to value the programs from a TRC or SCT perspective, whether they are participants or non-participants. A summary of the two tests and the factors that play into the computation of the test results is shown in Table 4-3. It is worth emphasizing that non-energy benefits are not just environmental externality and environmental resource benefits; increased energy security is a significant category of non-energy benefits for many citizens. Increasing energy security through improved grid resiliency and grid security is highly relevant to current public policy concerns spurred by significant climate events, national security, and cyber-security concerns. Interest in grid resiliency and security has spurred investment in a range of renewable and CHP DG technologies.

Table 4-3. Benefits and Costs in the Total Resource Cost and Societal Cost Tests

\begin{tabular}{lll}
\hline $\begin{array}{l}\text { Cost or Benefit } \\
\text { Category }\end{array}$ & $\begin{array}{l}\text { Treatment in the Total Resource } \\
\text { Cost Test }\end{array}$ & $\begin{array}{l}\text { Additional Factors Included in } \\
\text { the Societal Cost Test }\end{array}$ \\
\hline DG program costs & $\begin{array}{l}\text { All costs incurred by the participant } \\
\text { and the utility are included. }\end{array}$ & No additional factors \\
$\begin{array}{l}\text { Utility system } \\
\text { benefits }\end{array}$ & $\begin{array}{l}\text { All utility system benefits identified in } \\
\text { Table 4-2 are included. }\end{array}$ & No additional factors \\
$\begin{array}{l}\text { Benefits to } \\
\text { participants }\end{array}$ & Participant resource and fuel savings & No additional factors \\
\hline $\begin{array}{l}\text { Non-energy benefits } \\
\text { to participants }\end{array}$ & Participant O\&M savings or costs & Participant health \\
\hline $\begin{array}{l}\text { Non-energy benefits } \\
\text { to society }\end{array}$ & $\begin{array}{l}\text { Water quantity and quality benefits } \\
\text { The TRC represents all energy-related }\end{array}$ & $\begin{array}{l}\text { Air quality and energy security } \\
\text { benefits }\end{array}$ \\
\hline $\begin{array}{l}\text { Net social impact } \\
\text { costs and benefits as well as non- } \\
\text { energy benefits that are quantifiable, } \\
\text { and it is not affected by the rate } \\
\text { design or tariff design. }\end{array}$ & $\begin{array}{l}\text { costs and benefits plus certain } \\
\text { additional non-energy benefits, } \\
\text { primarily environmental. }\end{array}$ \\
\hline
\end{tabular}


The results from the TRC and SCT tests are useful in guiding the level of DG penetration that will be consistent with the public interest. The choice of a tariff option and the tariff attribute values selected (e.g., the level of any fixed or variable charge and the periodicity of netting if the tariff is a NEM tariff) are relevant to the TRC or SCT in so far as those choices are made to support the attainment of a socially beneficial level of DG penetration.

\subsection{Consequences of Getting Valuation Incorrect}

Although there is much discussion of conflicts among the perspectives of different stakeholders, it is worth reflecting on the mutual benefits of procuring cost-effective generation resources. The utility system benefits are enjoyed by all: participants, non-participants, utilities, and society as a whole. If the long-run marginal avoided cost associated with DG installations is greater than the cost imposed on non-participating customers, the discussion of non-participating customer harm should be a short one. The first step in assessing the extent to which conflict among customers exists and in assessing which customers are being subsidized should therefore be an accurate and complete accounting of long-run marginal avoided costs. If the net benefits are positive, it is worth assessing whether distributed generating customers are being paid enough.

\section{The Possibility of Non-Participants Cross-Subsidizing Distributed Generation Adopters}

If the utility system benefits created by DG do not exceed the cost to non-participating ratepayers, a commission will need to adopt a full definition of non-participant benefits to clarify the metric used to assess the presence or absence of cross-subsidization. Having adopted the metric and assessed the net value proposition for non-participants, the commission may then have to either mitigate any cross-subsidization from non-participants to participants or reward any crosssubsidization from participants to non-participants. Fairness demands that the test of whether cross-subsidization exists should factor in the possibility that participants are actually undercompensated for their resource.

To the extent a cross-subsidy exists, the cross-subsidy should be rectified by adjusting the terms of the tariff and the rate design applied in the tariff. The next section takes up the issue of how to equitably set the tariff terms and rate design.

\section{The Possibility That Too Little Distributed Generation is Being Added}

Another potential source of conflict among stakeholders might be the determination of the economic potential of DG (i.e., how many megawatts of DG are merited based on the net value proposition from a societal perspective). Answering this question starts with a commission determination of what benefits and costs should be included in the SCT or TRC test. The guiding principle in this discussion should be an interpretation of the public interest in light of any legislation, policy, or regulation that has been adopted to implement DG. To the extent the enabling language encompasses a broad range of non-energy benefits, that broad range should be reflected in the adopted valuation specification. This question is separate from the consideration of tariff and rate design. 


\section{The Possibility That Utility Financial Health and Reliability of Service will be Compromised}

Another source of potential conflict is the possibility that under-collection of revenue will affect utility financial health, which may in turn compromise reliable service. As DG becomes more economical and common, there may be a significant decline in revenue collection. To ensure the utility is not biased against cost-effective DG, decoupling should be considered (MigdenOstrander et al. 2014). The decoupling consideration is separate from the rate design and tariff consideration. However, over the longer term, the prospect of reduced revenue may require a tariff adjustment to ensure required grid services are adequately financed.

\section{The Possibility that Third-Party Entities will not have Access to Markets}

The value proposition presented through tariffs and rules has an effect on third-party energy service companies that install DG systems and provide leasing options. Third parties have provided innovative financing options and have the potential of aggregating customer-produced energy and customer-produced load in ways that can add value for all customers and for society as a whole. Ensuring that tariffs and rules are fair to third-party participants can accelerate DG adoption and innovation.

\subsection{Getting Valuation Right}

A first step in choosing and designing effective policies for Mexico should be to establish a reasonable value for DG technologies in the country. A valuation exercise reveals the key components of value, establishes the relative magnitudes of value components, specifies how the components vary by time and place, and translates these sources of value into value proposition metrics. The information generated in completing the valuation exercise helps ensure tariffs and rate designs are approximately fair, and it also helps reveal where policy activity is needed. For example, if the valuation exercise reveals that the value proposition for commercial customers is very favorable but the adoption of DG by commercial customers is meager, barriers to commercial adoption (e.g., interconnection rules or inability to sell excess energy at a reasonable price) need to be addressed. If, on the other hand, the exercise reveals that the value proposition for commercial customers is poor and unfair, the policy prescription needs to start with changing tariffs and rate design to reflect the underlying value of commercial projects. Once the full and fair value of DG technologies is established, policy options can be evaluated.

Choosing and designing effective DG policies for Mexico would be enhanced by implementation of a valuation exercise that seeks to identify the full and fair value of DG technologies in Mexico. 


\section{Designing Distributed Generation Tariff, Rate Design, and Policy Options}

Sections 1 and 2 described the power sector context for Mexico, Section 3 introduced a wide range of tariff and policy options based on international best practices, and Section 4 provided the valuation principles needed to design tariffs fairly. Section 5 focuses on building appropriate tariffs, rate design, and policies for Mexico using DG 1.0 mechanisms that gradually allow the transition to DG 2.0.

This section starts by introducing the basic options for policy when DG adoption is low; we will call these DG 1.0 mechanisms. NEM and FIT are DG 1.0 mechanisms - relatively simple instruments that approximate the value of DG and have typically been adopted to encourage the maturation of an infant DG industry. The international experience with getting beyond the infant industry stage requires tariffs that create a value proposition for adopters to encourage installations and move the industry toward maturation. The cost of early adopters is often higher because the supply chain of equipment and skilled installers is thin, so often a compensation premium is appropriate for first movers.

DG 1.0 mechanisms have a proven record of attracting private capital support and thus are worth considering in Mexico during the infant and early to middle maturation phases of the DG industry, using modest rate design adjustments to ensure compensation is approximately fair to both participants and non-participants.

This section then explores the next step, which is to evolve from DG 1.0 mechanisms toward a DG 2.0 world. As DG technologies become competitive and electricity system electronics, communications, and control technologies become more sophisticated, it becomes possible to more carefully establish tariffs and markets in ways that fine-tune the value proposition from the participant, non-participant, utility, and societal perspectives.

Adoption of DG in Mexico is currently concentrated in particular areas of the country, and thus the industry will likely mature in different parts of Mexico at different times. As a given location in Mexico reaches the point where moving beyond DG 1.0 toward DG 2.0 is timely, it will be important to update DG 1.0 tariffs with some new tariff mechanisms as well as rate designs that can take advantage of evolving information technology capabilities and increase the role of the market in communicating value. Jumping to DG 2.0 before sufficient DG penetration levels are reached and information technology capabilities have matured would likely stunt the growth of DG, so abandoning DG 1.0 abruptly is not advocated. When the time comes to transition from simple DG 1.0, pilot programs that test several use cases are a wise course of action, because a complete transition requires learning by all power sector actors - utilities, energy service companies, consumers, markets, and regulators - along with a suite of policies that allow for participation and maturation of each actor. This section concludes with a series of policy options that may prove beneficial in helping Mexico move toward DG 2.0.

Moving beyond DG 1.0 toward DG 2.0 at an appropriate time can help fine-tune the value proposition of DG to all stakeholders and encourage expanded and cost-effective DG adoption. 


\subsection{Typical DG 1.0 Mechanisms Net Metering Tariffs}

Under a net metering tariff, a customer is billed by his or her utility or load-serving entity based on net electricity consumption (i.e., the amount consumed minus the amount generated). For example, if a customer's system generated 1,000 kWh during a billing period, and the customer consumed 1,200 kWh during the same period, the customer would be billed for $200 \mathrm{kWh}$ of purchased electricity. Net consumption can be measured either (1) with a single meter that measures net energy and is capable of counting forward or backward or (2) with separate metering of the customer's generation and consumption and a calculation of the net value computed by the utility. The ability to use one meter represents the virtue of simplicity that characterizes net metering in many states.

\section{Feed-In Tariffs}

When a utility offers a FIT, it essentially offers to enter into a long-term power purchase agreement, under standard (non-negotiable) terms and conditions, with any customer who meets specified eligibility criteria. In this report, we distinguish a FIT from a standard-offer contract tariff by further stipulating that a FIT may offer the customer a price that exceeds the utility's avoided costs of purchasing unspecified energy and capacity. Recall that the premium often varies by technology and location based on differences in utility system value, and additional increments to the premium are sometimes justified based on non-priced attributes such as environmental or public health benefits.

\section{Typical DG 1.0 Rate Design}

Residential and small commercial service rates typically include a flat per- $\mathrm{kWh}$ charge that is assessed based on the volume of $\mathrm{kWh}$ consumed in the billing period. In some places, the $\mathrm{kWh}$ charge varies by time of use (with peak usage times carrying a higher rate) or by volume of consumption (with higher rates as consumption crosses higher thresholds in the billing period). The rate sometimes includes a small monthly fixed charge. ${ }^{23}$ Opportunities for improving rate design to move toward DG 2.0 are discussed in Section 5.3.

Large commercial and industrial customers typically pay a volumetric rate for consumption as well as a demand charge based on the customer's peak consumption in the time period. For commercial and industrial customers with behind-the-meter generation, such as users of CHP systems, additional tariff terms are included to cover the purchase of standby electric service for planned and unplanned customer generation outages. The tariff conditions that specify standby rates vary by jurisdiction; there is no one standard practice in the United States, but best practices can be inferred. ${ }^{24}$ Opportunities for improving large commercial and industrial rate design will be discussed in Section 5.4.

\footnotetext{
${ }^{23}$ For a more complete description of typical residential, commercial, and industrial rate designs with examples from around the world, see Lazar, J. (2013).

${ }^{24}$ For examples of typical rate designs for commercial and industrial customers with CHP DG systems, see Selecky, Iverson, and Al-Jabir (2014).
} 


\subsection{DG 2.0 Tariff Mechanisms: Where are We Heading?}

DG 2.0 will have arrived as DG penetration grows in Mexico and when markets develop to the point where improved visibility on the electric system makes two-way measurement and management of flows feasible. Utilities will still provide services to customers, but residential, commercial and industrial customers will also provide services to the utility and to the grid operator. Compensation for energy produced, whether it is produced on the customer side of the meter or the grid side of the meter, will migrate away from utility tariffs and toward market-based compensation. Grid services, such as spinning reserves, ramping service, load following, frequency response, and location-specific reliability services, will need to be procured by the system operator or the utility, but these will eventually be procured in the market rather than through tariffs. However, in the transition toward Grid 2.0 and DG 2.0, tariffs will continue to be necessary to create the financial certainty required to support investment in infrastructure, generation, and information technology.

Fortunately, changes in utility regulation can build on several of the principles upon which utility regulation has been founded for decades. The principal purposes of utility regulation are to ensure rates are fair, just, reasonable, and sufficient to allow a prudently managed utility to attract additional capital on reasonable terms. The need to create an environment where capital can be attracted to build the necessary infrastructure and generation has not changed, but what is changing is who needs to attract capital. Utilities still need to attract capital to ensure that adequate compensation for investment incurred to support the system will continue. However, in addition, regulators need to be concerned with creating a stable environment where third-party generation companies and service providers can attract capital. This means creating tariffs in the transition that provide the certainty required for investors to attract capital on reasonable terms.

Regulators also have a history of being concerned with ensuring rates are fair. Historically, regulators have interpreted a fair rate as one that reflects the cost of service and applies to all customers. Some regulators have chosen to base the cost of service on embedded costs (i.e., all costs incurred to date to provide current service), whereas others have chosen to base it on marginal costs (i.e., the incremental costs incurred to serve incremental needs). While the price a regulated utility charges its customers may be based on one or the other of these definitions of cost of service, the price charged by a firm operating in a competitive market environment will be based on its marginal cost of service. As an increasing proportion of generation and grid services come from independent companies, there will be an increasing need to align the price paid by customers for the marginal kilowatt-hours of service with the full and fair incremental cost of that service. That is, the long-run marginal cost needs to become the price point for marginal consumption in order to create a level playing field where investors in facilities on the customer side of the meter see the same market signal as investors on the grid side of the meter. This longrun marginal cost may be communicated through the "tailblock" rate of an inclining block rate structure until the information infrastructure matures, but eventually it will be communicated by time- and location-specific rates.

Evolutions of the concepts of financial stability and pricing are critical for DG tariffs such as NEM and FITs, because every utility customer (DG owner or not) is entitled to receive service on the same terms. These terms are based on an administered cost of service calculation. However, those DG customers who produce power are offering a long-term product with a 
service life of 20 years or more to the utility and are thus helping the utility and its customers avoid the long-run marginal cost of new resources. The valuation discussion above enumerated all of the sources of long-run marginal cost that may be avoided and that should be considered in such a calculation. Thus, it should not be surprising that the basis for the value of services offered by the utility to DG customers differs from the value of services offered by the DG customer to the utility.

\section{The Bottom Line: Toward a Two-Way Distribution Tariff}

The bottom line is that fairness indicates that the DG-producing customer should be paid the fair value of all the services it provides to the utility and its customers as a whole. The utility and its customers as a whole should be paid the fair value of all the services they provide to the DGproducing customer. This two-way, fair exchange of respective services indicates the need for tariffs that explicitly acknowledge those respective values that each party offers the other. Thus, the evolution of the DG tariff seems to be toward something like a two-way distribution tariff. We show in Section 5.3 how such a tariff could be implemented, but it is likely the United States and Mexico will not jump quickly to two-way tariffs but rather evolve toward them as the physical and information infrastructure becomes capable of supporting them.

Electricity markets and institutions are still evolving to a point where information, communication, and control systems technologies can be used effectively. This means the value of services provided is not yet transparent. Analysts talk about a transactive energy economy where all parties providing services are compensated for those services, but the information infrastructure in most places is not yet up to that task. The DG 1.0 constructs are likely to be with us for a while longer in both the United States and Mexico. That said, there are steps we can take now to make DG 1.0 mechanisms send better price signals as we evolve toward the DG 2.0 world, so that the move toward a two-way transactive grid will be easier when the physical and information infrastructure is in place.

\section{Pointing NEM and FIT in the Right Direction}

The key to pointing NEM and FIT in the right direction is for the regulator to make a conscious decision of what costs and benefits they will include in their valuation of DG. The implementation of DG tariffs that point in the right direction should apply the valuation methodology chosen and build on the two-way fair value principle enunciated above: the prices charged to DG customers for grid services should normally be based on the same principles as retail rates for other consumers, while the prices paid to those customers for their power production should normally be based on the same principles as wholesale power rates paid to other producers for long-term resources, taking into account all relevant resource attributes. Relevant resource attributes include the location on the grid where power is delivered, the time at which it is delivered, the duration over which it is offered, whether it is a renewable resource, and whether it has other non-energy attributes that the regulator has deemed applicable.

To ensure this is done equitably, regulators should ensure that a retail rate design aligns residential incremental rates with long-run incremental costs of service. The current cost-benefit debate related to DG has spawned a number of valuation studies that seek to quantify the costs and benefits of solar PV net metering programs. The Rocky Mountain Institute (Newcomb et al. 2013) recently compiled a comprehensive survey of these studies, which are summarized in 
Figure 5-1. The review indicates that the assessors' choices of which sources of value to include in valuation assessments drive differences among the states. Taking an "average" of the results of these studies is a crude way to summarize the results because they are founded on different methodological approaches. That said, the "average" VOS in these studies was just under $\$ 0.17 / \mathrm{kWh}$. Several U.S. states have completed studies since the Rocky Mountain Institute review was published, and each of these studies was commissioned by a U.S. state agency or commission with the instruction that the findings should reflect a public interest viewpoint. Results from these more recent studies included $\$ 0.115 / \mathrm{kWh}$ in California, $\$ 0.145 / \mathrm{kWh}$ in Minnesota, $\$ 0.17 / \mathrm{kWh}$ in Mississippi, $\$ 0.185 / \mathrm{kWh}$ in Nevada, $\$ 0.245 / \mathrm{kWh}$ in Vermont, and $\$ 0.335 / \mathrm{kWh}$ in Maine. Compared with the average U.S. residential retail rate of $\$ 0.125 / \mathrm{kWh}$, these results suggest that net metering produces net benefits from a public interest perspective.

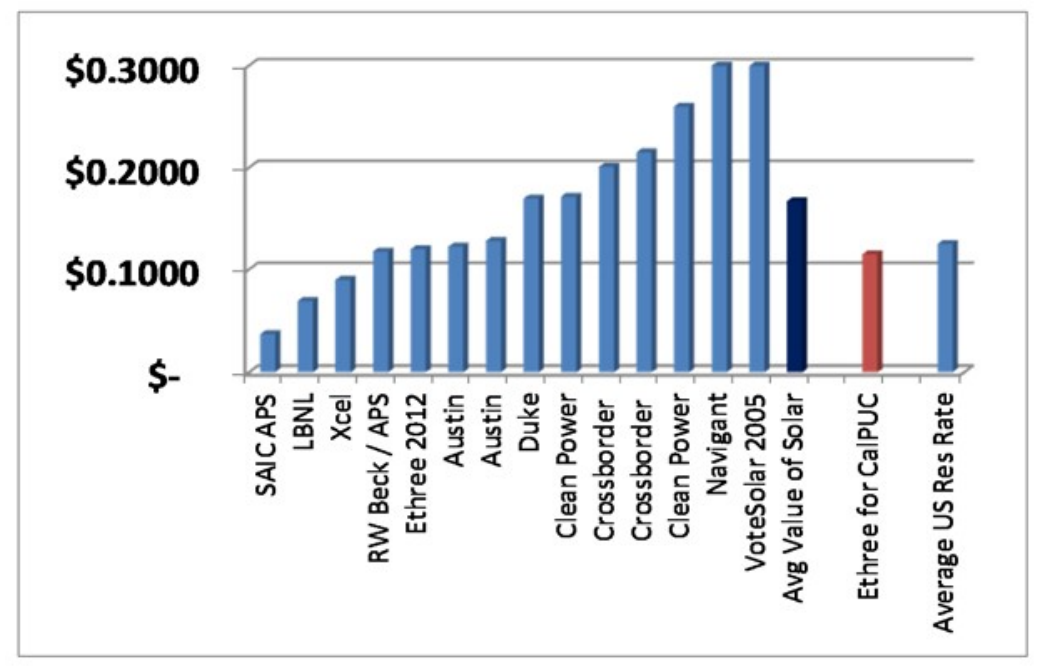

Figure 5-1: "Value of Solar" studies and U.S. residential rates

\section{SAIC APS = Science Applications International Corporation / Applied Physical Sciences; LBNL = Lawrence Berkeley National Laboratory}

Source: Hansen, et al. 2013; average retail rate from EIA 2013, retrieved from http://www.eia.gov/electricity/monthly/epm table grapher.cfm?t=epmt 5 3, November 16, 2013.

The range of values offered in this debate is wide, and it depends on geographic factors, the avoided costs considered, and the point in time when the study was prepared. Utilities are becoming fairly assertive that NEM is an "infant industry subsidy," that it should be phased out as the solar industry grows out of infancy, and that these customers should pay substantial fees for grid access and interconnection. Similarly, in places where FIT compensation was set at a premium above wholesale generation market values, utilities argue that this creates a condition of unfair competition where FIT-eligible resources do not have to compete with non-FIT-qualifying resources, whereas utility-scale resources must compete with conventional resources.

While aligning compensation of DG with long-run marginal cost is sound from the perspective of valuing DG resources relative to other generation options, the question of whether a utility will collect sufficient revenues and achieve adequate profit to maintain grid reliability can become a legitimate issue. The solution to the "lost" revenue portion of the issue is not to compromise efficient rate design but to implement separate mechanisms to address revenue stability, such as revenue decoupling. 


\subsection{Toward DG 2.0: Improving Net Energy Metering through Rate Design Improvements without Dynamic Pricing}

The guiding principles for evolving rate design for a smarter energy future are articulated in the Regulatory Assistance Project's recent paper, Smart Rate Design for a Smart Future (Lazar and Gonzalez 2015), and the following three principles will come into play in our evaluation of the options described in this section:

- Principle 1: Customers should be able to connect to the grid for no more than the actual cost of grid connection.

- Principle 2: Customers should pay for grid services and power supply in proportion to how much they use these services and how much power they consume.

- Principle 3: Customers who supply power to the grid should be fairly compensated for the full value of the power they supply.

Four rate design alternatives are considered to improve the fairness of NEM. These options are typically applied to residential rate design for individual residences or small commercial enterprises, but they are indicative of approaches that could apply more broadly. "Community solar" virtual net metering is gaining in popularity and could consider these same options. These virtual net metering proposals could use these rate design approaches. Approaches that incorporate dynamic pricing are taken up in Section 5.4. All options will be described briefly. Smart Rate Design for a Smart Future includes an in-depth discussion of options both with and without dynamic rates (Lazar and Gonzalez 2015).

The foundational principle of improving the fairness of a net-metered rate design is that the marginal kilowatt-hour should be compensated at the long-run marginal cost. If existing retail rates are not designed to reflect long-run marginal costs, those rates are measuring "cost" differently from the way in which any potential buyer would look at acquiring power from a new generation resource, and this discriminates against the net-metered supplier.

If retail prices are lower than long-run marginal costs, net metering will give the DG customer less compensation for excess electricity than the value of his or her product, which will lead to less than the optimal amount of net-metered resources being developed. On the other hand, if the netmetered supplier is providing power to the grid at less than long-run marginal cost, the non-DG customers are receiving the benefit of that power at a price lower than the utility would otherwise incur to acquire that power. One solution that does not require advanced dynamic metering is for the utility regulator to raise end-block energy rates and reduce grid access fixed charges and initial block rates in order to align the tailblock of an inclining block rate structure with long-run marginal costs.

A valuation study may find that this basic approach either produces inadequate revenues for the utility to maintain reliable service or it may produce a cross-subsidy where non-participants are overpaying and DG owners on NEM are underpaying. This is most likely to occur in places with high tailblock rates that exceed the long-run marginal cost of an incremental generation resource. A traditional current rate design and three alternatives are illustrated in Table 5-1. A fourth alternative, the minimum bill, will be introduced in the presentation of Option 1 as an alternative to raising the fixed charge. 
Table 5-1. A Typical Rate Design and Three Alternatives

\begin{tabular}{|c|c|c|c|c|c|}
\hline Type of Charge & Unit/Usage & $\begin{array}{l}\text { Typical } \\
\text { Current } \\
\text { Residential } \\
\text { Tariff }\end{array}$ & $\begin{array}{l}\text { Option 1: } \\
\text { Fixed Monthly } \\
\text { Charge }\end{array}$ & $\begin{array}{l}\text { Option 2: } \\
\text { Demand } \\
\text { Charge }\end{array}$ & $\begin{array}{l}\text { Option 3: } \\
\text { Bidirectional } \\
\text { Distribution } \\
\text { Charge }\end{array}$ \\
\hline Fixed Charge & \$/month & $\$ 5.00$ & $\$ 35.00$ & $\$ 5.00$ & $\$ 5.00$ \\
\hline $\begin{array}{l}\text { Demand } \\
\text { Charge }\end{array}$ & $\$ / \mathrm{kW} /$ month & & - & $\$ 3.00$ & - \\
\hline $\begin{array}{l}\text { Distribution } \\
\text { Charge }\end{array}$ & $\$ / k W h$ & & - & - & $\$ 0.03$ \\
\hline $\begin{array}{l}\text { Off-Peak } \\
\text { Energy }\end{array}$ & $\$ / k W h$ & $\$ 0.145$ & $\$ 0.08$ & $\$ 0.08$ & $\$ 0.08$ \\
\hline $\begin{array}{l}\text { On-Peak } \\
\text { Energy }\end{array}$ & $\$ / k W h$ & $\$ 0.145$ & $\$ 0.15$ & $\$ 0.15$ & $\$ 0.15$ \\
\hline \multicolumn{6}{|c|}{$\begin{array}{l}\text { Illustration of Costs for A Typical Rate Design and Three Alternatives for } \\
\text { a Customer using } 1000 \mathrm{kWh} \text { of Energy per Month }\end{array}$} \\
\hline Fixed Charge & \$/month & $\$ 5.00$ & $\$ 35.00$ & $\$ 5.00$ & $\$ 5.00$ \\
\hline $\begin{array}{l}\text { Demand } \\
\text { Charge }\end{array}$ & $\begin{array}{l}10 \mathrm{~kW} \\
\text { demand }\end{array}$ & - & - & $\$ 30.00$ & - \\
\hline $\begin{array}{l}\text { Distribution } \\
\text { Charge }\end{array}$ & $\begin{array}{l}1,000 \text { kwh } \\
\text { total energy }\end{array}$ & - & - & - & $\$ 30.00$ \\
\hline $\begin{array}{l}\text { Off-Peak } \\
\text { Energy }\end{array}$ & $\begin{array}{l}500 \mathrm{kWh} \text { on- } \\
\text { peak }\end{array}$ & $\$ 72.50$ & $\$ 40.00$ & $\$ 40.00$ & $\$ 40.00$ \\
\hline $\begin{array}{l}\text { On-Peak } \\
\text { Energy }\end{array}$ & $\begin{array}{l}500 \mathrm{kWh} \text { off- } \\
\text { peak }\end{array}$ & $\$ 72.50$ & $\$ 75.00$ & $\$ 75.00$ & $\$ 75.00$ \\
\hline $\begin{array}{l}\text { Total Monthly } \\
\text { Bill }\end{array}$ & & $\$ 150.00$ & $\$ 150.00$ & $\$ 150.00$ & $\$ 150.00$ \\
\hline
\end{tabular}

The assumptions represent typical prices and levels of consumption in the United States. Most tariffs for large U.S. utilities include a fixed monthly fee of $\$ 0$ to $\$ 10 /$ month plus one or more blocks of energy consumption. This magnitude of customer charge is appropriate because it recovers the fixed costs directly associated with connecting the customer to the system; therefore, it should be limited to recovering the cost of the line drop, the meter, and customer services. All other costs can be argued to vary with consumption because the sizing of the distribution system, transmission system, and generation resources are all variable in the long run and thus should be reflected in the long-run marginal cost and collected volumetrically.

For the sake of simplicity, the Table 5-1 shows a $\$ 5 /$ month fixed charge plus a flat per-kWh price of $\$ 0.145 / \mathrm{kWh}$ as the typical rate design. Alternatives include:

- A high fixed charge to recover distribution costs, with a lower per-kWh energy rate

- A demand charge to recover distribution costs, with a lower per-kWh energy rate 
- Bidirectional distribution pricing, charging customers for the distribution system whenever they are receiving or supplying power at the distribution level.

Each approach illustrated in the table produces $\$ 150$ per month in revenue from the average grid customer using 1,000 kWh per month. All of the alternatives include an off-peak and on-peak volumetric rate to emphasize that the value of production is related to the time of production.

Although the average customer may be indifferent to the rate design, specific customers will be very sensitive to the rate design. Apartment dwellers use much less energy than the average customer, and they will be adversely affected by an increased fixed charge. PV customers also use much less energy than the average customer, but they may have high demand on the utility after sunset, and they will be adversely affected by anything but the current rate design. The challenge for the utility regulator is to be "fair, just, and reasonable."

The bidirectional alternative operates best with a full advanced metering infrastructure, but the other options can be implemented without advanced metering.

\section{Option 1: A Fixed Charge for Distribution Costs}

Utilities often advocate mitigating revenue attrition from DG by adopting a fixed charge for distribution service that is generally equal for all customers. The Pedernales Electric Cooperative in Texas, with a $\$ 22.50 /$ month fixed charge, is one example of this, and other utilities are seeking larger fixed fees. ${ }^{25}$ This is generally known as "straight fixed/variable" rate design, with all fixed costs recovered through a fixed charge and only variable costs included in the per-kWh charge. From the perspectives of EE, renewable energy, and economic efficiency, this is probably the worst solution to the revenue attrition challenge. This type of rate design creates particularly severe impacts for small-use residential customers, including apartment dwellers for whom utility distribution costs are typically much lower (because of their geographic concentration). The effect of straight fixed/variable ratemaking has been studied extensively, and the adverse impacts are well documented. ${ }^{26}$

In comparison to the typical current rate design, a straight fixed/variable rate design promotes:

- Significant bill increases for small-use customers, such as apartment dwellers

- Cost shifts from suburban/rural (high-use, high distribution cost) customers to urban (lowuse, low distribution cost) customers

- Significant increases in overall usage, as customers respond to a lower price per kilowatthour for incremental electricity consumption

- Significantly less financial incentive for customers to install EE on onsite generation resources.

\footnotetext{
${ }^{25}$ SDG\&E proposed in a docket (R.12-06-013) a fixed fee that would reach \$38/month on residential rate design before the California PUC, but the California State Legislature took action to limit fixed charges to no more than $\$ 10$ per month.

${ }^{26}$ For a detailed explanation of how this type of rate design results in significant changes in usage and adverse impacts on small users, see Lazar (2013).
} 


\section{A Preferred Alternative to an Increased Fixed Charge: The Minimum Bill}

The minimum bill is a preferable alternative to increasing the monthly fixed charge because it achieves the goal of ensuring each customer pays a minimum level of monthly revenues but, unlike an increased fixed charge, it does not mute the price signal associated with marginal consumption. A fixed charge increase is compensated for with a volumetric rate decrease so that overall revenues collected do not increase. The problem is that the volumetric rate decrease is likely to induce consumers to consume more, eventually leading to additional system costs to serve increased load. A minimum bill achieves the goal of ensuring all customers pay revenues, including net-metered customers who consume zero net energy, but it leaves the price signal attached to volumetric consumption intact.

Table 5-2 illustrates the difference in consumption between a minimum bill and an increased fixed charge. Note that while the total bill remains $\$ 105$ in the example, the high customer charge leads to a $5 \%$ increase in consumption in the short run and an $18 \%$ increase in consumption in the long run, while the minimum bill without any customer charge actually induces decreased consumption.

Table 5-2. Higher Customer Charges vs. a Minimum Bill

\begin{tabular}{|l|l|l|l|}
\hline & $\begin{array}{l}\text { Conventional } \\
\text { Rate Design }\end{array}$ & $\begin{array}{l}\text { High Customer } \\
\text { Charge }\end{array}$ & $\begin{array}{l}\text { \$20 Minimum } \\
\text { Bill }\end{array}$ \\
\hline Minimum Bill: Usage of 1,000 kWh \\
\hline Customer Charge & $\$ 5.00$ & $\$ 30.00$ & \\
\hline Minimum Bill & & & $\$ 20.00$ \\
\hline Per-kWh Charge & $\$ 0.100$ & $\$ 0.075$ & $\$ 0.105$ \\
\hline Total Bill (1,000 kWh) & $\$ 105.00$ & $\$ 105.00$ & $\$ 105.00$ \\
\hline Elasticity Impact & & & \\
\hline Rate Difference & & $-\$ 0.025$ & $\$ 0.005$ \\
\hline \% Rate Difference & & $-25 \%$ & $5 \%$ \\
\hline Short-Run Elasticity & -0.20 & $5 \%$ & $-1 \%$ \\
\hline Long-Run Elasticity & -0.70 & $18 \%$ & $-3 \%$ \\
\hline
\end{tabular}

If a utility requests a fixed customer charge to address revenue sufficiency concerns related to increased $\mathrm{EE}$, conservation, and DG, a minimum bill is a good alternative because:

- A minimum bill avoids the need to increase fixed charges.

- A minimum bill preserves appropriate marginal price signals reflected either in inclining block or time-of-use rates.

- A minimum bill can actually enable a decrease in the fixed charge, which encourages cost effective conservation. 


\section{Option 2: A Demand Charge-Based Distribution Charge and Time-Of-Use (TOU) Rate}

A second approach would be to charge residential customers a monthly fee based on their maximum usage at any hour during the month. This could be done through a rate element called a "demand charge" that is applied to the highest kilowatt usage. This is commonly seen in tariffs for commercial and industrial customers, but it is very uncommon in the United States for residential consumers. Our Table 5-1 example includes a TOU rate design with higher energy prices during on-peak than during off-peak hours.

This approach is often considered "fair" by distribution engineers because each component of the distribution grid is sized to a particular level of demand, and the costs are somewhat linear with increased demand. It is still a volumetric form of rate design, but it is based on the maximum volume during a period of the month rather than the total volume for the month. Because apartment dwellers typically have lower kilowatt-hour consumption and lower kilowatt usage, they will, appropriately and typically experience lower bills than they will with a tariff change that increases the fixed monthly charge equally for all customers.

However, it is critical that if a demand charge is implemented at the residential level, certain precautions are taken:

- The demand charge should be applied to the highest hour (or multiple hours) of demand, not to a shorter period of usage. Although there are instances of commercial rates being based on the highest 15 minutes of demand, regulators should avoid shorter periods because they increase the risk of certain random or inadvertent behavior driving charges beyond their ability to effectively manage. Large commercial customers subject to demand charges typically have the diversity of multiple uses on the customers' side of the meter, so that intermittent uses tend to average out at the meter. Residential consumers do not have this diversity. Using a short period to measure demand could unduly penalize smaller consumers, especially residential consumers who happened to have the coffee pot, microwave, and hair dryer going for a few minutes at the same time.

- The level of the demand charge must be carefully calculated to take into account the diversity of customer demands in order to produce the correct level of revenue.

- Just as the customer charge is limited to the direct fixed cost of connecting the customer, the demand charge should be based on recovering the cost of the local transformer because that is the portion of the distribution system that is affected by the peak consumption of an individual residence.

A peak demand for residential customers is typically varied, with many different peak hours occurring among the members of that class. The sum of residential customers' individual hourly demand is likely to be much higher than the maximum class demand imposed at the time of the system peak. The residential demand charge can be expected, therefore, to be significantly lower than it would be for the class of commercial customers. However, when applied to the higher sum of individual demands, it should produce a similar level of revenue based on the system peak demand contribution of each class. 
A residential demand charge is an option that can be easily implemented on systems that do not have advanced metering infrastructure installed, because it requires only that a demand meter be installed in place of a kWh meter. Nearly all utilities have these for their commercial customers, and their meter readers and billing systems are set up to handle these data. The next option, the bidirectional energy-based distribution rate, is preferred where advanced metering infrastructure is available.

The Arizona Corporation Commission adopted a variation on demand-charge-based distribution charge and TOU rate for the utility Arizona Public Service in a decision issued in November 2013. Beginning in 2014, the utility's net metering tariff for new PV installations includes a monthly demand charge of $\$ 0.70 / \mathrm{kW} / \mathrm{month}$, which is applied based on the kilowatt capacity of the PV system (about $\$ 4.90$ per month for a typical 7-kW residential rooftop PV system). This compensates the grid for the customer-specific distribution costs associated with providing service, but it is far less than the full local loop costs that the utility sought (APS 2013).

Net-metered PV customers will likely prefer a conventional residential rate design over a demand charge, because their peak demand on the utility likely occurs at a time of the day after the PV system is no longer producing power, whereas their net energy use may be very small, zero, or even negative. A demand charge will likely apply in the morning or evening, when their PV system is not producing enough power to meet their needs. This customer will pay more because of the demand charge, as it is based on their highest level of usage, but the customer will also benefit from the TOU rate design.

\section{Option 3: A Bidirectional Distribution Rate}

A bidirectional distribution rate is a fundamentally different approach, but would produce similar results to a demand charge for typical customers without imposing a complex rate design on the small customers who do not own DG systems.

Under this approach, when a net metering customer is taking power from the grid, he or she would pay the full grid cost, including production, transmission, and distribution system expenses. When reverse-metering to the grid, he or she would also pay for grid access but would pay only the distribution rate of a few cents per kilowatt-hour. The concept is that the net metering customer taking power from the grid needs the grid to have reliable service and should pay the same rate as other customers. This same customer, however, also "needs" the grid when he or she is in an exporting condition, and he or she pays the same distribution charge when feeding power to the grid.

This approach requires metering able to measure power flows in either direction. Most smart meter systems can do this, but the meter data management systems must be programmed to collect the data. With these data, at the end of the billing period, the net metering customer would receive a multipart bill with a:

- Fixed charge (for metering and billing, in our example)

- Charge for power received, on a TOU basis

- Charge for grid service for power received 
- Charge for grid service for power provided

- Credit for power provided, on a TOU basis.

What is most different about this approach is that the customer is paying for grid service whether he or she is receiving power or supplying it to the grid. The theory is that the customer has built a system that requires a grid in order for all of the power to be used, and he or she should contribute to the cost of the grid for both uses. This is a significant change from traditional rate making, in which "loads," not power suppliers, pay for all grid services.

The strength of this proposal is that it collects revenues to cover some grid costs from NEM customers, whether they are receiving or exporting power, but it allows these costs to remain entirely volumetric in proportion to actual energy flows. It also provides for all customers, not just those net metering, to pay for their electricity service on a volumetric basis, thus preserving the incentive to both conserve electricity (for all customers) and size their DG systems to their onsite needs (for customers who have DG.) It should also be noted that smart meters would need to be installed for customers with DG, but not for other customers.

\section{Comparing the Options}

It is illustrative to develop hypothetical rates for each rate option and then compare these options for some customers. The hypothetical rates begin with an assumed flat rate and then develop three different options, each with a TOU rate design. With hypothetical rate designs, one can then measure customer bills for typical customers. For this purpose, we have identified four hypothetical customers:

- Apartment Dweller: 5-kW maximum demand; $500 \mathrm{kWh}$ consumption, $50 \%$ on-peak

- Typical Residence: 10-kW maximum demand; 1,000 kWh consumption, 50\% on-peak

- Large Residence: 20-kW maximum demand; 2,000 kWh consumption, 50\% on-peak

- PV Customer: $10-\mathrm{kW}$ maximum demand; $1,000 \mathrm{kWh}$ total consumption, $50 \%$ on-peak; $1,000 \mathrm{kWh}$ total onsite production; $500 \mathrm{kWh}$ imported from grid off-peak; $500 \mathrm{kWh}$ exported to grid on-peak.

Using the illustrative rate design, and the illustrative customers, we can compare customer bills. With each of the three options, Table 5-3 demonstrates that the PV customer winds up with a bill of zero, a happenstance that occurs because of the sharp TOU rate differential and the assumed onpeak export, on-peak consumption built into the illustrative customer characteristics. The actual bill for each customer would, of course, depend on their actual load shape. However, this alone does not convey how much each customer would pay for distribution service; for the net metering PV customer, we show the breakdown of his or her bill under each rate design in Table 5-4. 
Table 5-3. Comparison of Hypothetical Customer Bills

\begin{tabular}{|c|c|c|c|c|c|}
\hline $\begin{array}{l}\text { Type of } \\
\text { Charge }\end{array}$ & Unit/Usage & $\begin{array}{l}\text { Typical } \\
\text { Current } \\
\text { Residential } \\
\text { Tariff }\end{array}$ & $\begin{array}{l}\text { Option 1: } \\
\text { Fixed Monthly } \\
\text { Charge }\end{array}$ & $\begin{array}{l}\text { Option 2: } \\
\text { Demand } \\
\text { Charge }\end{array}$ & $\begin{array}{l}\text { Option 3: } \\
\text { Bidirectional } \\
\text { Distribution } \\
\text { Charge }\end{array}$ \\
\hline $\begin{array}{l}\text { Monthly Fixed } \\
\text { Charge }\end{array}$ & \$/month & $\$ 5.00$ & $\$ 35.00$ & $\$ 5.00$ & $\$ 5.00$ \\
\hline $\begin{array}{l}\text { Demand } \\
\text { Charge }\end{array}$ & $\$ / \mathrm{kW} /$ month & & $\$-$ & $\$ 3.00$ & $\$-$ \\
\hline $\begin{array}{l}\text { Distribution } \\
\text { Charge }\end{array}$ & $\$ / k W h$ & & $\$-$ & $\$-$ & $\$ 0.03$ \\
\hline $\begin{array}{l}\text { Off-Peak } \\
\text { Energy }\end{array}$ & $\$ / k W h$ & $\$ 0.145$ & $\$ 0.08$ & $\$ 0.08$ & $\$ 0.08$ \\
\hline $\begin{array}{l}\text { On-Peak } \\
\text { Energy }\end{array}$ & $\$ / k W h$ & $\$ 0.145$ & $\$ 0.15$ & $\$ 0.15$ & $\$ 0.15$ \\
\hline $\begin{array}{l}\text { Apartment } \\
\text { Dweller }\end{array}$ & $\begin{array}{l}5-\mathrm{kW} \text { demand, } \\
500 \mathrm{kWh}\end{array}$ & $\$ 77.50$ & $\$ 92.50$ & $\$ 77.50$ & $\$ 77.50$ \\
\hline $\begin{array}{l}\text { Average } \\
\text { Customer }\end{array}$ & $\begin{array}{l}\text { 10-kW } \\
\text { demand, } 1,000 \\
k W h\end{array}$ & $\$ 150.00$ & $\$ 150.00$ & $\$ 150.00$ & $\$ 150.00$ \\
\hline Large User & $\begin{array}{l}\text { 20-kW } \\
\text { demand, 2,000 } \\
\text { kWh }\end{array}$ & $\$ 295.00$ & $\$ 265.00$ & $\$ 295.00$ & $\$ 295.00$ \\
\hline PV Customer & $\begin{array}{l}10-\mathrm{kW} \\
\text { demand, } \\
1,000 \mathrm{kWh} \\
\text { total usage } \\
\text { (500 exported } \\
\text { on-peak, } \\
500 \text { imported } \\
\text { off-peak) }\end{array}$ & $\$ 5.00$ & $\$-$ & $\$-$ & $\$-$ \\
\hline
\end{tabular}


Table 5-4. PV Customer Bill Breakdown under Each Rate Design

\begin{tabular}{|l|l|l|l|l|}
\hline Rate Element & $\begin{array}{l}\text { Typical Current } \\
\text { Residential Tariff }\end{array}$ & $\begin{array}{l}\text { Option 1: Fixed } \\
\text { Monthly Charge }\end{array}$ & $\begin{array}{l}\text { Option 2: } \\
\text { Demand Charge }\end{array}$ & $\begin{array}{l}\text { Option 3: } \\
\text { Bidirectional } \\
\text { Distribution } \\
\text { Charge }\end{array}$ \\
\hline Fixed Charge & $\$ 5.00$ & $\$ 35.00$ & 5.00 & 5.00 \\
\hline Demand Charge & $\$-$ & $\$-$ & 30.00 & - \\
\hline $\begin{array}{l}\text { Distribution } \\
\text { Charge }\end{array}$ & $\$-$ & $\$-$ & $\$-$ & $\$ 30.00$ \\
\hline Off-Peak Energy & $\$ 72.50$ & $\$ 40.00$ & $\$ 40.00$ & $\$ 40.00$ \\
\hline On-Peak Energy & $\$-72.50$ & $\$-75.00$ & $\$-75.00$ & $\$-75.00$ \\
\hline Total Bill & $\$ 5.00$ & $\$-$ & $\$-$ & $\$-$ \\
\hline \hline $\begin{array}{l}\text { Total Distribution } \\
\text { Service }\end{array}$ & $\$ 5.00$ & $\$ 35.00$ & $\$ 35.00$ & $\$ 35.00$ \\
\hline
\end{tabular}

With this breakdown, we can see that in each of the three rate options, the illustrative PV customer is paying $\$ 35$ for distribution service, which is about what a customer would pay under the fixed charge approach. The PV customer, under the bidirectional rate, is paying $\$ 0.03 / \mathrm{kWh}$ for $500 \mathrm{kWh}$ received from the grid, and $\$ 0.03 / \mathrm{kWh}$ for $500 \mathrm{kWh}$ delivered to the grid, plus the billing and collection fee of $\$ 5 /$ month. But, because a net metering customer buys power from the grid during off-peak hours (when power is less expensive) and sells it to the grid during on-peak hours (when power is more expensive), his or her "net bill" comes to zero under the illustrative assumptions.

The point of this is that a properly designed TOU rate can provide benefits to the PV customer that may offset the distribution costs, under any approach for recovery of distribution system costs.

\section{Advantages and Disadvantages of a Bidirectional Rate}

The bidirectional rate has a number of advantages and disadvantages compared with conventional net metering pricing schemes.

The biggest advantage is explicit recognition of the fair compensation to the utility for services provided to the customer, and likewise the explicit recognition of fair compensation to the PV customer for services provided to the utility. As technology and the electricity system continue to evolve, explicitly accounting for the value of services flowing in each direction will become increasingly important. Improvements in information, communications, and electric system control technologies will increasingly blur the distinction between (1) production and services provided from the customer side of the meter and (2) those services provided from the utilities side of the meter. As third-party providers, such as independent power generators and aggregators, play an increasing role and as the utility role changes over time, being explicit about the value of services provided will become more complicated - and more important - to accurately account for and compensate costs properly. Without explicit recognition of the value 
of some of these services, there is a danger that some important reliability services will continue to be undercompensated, an outcome that could lead to their scarcity and related electric system reliability risks.

Another advantage is that the TOU rate structure provides the PV customer a strong incentive to maximize system output and minimize onsite consumption during higher-value hours. Finally, because net metering customers would pay for distribution in a way that reflects their actual use of the grid, this approach provides an incentive to size the system to the load, thereby ultimately diminishing the load that the local distribution grid must carry.

The principal disadvantage of a bidirectional rate is that it is relatively complex, and simplicity is generally considered a virtue in rate design. Some analysts will argue that the network distribution costs should be charged to all distribution customers on a subscription basis, because when the PV systems are displacing the network capacity, it is unlikely to be redeployed to serve other loads.

Others may argue that tariff design should price all distribution service on a capacity basis, because that is the engineering criterion by which they are designed. It is worth noting that most prices to residential consumers are volumetric, and that the bidirectional rate would retain this approach.

The most common rate design advocated by electric utilities is a flat charge for distribution service, an approach that is beneficial to utilities for revenue stability, beneficial to large users in the form of lower bills, and harmful to small users, including apartment dwellers who have the lowest cost of distribution service because of their geographic concentration and low percustomer capacity requirements.

\subsection{Toward DG 2.0: Dynamic Pricing}

Many analysts recommend going beyond TOU pricing to "dynamic pricing" or sometimes "real time nodal pricing," where the price charged (or paid) varies with market supply conditions. On a hot summer day, prices may rise to $\$ 1.00 / \mathrm{kWh}$ or more, and during night-time hours or slack periods when nuclear, wind, or solar power gluts the market, prices would drop significantly. While the two-way distribution tariff requires all DG customers to have advanced metering, dynamic pricing requires even more infrastructure. Dynamic pricing requires the system operator to create a real-time market and all customers to have advanced metering so that how much they pay or are paid can be correlated to the real-time market-clearing prices at the time of consumption. Nodal pricing at the distribution system level requires real-time information be collected and processed on a more granular basis than real-time pricing on the wholesale transmission system.

We did not present dynamic pricing within our three options because it is too complex to show a simple numeric example, but it is equally applicable to Options 1,2, and 3, as an alternative to TOU pricing. However, evidence suggests that customers will sharply curtail their peak demand in response to dynamic prices. Most of the experiments have been with what is known as "critical peak pricing" (or CPP) in which customers have a predictable TOU rate, as do those included in the options above (except that for a limited number of hours per year, the utility can raise the price sharply). A typical CPP allows the utility to call 15 "events" per year of no more than four 
hours per event. A true "real-time price" (RTP) allows the utility to change the price every hour (or even sub-hourly) without limitation.

Figure 5-2 shows how different types of advanced pricing, including the use of TOU rates, peaktime rebates (PTR), CPP, and RTP, can affect peak demand (Faruqui et al. 2012).

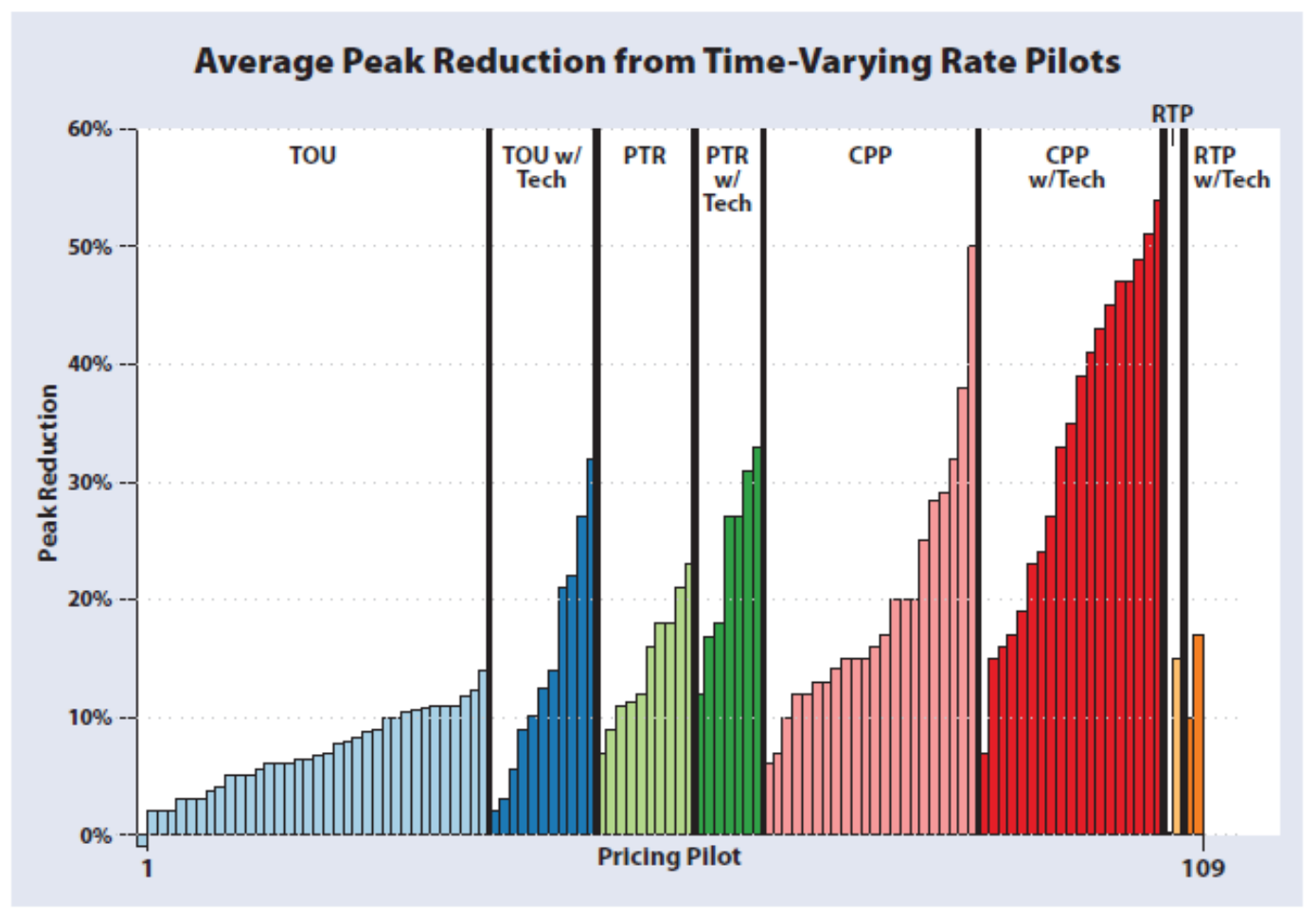

Figure 5-2. Average peak reduction from time-varying rate pilots

What this shows is that using CPP or RTP is likely to produce a higher peak load reduction than simple TOU prices because the price signal is concentrated in a short period and customers can adjust their consumption patterns for that short period if they have smart meters and smart energy management technology.

\subsection{Toward DG 2.0: Value of Solar and Buy-All/Sell-All Arrangements}

Many utilities prefer "buy all/sell all" agreements over NEM tariffs. A buy-all/sell-all agreement requires that the utility take $100 \%$ of the output of a DG system, but the consumer purchases $100 \%$ of his or her needs at the applicable utility tariff. The benefits for utilities include:

1. All of the purchased power cost can flow through the purchased power and fuel adjustment clause, avoiding any risk for net revenue loss (which can otherwise be addressed with a revenue stabilization mechanism such as decoupling).

2. All of the power from a renewable DG system can then be claimed to help the utility meet a state-imposed renewable portfolio standard. 
3. The customer is not being "subsidized" because he or she is paying the same retail tariff as other customers for power consumed (even though it may be lower than the price he or she receives for their renewable production).

One consideration for consumers is that the retail rate paid for power may include up to $15 \%$ in local and state taxes, whereas consuming onsite power avoids these utility revenue taxes. A buyall/sell-all arrangement removes this potential cost advantage to the consumer.

Austin Energy in Texas has been a leader in this area, with a premium VOS formula for setting a purchased power price that generally exceeds the retail distribution tariff. ${ }^{27}$ Austin Energy has structured its inclining block rate design so that the customer generally saves money under this arrangement, compared with net metering.

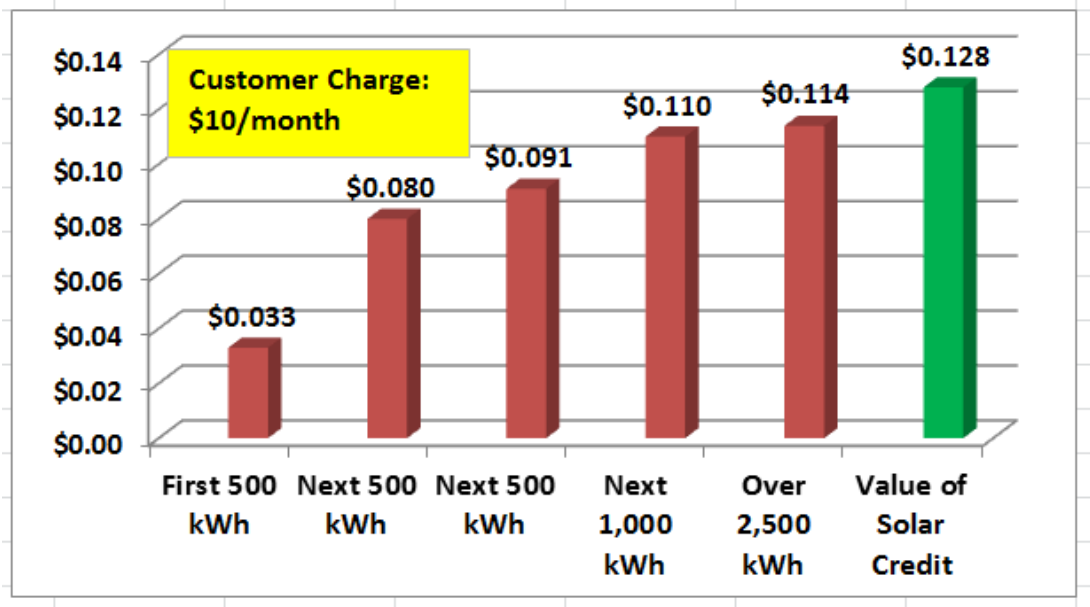

Figure 5-3. Austin Energy residential rate and value of solar credit

\subsection{Toward DG 2.0: FIT Improvements}

As contrasted with NEM, which allows customers to shave their bill by feeding excess usage to the grid at the retail price, a FIT is typically different from the retail consumption rate. With a FIT, the rate designs presented in Section 5.3 and 5.4 could still be used for consumption, but the compensation for production is tied to the FIT rate. And, as we noted in our definition, a FIT rate is typically higher than the otherwise applicable value of nonrenewable power. While NEM is typically capped at some maximum size of system (often between $100 \mathrm{~kW}$ and $2 \mathrm{MW}$ ) and thus is only offered to "smaller customers," a FIT may be offered to commercial and industrial systems that are substantially larger.

The principal purpose of a FIT is to provide a simplified and defined price that a small power producer can secure with a minimum of negotiation or other transaction costs. A secondary purpose is to establish, typically, a premium price for a premium (i.e., renewable) resource. Although these purposes are separable, the term "feed-in tariff," or FIT, has been used in this report to include both.

\footnotetext{
${ }^{27}$ See Austin Energy's description of this program at http://austinenergy.com/wps/portal/ae/rates/residentialrates/residential-solar-energy-rate.
} 
For the purposes of this report, we have defined a FIT as a standard price offer to a small distributed generator, with a premium above the utility's avoided cost to reflect (at least) locational and environmental benefits of eligible resources. This distinguishes a FIT from simple avoided cost pricing, or what we have called a "PURPA tariff." The magnitude of the premium is generally determined by the regulator. In some cases, the premium is related to explicit benefits, such as line loss reduction, avoided reserves, delivery to the utility in the service territory avoiding transmission costs and risks, avoidance of fuel cost risk, and compliance with renewable energy mandates.

The earliest experiences in the United States with FITs were the standard offer prices developed in California in the early 1980s. These were primarily directed at industrial cogeneration at oil refineries, at forest products facilities, and in other industries. In these, a premium price was incorporated, in part to recognize the risk reduction to utilities associated with having other investors accept the risk of project non-performance. More recently, FITs have been implemented in many states and localities. These range from a traditional degressional FIT in Jacksonville, Florida, to the VOS pricing methodology adopted by Austin Energy of Texas. Nearly all of these contain some premium over the otherwise applicable avoided costs that a nonrenewable generator would receive for equivalent energy delivered to the grid.

California introduced a FIT approach for DG less than $20 \mathrm{MW}$ where the price is set to the Marginal Price Referent which is based on the fixed and variable cost of an incremental combined cycle generation addition. Up to a $10 \%$ premium over the Marginal Price Referent cost is allowed for CHP projects that have specific locational system benefit (DOE 2013).

Experience in Germany and Spain demonstrated that FITs carrying a high premium for solar and wind projects were very successful at attracting developers but ultimately were found to impose too severe a cost on nonparticipants, and they were greatly constrained after the economic crisis of 2008. The characteristics of the European FITs included differentiation between energy sources and size of generating units. This was done to make smaller units profitable without providing windfall profits to larger units. As illustrated in Table 5-5, the Gainesville, Florida, FIT follows the European model.

Table 5-5. Gainesville, Florida, FIT for Systems Energized in 2013

\begin{tabular}{|l|l|}
\hline Amount & $\begin{array}{l}\text { Rooftop- or pavement-mounted systems }<10 \mathrm{~kW}: \$ 0.21 / \mathrm{kWh} \\
\text { Ground-mounted systems }<10 \mathrm{~kW}: \$ 0.21 / \mathrm{kWh} \\
\text { Rooftop- or pavement-mounted systems }>10 \mathrm{~kW} \text { to } 300 \mathrm{~kW}: \\
\$ 0.18 / \mathrm{kWh} \\
\text { Ground-mounted systems }>10 \mathrm{~kW} \text { to } 25 \mathrm{~kW}: \$ 0.18 / \mathrm{kWh} \\
\text { Ground-mounted systems }>25 \mathrm{~kW} \text { to } 1,000 \mathrm{~kW}: \$ 0.15 / \mathrm{kWh}\end{array}$ \\
\hline Terms & $\begin{array}{l}20 \text {-year contract } \\
\text { Eligible system size }\end{array}$ \\
& $\begin{array}{l}\text { Ground-mounted systems maximum: } 1,000 \mathrm{~kW} \\
\text { Building- or pavement-mounted systems: } 300 \mathrm{~kW}\end{array}$ \\
\hline
\end{tabular}


A FIT is distinguished from net metering in several ways. First, it typically provides for a fixed price (or price formula) for the length of the commitment, as opposed to a rate that automatically adjusts whenever retail prices change. Second, it is normally designed based on the voltage level at which power is delivered to the buyer, with a higher price paid for power delivered at the distribution voltage level. Third, it is often subject to a higher maximum size (up to $80 \mathrm{MW}$ under the PURPA definition of "small power producer"), whereas most net metering tariffs limit system size to the estimated onsite energy requirements.

From a utility perspective, a FIT is also different in several ways. First, the customer is normally required to deliver all output of his or her facility to the utility; diversion for onsite usage is normally not allowed. This means that the utility is ensured of receiving the full load shape of the resource; for solar, this is particularly important, because solar output tends to peak during the business day. At least under current penetration levels, this coincides with the time of day during which power is generally more valuable. Probably more important, from the utility's perspective, is that the customer purchases from the utility all of the energy it consumes onsite and is therefore paying his or her "share" of the fixed costs recovered in rates.

The customer may be required to meet interconnection standards that are more restrictive than those for smaller net metering resources. Finally, the purchaser may have the authority to "dispatch" the FIT resource. For CHP, the ability to dispatch may actually involve ramping the unit up and down as utility load changes; for solar or wind resources, it may involve curtailment of deliveries when other resources must run for economic or operational reasons.

\section{Elements that Utilities Seek in a FIT}

Utilities typically seek elements that protect the utility shareholders and non-participating bill payers from significant adverse impacts of a FIT. These elements often include:

- A price that is related to the utility's short- and long-run avoided costs; the ideal price would start low and grow over time to reflect rising values over time and achieve intergenerational equity. ${ }^{28}$

- Prices that are not higher for smaller systems, unless the value of the output can be shown to be greater

- A contract term long enough to allow deferral of other generating capacity

- Ability to control the output of the generator within reasonable limits

- Contractual terms that tie compensation to customer generator performance.

\footnotetext{
${ }^{28}$ This is quite different from the trajectory of utility-owned resources, which are most expensive in the early years, because the rate-making formula initially provides a return on the entire investment plus depreciation expense; whereas in later years, the capital recovery reflected in rates declines as the investment is depreciated and the rate base goes down.
} 


\section{Elements that Investors Seek in a FIT}

In considering various aspects of a FIT, investors ${ }^{29}$ seek the following attributes:

- A price that is related to the system cost, including a return on investment; this typically means prices that are higher for smaller systems.

- A flat price over the project lifetime, or a front-loaded price, to help make the project economics feasible and reduce investment risk ${ }^{30}$

- Recognition that the power is usually coming to the utility at a favorable point of interconnection

- A contract term long enough to recover the capital investment

- Assurance that all of the output of the system that is made available to the utility will be paid for.

Third-party PV leasing companies seek an additional element that is frequently lacking in FIT policies, namely that the FIT be enduring and stable. These companies do not raise capital one PV system one at a time; rather, they raise enough capital to allow installation of large numbers of PV systems over a given period. To do this, investors need to know with relative certainty that a favorable tariff will be available later when investors deploy this capital and install PV systems. There is a sense among these companies that net metering policies, which tend to have a longer history and larger program caps than FIT policies, are more enduring and stable. As previously noted, the United States' experience with FITs includes several examples of small program caps that were achieved (fully subscribed) relatively rapidly.

\subsection{Toward DG 2.0: Interconnection Policy}

DG interconnection policy was identified in Section 2 as a significant barrier to rapid DG deployment in Mexico. Section 2 refers to some of the factors that need to be considered in the interconnection process and interconnection agreement to ensure a safe and effective interconnection. These standards are described more fully in the IEEE 1547 Standard for Interconnecting Distributed Resources to Electric Power Systems (IEEE 2015). International experience with interconnection policy indicates a number of best practices for interconnection. The rest of this section summarizes key findings from several sources that provide more detailed information and analysis. ${ }^{31}$

Implementing a best practice interconnection standard involves a number of actions, including:

- Set appropriate interconnection fees

\footnotetext{
${ }^{29}$ We use the term "investors" here to refer to the parties providing the capital and taking the financial risk in an energy facility. This may be the owner of the facility, it may be a financier, or there may be shared risk between them.

${ }^{30}$ Sometimes investors are able to accept lower returns in early years if accelerated depreciation or other tax benefits are available.

${ }^{31}$ Important references for this section include IREC (2013), CPUC (2014), Sheaffer, Schwartz, and Basso (2011), and DOE (2013).
} 
- Streamline all interconnections by adopting appropriate decision tree screens

- Adopt streamlined interconnection for larger DG units that are not covered by net metering

- Adopt standardized technical requirements

- Provide standardized, simplified application forms and contracts

- Define a process to address disputes

- Allow DG systems to interconnect to both radial and network grids.

The reader is directed to the references section for detailed discussion of how to implement these best practices, but an example of a decision tree screen illustrates one aspect of best practice interconnection and can be used clarify the final best practice recommendation.

Figure 5-4, from Sheaffer, Schwartz, and Basso (2011), provides an example of an interconnection decision tree screen that provides the decision points in a screening process to determine the level of interconnection review required (Sheaffer, Schwartz, and Basso 2011). Simple interconnections below a pre-determined size threshold, 11 kilo-volt-ampere (kVA) in this example, should be executed on a very short timeframe. While larger systems receive some additional scrutiny, an effort should be made to streamline the interconnection review and approval process for all sizes of DG systems.

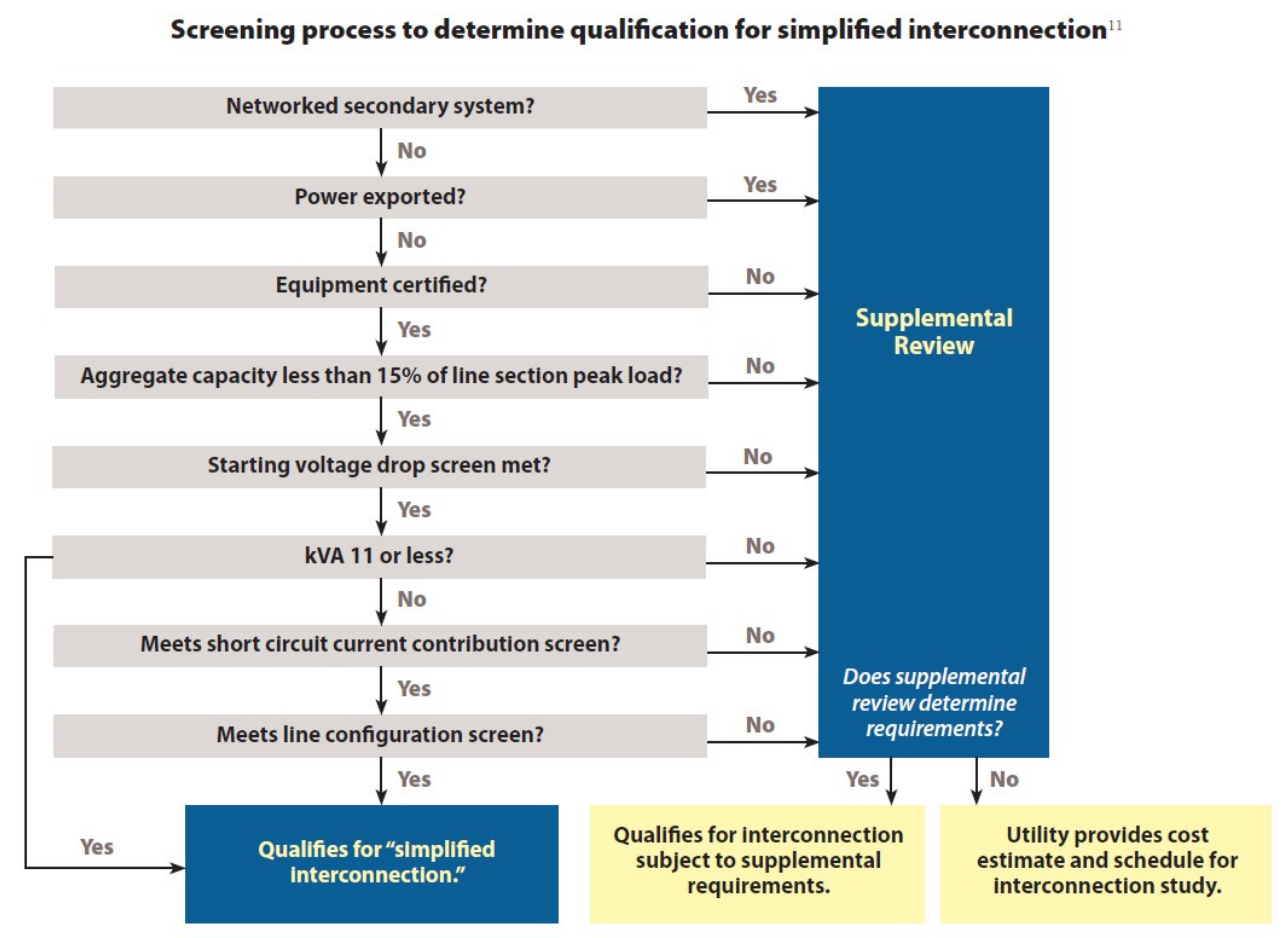

Figure 5-4. A sample screening process decision tree

Finally, we consider the importance of allowing interconnection to radial and network grids. Early DG interconnection policies in the United States limited interconnection of larger systems to radial grids, but interconnection of DG to networks is becoming increasingly important. Interconnection in network or local distribution networks present protection and grid operational 
challenges to address inadvertent back feed into the local grid that can cause safety concerns and failure to serve loads. However, with careful operational planning and system protection review, DG can be accommodated, and IEEE 1547.6 was drafted to establish the proper review procedure.

\subsection{Toward DG 2.0: Commercial and Industrial DG Tariff and Market Access Issues}

Larger commercial and industrial customers do not typically qualify for NEM, but they may qualify for standard offer contracts or FITs, or they may buy and sell into the wholesale electricity market. While a customer may choose to be off-grid as a separate microgrid - and some customers do indeed choose this path-most customers choose to be interconnected with the local utility and rely on the electricity grid for some services. Their purchase of electricity from the utility is governed by a different set of tariffs than the ones that govern residential purchases. A detailed description of the tariffs is beyond the scope of this report, but a summary of the differences between preferred tariffs for residential customers and other types of customers that lead all customers toward the DG 2.0 world is summarized in Table 5-6.

Table 5-6. Rate Design Options Taken from "Smart Rate Design for a Smart Future"

\begin{tabular}{|c|c|c|c|c|c|c|}
\hline \multicolumn{7}{|c|}{ Rate Design Options by Customer Class } \\
\hline & $\begin{array}{c}\text { Typical } \\
\text { Pre-AMI Rate } \\
\text { Design }\end{array}$ & $\begin{array}{l}\text { Inclining } \\
\text { Block Rate }\end{array}$ & $\begin{array}{c}\text { TOU Rate } \\
\text { Fixed Time } \\
\text { Period }\end{array}$ & $\begin{array}{c}\text { TOU plus } \\
\text { Critical Peak } \\
\text { Pricing } \\
\end{array}$ & $\begin{array}{c}\text { Baseline- } \\
\text { Referenced Real } \\
\text { Time Pricing }\end{array}$ & $\begin{array}{c}\text { Market } \\
\text { Indexed Real } \\
\text { Time Pricing }\end{array}$ \\
\hline Residential & $\begin{array}{l}\text { Flat Energy } \\
\text { Charge }\end{array}$ & $\begin{array}{l}\text { Default } \\
\text { (if kwh-only } \\
\text { metering } \\
\text { in place) }\end{array}$ & $\begin{array}{c}\text { Default } \\
\text { (if TOU } \\
\text { meters or } \\
\text { AMI in place) }\end{array}$ & $\begin{array}{l}\text { Optional if } \\
\text { AMI in place }\end{array}$ & Pilot & $\begin{array}{c}\text { Not } \\
\text { Available }\end{array}$ \\
\hline $\begin{array}{c}\text { Small } \\
\text { Commercial } \\
0-20 \mathrm{kw} \\
\text { Demand }\end{array}$ & $\begin{array}{l}\text { Flat Energy } \\
\text { Charge }\end{array}$ & $\begin{array}{c}\text { Not } \\
\text { Available }\end{array}$ & $\begin{array}{l}\text { Default } \\
\text { (if TOU } \\
\text { meters in } \\
\text { place) }\end{array}$ & $\begin{array}{c}\text { Optional if } \\
\text { AMI in place }\end{array}$ & Pilot & $\begin{array}{c}\text { Not } \\
\text { Available }\end{array}$ \\
\hline $\begin{array}{c}\text { Medium } \\
\text { General } \\
\text { Service } \\
20-250 \mathrm{kw}\end{array}$ & $\begin{array}{c}\text { Demand Charge } \\
\text { Flat Energy } \\
\text { Charge }\end{array}$ & $\begin{array}{c}\text { Not } \\
\text { Available }\end{array}$ & $\begin{array}{l}\text { Default } \\
\text { (until AMI } \\
\text { installed) }\end{array}$ & $\begin{array}{l}\text { Default } \\
\text { (after AMI } \\
\text { installed) }\end{array}$ & Optional & $\begin{array}{c}\text { Not } \\
\text { Available }\end{array}$ \\
\hline $\begin{array}{c}\text { Large } \\
\text { General } \\
\text { Service } \\
250- \\
2,000 \mathrm{kw}\end{array}$ & $\begin{array}{c}\text { Demand Charge } \\
\text { Flat Energy } \\
\text { Charge }\end{array}$ & $\begin{array}{c}\text { Not } \\
\text { Available }\end{array}$ & $\begin{array}{c}\text { Not } \\
\text { Available }\end{array}$ & Default & Optional & Optional \\
\hline $\begin{array}{l}\text { Extra Large } \\
\text { General } \\
\text { Service } \\
>2000 \mathrm{kw}\end{array}$ & $\begin{array}{c}\text { Demand Charge } \\
\text { Flat Energy } \\
\text { Charge }\end{array}$ & $\begin{array}{c}\text { Not } \\
\text { Available }\end{array}$ & $\begin{array}{c}\text { Not } \\
\text { Available }\end{array}$ & $\begin{array}{c}\text { Not } \\
\text { Available }\end{array}$ & $\begin{array}{r}\text { Customer 1 } \\
\text { Between Thes }\end{array}$ & $\begin{array}{l}\text { ust Choose } \\
\text { Two Options }\end{array}$ \\
\hline
\end{tabular}

Note: AMI means advanced metering infrastructure.

Tariffs that describe the terms of service for commercial or industrial customers with larger DG systems are typically called "standby" or "partial requirements" service tariffs. The service is 
offered to customers who operate onsite, non-emergency generation. Utility standby rates cover some or all of the following services:

- Backup power during an unplanned generator outage

- Maintenance power during scheduled generator service for routine maintenance and repairs

- Supplemental power for customers whose onsite generation under normal operation does not meet all of their energy needs, typically provided under the full requirements tariff for the customer's rate class

- Economic replacement power when it costs less than onsite generation

- Delivery associated with these energy services.

Describing the best practices in standby rates is beyond the scope of this report, but "Standby Rates for Combined Heat and Power Systems" and "Guide to Successful Implementation of State Combined Heat and Power Policies" are two resources that provide good guidance. ${ }^{32}$

Another key issue for larger commercial and industrial DG projects is access to nondiscriminatory wholesale markets. While standard offer contracts and FITs offer larger systems opportunities to enter into contracts for energy sales, the direction of the two-way (or really "n-way") grid is toward engaging distributed resources in energy, capacity, ancillary services, and flexibility resource markets. Initially, this participation may take the form of DG resources becoming eligible to bid into utility and system operator procurement solicitations. As markets develop more fully, this means getting DG qualified to play in the respective markets.

The steps to getting DG and other distributed energy resources (DER) qualified to bid into markets include making the needs of the electric system more transparent so the need for certain resource capabilities becomes transparent; getting utilities, system operators and market operators to declare the capabilities that a resource must have in order to play in a particular market segment; and getting resources qualified to bid into certain market segments on a nondiscriminatory basis.

Each of these steps sounds straightforward but in practice can be difficult. Making system needs transparent includes identifying the need for new capabilities (e.g., resource flexibility), quantifying the magnitude of the need in different places and at different times on the system, and making the need transparent to the market and market participants. Getting the qualification criteria established for specific capabilities also requires persistence. For example, experience has shown that capability criteria tend to be overly rigid and they tend to be anchored on terms that favor conventional grid-scale fossil resources, so establishing flexible terms that are nondiscriminatory and allow participation by third-party resource providers requires persistence. Getting resources qualified to bid is also difficult. Finally, a streamlined process needs to be established whereby DG and DER resources can become qualified to bid into procurement and market processes. Much like establishing an interconnection, establishing an agreement that a

\footnotetext{
${ }^{32}$ See Selecky et al. (2014) and U.S. DOE (2013), op cit.
} 
resource possesses the requisite capabilities to provide a certain service, such as frequency response, can be easy or difficult.

\subsection{Toward DG 2.0: Best-Practice Economic and Market Development Support Policies}

Rate design, tariff design, and interconnection policies are important market development supports in their own right, but some additional policies should be considered in seeking to move toward DG 2.0. The policy documents produced by the Mexican government emphasize giving customers more options and moving away from command and control regulation to more marketbased regulation. As a result, it seems appropriate to focus on economic and market development support policies that do not depend primarily on subsidies and preferential tax policies but rather enable customers and energy service providers to attract capital for new DG facilities.

As discussed in Section 3, the two highest impact policies that are "democratizing" DG ownership in the United States are solar leasing programs and shared renewable programs. Solar leasing programs, which could also be offered as solar DG programs to allow a broader range of DG investment, overcome the high initial capital cost barrier by offering lease finance options as an alternative to self-finance. Leasing programs in some places actually reduce customers' monthly bills by offering a monthly lease payment that is low enough that the combination of the lease payment and utility bill of the customer after installing DG is less than the energy bill before installing DG. Lease programs democratize access to solar because the threshold criteria for wanting and being able to afford a DG system shift from whether one has the independent access to savings or capital to finance their system to one where anyone who has the requisite credit rating can choose to participate. Solar leasing programs can be offered by the utility where the utility serves as the conduit for lease-based financing or they can be offered by third-party solar developers. Most U.S. residential solar installations today are acquired through lease purchases.

Shared renewable energy programs are still emerging, but they hold promise for further democratizing the access to DG benefits. Apartment dwellers, homeowners who do not have an exposed south- or west-facing roof, small businesses, and nonprofits can each participate in a shared renewable energy program. Shared renewable programs sell shares in a renewable energy project to individuals. An individual can choose how much capacity to purchase, and participation can occur through direct purchase or through lease purchase. Grid-scale, ground-mounted renewable energy systems can enjoy economies of scale and thus are often less expensive per kilowatt than rooftop-solar systems. If the shared renewable program is offered on a virtual net metering basis to residential and small commercial customers, behind-the-meter systems and community-based systems can be procured under very similar terms.

Training and certification programs for electricians and DG installers represent an additional market support policy that can facilitate maturation of the DG industry. Building the labor pool to a critical mass can support accelerated DG deployment.

Other economic market supports fall into the category of subsidies and tax breaks. The Smart Grid Framework appears to de-emphasize subsidies and tax breaks relative to enabling market development through infrastructure investment and financial innovation, but subsidies and tax 
breaks are an option to consider. See Section 3 for a summary of the policies that could be adapted and applied in Mexico.

\subsection{Toward DG 2.0: Best-Practice Performance Regulation Options}

The introduction of an independent system operator, competitive wholesale markets, and increased resources on the customer side of the meter, such as DG and other DERs, will require regulators to gather and evaluate new information. Regulation will not be simply a matter of reviewing utility filings and ensuring prudent behavior; it will become a matter of engendering the transformation of the power sector. In other words, implementing the Smart Grid Framework is not just a matter of evolving the role and business model of the utility. It is equally a matter of evolving the role and processes of the regulator. An important tool that regulators in Mexico should consider is performance regulation.

Performance regulation starts with recognizing which aspects of utility and market performance need to be measured and tracked over time. While compensating utilities based on their performance relative to high priority metrics might eventually play into the evolution of utility regulation in Mexico, it is certainly true that regulators need to be collecting and tracking new information to ensure adequate progress toward the Smart Grid Framework implementation.

A recent paper by Synapse Energy Economics has attempted to provide a comprehensive set of metrics. ${ }^{33}$ Table 5-7 shows the categories of performance that traditionally have been tracked by regulators in some form. Table 5-8 shows some additional categories of performance that will need to be tracked given the evolution of the power sector.

Table 5-7. Conventional Areas of Performance Measurement

\begin{tabular}{|ll|}
\hline Performance Dimension & Purpose \\
\hline Reliability & $\begin{array}{l}\text { To indicate the extent to which service is reliable and interruptions are } \\
\text { remedied quickly }\end{array}$ \\
\hline Pustomee Safety & To ensure that employees are not subjected to excessive risks \\
\hline Costs & $\begin{array}{l}\text { To ensure that the utility is providing adequate levels of customer } \\
\text { service }\end{array}$ \\
\hline
\end{tabular}

Source: Whited, Woolf, and Napoleon 2015.

${ }^{33}$ Whited, Woolf, and Napoleon, 2015. 
Table 5-8. Emerging Areas of Performance Measurement

\begin{tabular}{|ll|}
\hline Performance Dimension & Purpose \\
\hline Sostem Efficiency & $\begin{array}{l}\text { To indicate the extent to which the utility system as a whole is being } \\
\text { operated more efficiently }\end{array}$ \\
\hline Environmental Goals & $\begin{array}{l}\text { To indicate the extent to which customers are participating in demand- } \\
\text { side programs or installing demand-side resources }\end{array}$ \\
\hline To indicate the extent to which the utility and its customers are \\
reducing environmental impacts, particularly related to climate change
\end{tabular}

Source: Whited, Woolf, and Napoleon 2015.

A complete discussion of metrics is beyond the scope of this report, and we refer the reader to the Synapse handbook for more information. However, it is instructive to examine two of the categories addressed by Synapse, given their relevance to DG 2.0. Table 5.9 provides the metrics suggested to track customer engagement. While the entire table is interesting, focusing on the DG measures of progress is highly relevant toward tracking the effectiveness of the DG policy supports that Mexico ultimately decides to implement. 
Table 5-9. Customer Engagement Performance Metrics

\begin{tabular}{|c|c|c|c|}
\hline & Metric & Purpose & Metric Formula \\
\hline & \multirow{4}{*}{$\begin{array}{l}\text { Energy efficiency } \\
\text { (EE) }\end{array}$} & \multirow{4}{*}{$\begin{array}{l}\text { Indication of participation, energy } \\
\text { and demand savings, and cost } \\
\text { effectiveness of EE programs }\end{array}$} & Percent of customers per year \\
\hline & & & Annual and lifecycle energy savings \\
\hline & & & $\begin{array}{l}\text { Annual and lifecycle peak demand } \\
\text { savings (MW) }\end{array}$ \\
\hline & & & Program costs per MWh energy saved \\
\hline & \multirow{4}{*}{$\begin{array}{l}\text { Demand response } \\
\text { (DR) }\end{array}$} & \multirow{4}{*}{$\begin{array}{l}\text { Indication of participation and } \\
\text { actual deployment of DR resources }\end{array}$} & Percent of customers per year \\
\hline & & & Number of customers enrolled \\
\hline & & & MWh of DR provided over past year \\
\hline & & & $\begin{array}{l}\text { Potential and actual peak demand } \\
\text { savings (MW) }\end{array}$ \\
\hline & \multirow{5}{*}{$\begin{array}{l}\text { Distributed } \\
\text { generation (DG) }\end{array}$} & \multirow{5}{*}{$\begin{array}{l}\text { Indication of the technologies, } \\
\text { capacity, and rate of DG } \\
\text { installations, and whether net } \\
\text { metering policies are supporting } \\
\text { DG growth }\end{array}$} & Number of installations per year \\
\hline & & & Net metering installed capacity (MW) \\
\hline & & & Net metering MWh sold back to utility \\
\hline & & & Net metering number of customers \\
\hline & & & $\begin{array}{l}\text { MW installed by type (PV, CHP, small } \\
\text { wind, etc.) }\end{array}$ \\
\hline & \multirow{3}{*}{ Energy storage } & \multirow{3}{*}{$\begin{array}{l}\text { Indication of the technologies, } \\
\text { capacity, and rate of customer- } \\
\text { sited storage installations and their } \\
\text { availability to support the grid }\end{array}$} & Number of installations per year \\
\hline & & & $\begin{array}{l}\text { MW installed by type (thermal, } \\
\text { chemical, etc.) }\end{array}$ \\
\hline & & & $\begin{array}{l}\text { Percent of customers with storage } \\
\text { technologies enrolled in demand } \\
\text { response programs }\end{array}$ \\
\hline & \multirow{2}{*}{$\begin{array}{l}\text { Electric vehicles } \\
\text { (EVs) }\end{array}$} & \multirow{2}{*}{$\begin{array}{l}\text { Indication of customer adoption of } \\
\text { EVs and their availability to support } \\
\text { the grid }\end{array}$} & Number of additions per year \\
\hline & & & $\begin{array}{l}\text { Percent customers with EVs enrolled in } \\
\text { DR programs }\end{array}$ \\
\hline & \multirow{2}{*}{$\begin{array}{l}\text { Information } \\
\text { availability }\end{array}$} & \multirow{2}{*}{$\begin{array}{l}\text { Indicator of customers' ability to } \\
\text { access their usage information }\end{array}$} & $\begin{array}{l}\text { Number of customers able to access } \\
\text { daily usage data via a web portal }\end{array}$ \\
\hline & & & $\begin{array}{l}\text { Percent of customers with access to } \\
\text { hourly or sub-hourly usage data via web }\end{array}$ \\
\hline & Time-varying rates & $\begin{array}{l}\text { Indication of saturation of time- } \\
\text { varying rates }\end{array}$ & $\begin{array}{l}\text { Number of customers on time-varying } \\
\text { rates }\end{array}$ \\
\hline
\end{tabular}

Source: Whited, Woolf, and Napoleon 2015. 
Table 5-10 offers metrics suggested to track progress in providing network support services. These categories and metrics seem highly relevant both for tracking the rollout of advanced infrastructure as well as tracking whether the evolution of regulation is leading to desirable outcomes, such as an open and interoperable grid and increased participation by customers and third parties on the grid platform.

Table 5-10. Network Support Services Performance Metrics

\begin{tabular}{|c|c|c|c|}
\hline & Metric & Purpose & Metric Formula \\
\hline & \multirow{2}{*}{$\begin{array}{l}\text { Advanced metering } \\
\text { capabilities }\end{array}$} & \multirow{2}{*}{ Indication of metering functionality } & $\begin{array}{l}\text { Number of customers with AMI and } \\
\text { AMR }\end{array}$ \\
\hline & & & Energy served through AMI \\
\hline & \multirow{2}{*}{$\begin{array}{l}\text { Interconnect-ion } \\
\text { support }\end{array}$} & \multirow{2}{*}{$\begin{array}{l}\text { Indication of DG installation } \\
\text { support }\end{array}$} & $\begin{array}{l}\text { Average days for customer } \\
\text { interconnection }\end{array}$ \\
\hline & & & $\begin{array}{l}\text { Customer satisfaction with interconnect } \\
\text { process }\end{array}$ \\
\hline & \multirow[t]{2}{*}{ Third-party access } & \multirow{2}{*}{$\begin{array}{l}\text { Indication of network access by } \\
\text { third-party vendors }\end{array}$} & $\begin{array}{l}\text { Open and interoperable smart grid } \\
\text { infrastructure that facilitates third-party } \\
\text { devices }\end{array}$ \\
\hline & & & $\begin{array}{l}\text { Third-party vendor satisfaction with } \\
\text { utility interaction }\end{array}$ \\
\hline & \multirow{3}{*}{$\begin{array}{l}\text { Provision of } \\
\text { customer data }\end{array}$} & \multirow{3}{*}{$\begin{array}{l}\text { Indication of customer access to } \\
\text { relevant data }\end{array}$} & $\begin{array}{l}\text { Customers able to authorize third-party } \\
\text { access electronically }\end{array}$ \\
\hline & & & $\begin{array}{l}\text { Percent of customers who have } \\
\text { authorized third-party access }\end{array}$ \\
\hline & & & $\begin{array}{l}\text { Third-party data access at same } \\
\text { granularity and speed as customers }\end{array}$ \\
\hline
\end{tabular}

Source: Whited, Woolf, and Napoleon 2015.

Regulators should consider collecting information on these metrics immediately so that a baseline can be established to evaluate progress toward DG 2.0 evolution. At some point, regulators may wish to consider evolving regulation to tie utility compensation (rewards and punishments) to performance metrics, but to start it makes sense to begin gathering this information to help regulators assess their own effectiveness in promoting grid evolution. 


\section{Policy Goals and Enabling Actions for Mexico}

Section 5 examined the range of policy options available to Mexico and described how each might work in the Mexican context. Section 6 proposes 5 DG policy goals and offers 14 action items that Mexico could implement to assist in achieving these goals. These goals and action items represent the Regulatory Assistance Project's opinion on what implementing DG policy and tariffs should look like in Mexico, as well as the Regulatory Assistance Project's best current thinking on the policies that SENER should consider as it seeks to meet Mexico's laudable and ambitious clean energy goals.

The five goals are:

1. Ensure retail DG Resource compensation is fair

2. Ensure wholesale DG has access to markets

3. Improve the interconnection process

4. Improve DG access to capital markets

5. Expand customer access to DG participation options.

For each goal, several action items are provided and a set of performance metrics is suggested. The performance metrics are intended to be used to track Mexico's progress in meeting the respective goals as the action items are implemented.

\section{Goal 1: Ensure Retail DG Resource Compensation is Fair Action Item 1: Identify and Measure the Benefits and Costs of DG}

Ensuring fair retail DG compensation starts with ensuring fair valuation. The Utility Cost Test and the Total Resource Cost Test are good options to identify the sources of benefits and costs that should be measured. Previous studies can be used as a guide to select a methodology for quantifying each individual benefit and cost.

Section 4, and especially Tables 4-2 and 4-3, provides guidance to Mexico in how to implement the valuation exercise.

\section{Action Item 2: Establish Fair DG Residential and Small Commercial DG Tariffs}

A NEM, FIT, or VOS tariff can be fair if the parameters of the tariff are calibrated with sound valuation principles. The NEM tariff has been very effective at inducing DG expansion and is a good option as Mexico moves from DG 1.0 to DG 2.0, but the alternatives can work well if designed well. The NEM should be applied with a rate design that supports evolution toward DG.

Testing whether the ultimate value proposition is fair includes ensuring that the net benefit to the system is positive. Jurisdictions differ on whether the UCT, TRC, or SCT is used to assess net benefits, so Mexico will need to pick one, include all of the sources of cost and benefit that apply, and endeavor to measure each source and cost and benefit well.

Sections 3.2, 5.1, 5.2, 5.5, and 5.6 provide guidance to Mexico on implementing fair DG tariffs. 


\section{Action Item 3: Establish Rate Design Principles that Deliver Fair Value}

The rate design principles that lead to fair valuation of DG and other DER are:

- Principle 1: Customers should be able to connect to the grid for no more than the cost of connecting to the grid.

- Principle 2: Customers should pay for grid services and power supply in proportion to how much they use these services and how much power they consume.

- Principle 3: Customers who supply power to the grid should be fairly compensated for the full value of the power they supply.

A corollary to these principles is that people should pay and be paid according to locational and temporal conditions when possible. Until locational and temporal values are available, these principles indicate an inclining block volumetric rate with a small customer charge and possibly a small demand charge. As the quality of information improves, TOU rates and possibly dynamic pricing can be incorporated into the tariff.

If revenues collected are inadequate to ensure reliable utility service, a minimum bill or demand charge approach should be considered to stabilize revenue. Fixed customer charge increases promote perverse economic incentives and lead to over-consumption.

Sections 5.3 through 5.5 provide guidance to Mexico on establishing a fair rate design.

\section{Action Item 4: Establish Fair Tariffs for Other Customer Classes}

Commercial, industrial, and public sector customers may wish to adopt DG technologies as well. While many of these customers may be able to directly buy from and sell into wholesale markets, most will continue to have a tariff with the utility. The most common tariff is called a standby or partial requirements services tariff. The tariff terms should be fair and, to the extent that compensation under the tariff is established by regulation rather than a market, the cost paid to the utility and system operator for energy and services procured and the compensation paid to the customer for energy and services provided should be fair. The principles of fairness should be consistent with those described in Recommendation 2 and Recommendation 3 as much as possible.

Sections 5.6 and 5.8, and especially Table 5-6, describe how Mexico can ensure that tariffs for non-residential customer classes are fair. Text Box 3 lists the performance metrics for Goal 1. 


\section{Text Box 3. Performance Metrics for Goal 1}

- Stakeholder satisfaction with tariffs

- Residential customers

- Commercial and industrial customers

- Utility representatives

- DG industry representatives

- DG adoption rates

- DG value estimates vs. adoption rates by location.

\section{Goal 2: Ensure Wholesale DG Access to Markets is Fair}

\section{Action Item 5: Make Electricity System Needs More Transparent}

Investment in information, communications, and system control technologies will allow utilities and system operators to more accurately forecast needs on the distribution system and the wholesale electric system. The forecasted need for flexibility service, ramping service, and conventional ancillary services should improve, as should the locational and temporal granularity of needs. Improved forecasting will allow solutions to the integration challenge discussed in Sections 2.3 and 3.2 to be addressed through competitive mechanisms. Needs should become more transparent in markets and in procurement solicitations over time so that renewable energy providers and wholesale DG providers have the opportunity to compete to meet the needs.

Sections 2.3, 3.2, and 5.8 provide guidance to Mexico on ensuring that electricity system needs are transparent.

\section{Action Item 6: Qualify Wholesale DG Providers to Compete in Energy, Capacity, Flexibility, and Ancillary Services Markets and Procurements}

Wholesale DG owners should have the ability to compete in markets or in procurements if they can demonstrate that their system can reliably meet the need solicited. Distributed generation technologies and DG system installations will differ in what services they can be qualified to provide to the system operator or utility. That said, all wholesale DG owners, and indeed all DER owners, should have the opportunity to be qualified to provide any competitive service. A process should be in place that allows all DG and DER owners and all aggregators of DG and other DER resources to apply to become qualified bidders for any competitive service. Robust competition that includes DG and DER resource capabilities will produce competitive solutions to the integration challenges that arise as increasing levels of variable generation are added.

Sections 2.3, 3.2, and 5.8 provide guidance to Mexico on ensuring that wholesale DG providers have access to markets. 


\section{Action Item 7: Encourage Infrastructure and Information Technology Investments}

that Enable Greater Transparency of System Needs, Active DG, and other DER Participation

Utility and system operator investment in technologies that (1) identify and communicate needs and (2) enable active DG and DER participation should be fostered. DG and DER system owners should be encouraged to invest in technologies that enable their resources to be active in meeting system needs. The utility and third-party aggregators should be encouraged to invest in capabilities that enable them to aggregate DG and DER resources for the purpose of meeting system needs.

Sections 2.1, 2.2, 2.3, 5.8, and 5.10 provide guidance to Mexico on supporting infrastructure investment that engenders DG and DER participation in markets. Text Box 4 lists the performance metrics for Goal 2.

\section{Text Box 4. Performance Metrics for Goal 2}

- Stakeholder satisfaction with market access:

○ Residential customers

- Commercial and industrial customers

○ Utility and system operator representatives

○ Third-party energy service providers

- DG and DER participation rates in energy service market bids by location over time

- DG and DER selection rates in energy service markets relative to bids submitted by location and over time.

\section{Goal 3: Improve the DG Interconnection Process Action Item 8: Adopt Best-Practice Interconnection Processes}

Best practice interconnection processes include setting appropriate interconnection fees; streamlining all interconnections by adopting appropriate decision tree screens; adopting streamlined interconnection for larger DG units that are not covered by net metering; adopting standardized technical requirements; providing standardized, simplified application forms and contracts; defining a process to address disputes; and allowing DG systems to interconnect to both radial and network grids.

Sections 2.3 and 5.7 provide guidance to Mexico on improving interconnection. Text Box 5 lists the performance metrics for Goal 3. 
Text Box 5. Performance Metrics for Goal 3

- Stakeholder satisfaction with interconnection:

○ Residential customers

- Commercial and industrial customers

○ Utility representatives

○ DG industry representatives

- Quantity of DG being interconnected by location over time

- Time to interconnect by location and system size over time

- Cost of interconnection by location and system size over time.

\section{Goal 4: Improve DG Access to Capital Markets}

\section{Action Item 9: Establish Regulations and Compensation Mechanisms for DG Developers, Adopters, and Aggregators that are Stable and Fair}

Capital markets like well-defined rules that are applied consistently and well. Capital markets like companies who can rely on fair compensation for services provided. Distributed generation developers, adopters, and aggregators will have better access to capital if regulators establish an environment of stability and fair compensation. Stability requires mechanisms that are perceived to be fair from the perspective of DG adopters, non-DG adopting customers, the utility, and society as a whole.

Sections 2-4 provide guidance to Mexico on improving access of DG to wholesale markets.

\section{Action Item 10: Encourage the Maturation of the Network of Suppliers, Materials, and Skilled Labor}

Capital markets favor an industry where the network of suppliers, materials, and labor is maturing.

Section 2 provides guidance to Mexico on improving the network of suppliers, materials, and labor.

\section{Action Item 11: Facilitate Innovative Financing Mechanisms and Opportunities}

Increasing the size of the market by allowing DG leasing options and shared renewable programs will attract financing. Supporting innovative financing approaches such as yieldcos-in which parent companies bundle conventional and/or renewable energy assets to generate predictable cash flow $^{34}$ _ can attract capital. Facilitating public-private financing opportunities will likewise increase the capital flowing to the DG sector. Mexico should be seeking ways to improve the financing opportunities for DG adopters as well as for potential DG industry investors.

\footnotetext{
${ }^{34}$ See NREL. A Deeper Look Into Yieldco Structuring. Retrieved from https://financere.nrel.gov/finance/content/deeper-look-yieldco-structuring
} 
Sections 3.2, 3.3, and 5.9 provide guidance on financing mechanisms that could be helpful in Mexico. Text Box 6 lists the performance metrics for Goal 4.

\section{Text Box 6. Performance Metrics for Goal 4}

- Stakeholder satisfaction with financing options:

- Residential customers

○ Commercial and industrial customers

○ DG industry representatives

○ Third-party aggregators and service providers

- Quantity of capital market finances invested in DG-related investments and services by location and over time.

\section{Goal 5: Expand Customer Access to DG Participation Options Action Item 12: Expand Ownership, Leasing, and Rooftop Rental Options Available to Customers}

\section{Action Item 13: Introduce Ownership and Leasing Options for Shared Renewable} Projects

\section{Action Item 14: Introduce DG Participation Options for Low-Income Housing and Low-Income Customers}

Each of these action items adds participation options and expands the potential market for DG projects.

Sections 3.3 and 5.9 provide guidance to Mexico on implementing Action Items 12 through 14. Text Box 7 lists the performance metrics for Goal 5.

\section{Text Box 7. Performance Metrics for Goal 5}

- Customer satisfaction with ability to participate:

○ Homeowners

○ Renters

○ Low-income customers

○ Commercial, industrial, and public sector customers

○ DG industry representatives

- Proportion of customers who have access to a DG option

- DG adoption rates by location and type of customer. 


\section{References}

APS. (2013, November 14). Arizona Corporation Commission Sets New Direction for Net Metering Policy [Press release]. Retrieved from http://www.azenergyfuture.com/blog/november2013/news-release-arizona-corporation-commission-sets/.

California Public Utilities Commission (CPUC). (2013). Biennial Report on Impacts of Distributed Generation.

CPUC. (2016, February 5). Decision 16-01-044: Adopting Successor to Net Energy Metering Tariff. Retrieved from http://docs.cpuc.ca.gov/PublishedDocs/Published/G000/M158/K181/158181678.pdf.

Center for Clean Air Policy. (2011, October). Mexico's Renewable Energy Program: A Step-byStep Approach for Overcoming Barriers to Renewable Energy Deployment [Discussion draft]. Washington, D.C.: Center for Clean Air Policy. Retrieved from http://ccap.org/assets/MexicosRenewable-Energy-Program-A-Step-by-Step-Approach-for-Overcoming-Barriers-to-RenewableEnergy-Deployment_CCAP-October-2011.pdf.

Cost-Effectiveness Working Group. (2013, February 2013). A Framework for Evaluating the Cost- Effectiveness of Demand Response. Prepared for the National Forum on the National Action Plan on Demand Response. Retrieved from http://emp.lbl.gov/sites/all/files/napdr-costeffectiveness.pdf.

CPUC. (2014, December 22). Interim Decision Adopting Revisions to Electric Tariff Rule 21 for PG\&E, SCE and SDG\&E to require "Smart" Inverters. Decision D. 14-12-035. Retrieved from http://docs.cpuc.ca.gov/PublishedDocs/Published/G000/M143/K827/143827879.PDF.

E3 (Energy and Environmental Economics). (2013, September). Draft California Net Energy Metering Evaluation.

Electric Research Institute. (2007). Estado del Arte de la Medición Neta para Microgeneración Domiciliariay de Códigos de Red para Centrales Eólicas (State of the Art Net Metering for Residential Microgeneration and Network Codes for Micro Wind Farms.) Retrieved from http://www.cre.gob.mx/estudios/ae0107.pdf.

Energy Efficiency Screening Coalition. (2013, November). Recommendations for Reforming Energy Efficiency Cost-Effectiveness Screening in the United States. Retrieved from http://www.nhpci.org/campaigns.html.

Energy Regulatory Commission. (2012, May). General Rules of Interconnection to the National Electric System for Generators or Permit Holders with Renewable Energy Sources or Efficient Cogeneration. Retrieved from http://www.cre.gob.mx/documento/2195.pdf. 
Faruqui, A., Hledik, R., \& Palmer, J. (2012). Time-Varying and Dynamic Rate Design.

Montpelier, VT: Regulatory Assistance Project. Retrieved from

http://www.raponline.org/document/download/id/5131.

GTM/SEIA. (2014). U.S. Solar Market Insight. http://www.seia.org/research-resources/us-solarmarket-insight.

IEEE Standards Association. (2015). IEEE 1547 Standard for Interconnecting Distributed Resources with Electric Power Systems. Retrieved from

http://grouper.ieee.org/groups/scc21/1547/1547 index.html.

International Energy Agency (IEA). (2008). Empowering Variable Renewables: Options for Flexible Electricity Systems, p. 5. Paris: IEA. Retrieved from

https://www.iea.org/publications/freepublications/publication/Empowering_Variable Renewable s.pdf.

IEA. (2014). Law for the Development of Renewable Energy and Energy Transition Financing (LAERFTE). Retrieved from http://www.iea.org/policiesandmeasures/pams/mexico/name24706-en.php.

IEA. (2016). Mexico Energy Outlook. Retrieved from

https://www.iea.org/publications/freepublications/publication/MexicoEnergyOutlook.pdf.

IREC. (2013). Model Interconnection Procedures. Retrieved from

http://www.irecusa.org/publications/model-interconnection-procedures/.

Kenning, T. (2015, April 30). Three Brazil states granted VAT exemptions for solar net-metering. $P V$-Tech. Retrieved from http://www.pv-

tech.org/news/three_brazil_states_granted_vat_exemptions_for_solar_net_metering.

Lazar, J., Weston, F., \& Shirley, W. (2011). Revenue Regulation and Decoupling: A Guide to Theory and Application. Montpelier, VT: Regulatory Assistance Project. Retrieved from http://www.raponline.org/document/download/id/902.

Lazar, J. (2013). Rate Design where Advanced Metering Infrastructure Has Not Been Fully Deployed. Montpelier, VT: Regulatory Assistance Project. Retrieved from http://www.raponline.org/document/download/id/6516.

Lazar, J., \&d Gonzalez, W. (2015, July). Smart Rate Design for a Smart Future. Montpelier, VT: Regulatory Assistance Project. Retrieved from http://www.raponline.org/document/download/id/7680.

Lazard. (2016, December). Levelized Cost of Energy Analysis 10.0. Retrieved from https://www.lazard.com/perspective/levelized-cost-of-energy-analysis-100/ .

Linvill, C., Shenot, J., \& Lazar, J. (2013). Designing Distributed Generation Tariffs Well. Montpelier, VT: Regulatory Assistance Project. Retrieved from http://www.raponline.org/document/download/id/6898. 
Migden-Ostrander,J., Watson, B., Lamont, D., \& Sedano, R. (2014). Decoupling Case Studies: Revenue Regulation Implementation in Six States. Montpelier, VT: Regulatory Assistance Project. Retrieved from http://www.raponline.org/document/download/id/7209.

Hansen, L., \& Lacy, V. (2013, September). A Review of Solar PV Benefit \& Cost Studies. Rocky Mountain Institute. Retrieved from http://www.rmi.org/Knowledge-

Center\%2FLibrary\%2F2013-13 eLabDERCostValue.

NREL (National Renewable Energy Laboratory). (2015). Value-of-Solar Tariffs. Retrieved from http://www.nrel.gov/tech deployment/state local governments/basics value-ofsolar tariffs.html.

Pyper, J. (2015. March 16). Utilities Wrestle with Educating Residential Customers on Energy Savings. GreenTechMedia. Retrieved from http://www.greentechmedia.com/articles/read/WhenIt-Comes-to-Residential-Customer-Education-the-Struggle-for-Utilities .

Scheaffer, P., \& Schwartz, L. (2011). Interconnection of Distributed Generation Systems in the United States. Montpelier: VT, Regulatory Assistance Project. Retrieved from http://www.raponline.org/document/download/id/4572.

Selecky, J., Iverson, K., \& Al-Jabir, A. (2014). Standby Rates for Combined Heat and Power Systems. Montpelier, VT: Regulatory Assistance Project. Retrieved from http://www.raponline.org/document/download/id/7020.

SENER. (2014a). Estrategia Nacional de Transicion Energetica y Aprovechamiento Sustentable de la Energia. Retrieved from http://www.gob.mx/cms/uploads/attachment/file/215/ENTEASE_2014.pdf.

SENER. (2014b). Programa Especial para el Aprovechamiento de las Energías Renovables. Retrieved from https:/www.gob.mx/sener/acciones-y-programas/programa-especial-para-elaprovechamiento-de-las-energias-renovables-2014-2018-10375. .

SENER. (2015). Programa de Desarrollo del Sistema Eléctrico Nacional. Retrieved from http://www.gob.mx/cms/uploads/attachment/file/37775/PRODESEN_2015_2029.pdf.

U.S. Department of Energy. (2013). Guide to Successful Implementation of State Combined Heat and Power Policies. U.S. DOE State and Local Energy Efficiency Action Network (SEEAction). Retrieved from https://www4.eere.energy.gov/seeaction/publication/guide-successfulimplementation-state-combined-heat-and-power-policies .

WEC/BNEF (World Energy Council and Bloomberg New Energy Finance). 2013. World Energy Perspective: Cost of Energy Technologies. Retrieved from http://www.worldenergy.org/wpcontent/uploads/2013/09/WEC_J1143 CostofTECHNOLOGIES 021013_WEB Final.pdf. 
Whited, M., Woolf, T., \& Napoleon, A. (2015, March). Utility Incentive Performance Mechanisms: A Handbookfor Regulators. Synapse Energy Economics. Retrieved from http://www.synapse-

energy.com/sites/default/files/Utility\%20Performance\%20Incentive\%20Mechanisms\%2014098 0.pdf.

Woolf, T., Malone, E., Neme, C., \& LeBaron, R. (2014, October). Unleashing Energy Efficiency. Public Utilities Fortnightly, October 2014. Retrieved from https://www.fortnightly.com/fortnightly/2014/10/unleashing-energy-efficiency. 